\title{
Functional characterisation of Syndecan, a heparan sulphate proteoglycan, in Slit/Robo signalling
}

\section{PhD Thesis}

\author{
in partial fulfilment of the requirements \\ for the degree "Doctor of Philosophy (PhD)" \\ in the Molecular Biology Program \\ at the Georg August University Göttingen, \\ Faculty of Biology
}

submitted by

Bhavna Chanana

born in

New Delhi, India 
I hereby declare that the $\mathrm{PhD}$ thesis entitled, "Functional characterisation of Syndecan, a heparan sulphate proteoglycan, in Slit/Robo signalling", has been written independently and with no other sources and aids than quoted.

Bhavna Chanana 
"Dream is not what you see in sleep, dream is the thing which does not let you sleep."

- Dr. A.P.J. Abdul Kalam, XI President of India. 
The following work was done in the Department of Molecular Developmental Biology at the Max-Planck-Institute for Biophysical Chemistry in Göttingen under the supervision of Dr Gerd Vorbrüggen.

I am grateful to my supervisor, Dr. Gerd Vorbrüggen, for his guidance and frequent discussions, which shaped and provided direction to this work.

My sincere thanks to Prof. Dr. Herbert Jäckle for giving me the opportunity to carry out my dissertation in his department and for his constant support and encouragement.

I thank my doctoral committee members, Prof. Dr. Tomas Pieler and Prof. Dr. Ernst Wimmer for their time and support.

I am indebted to Patrick Steigemann for teaching me the basics of fly work and genetics and guiding me with daily discussions during the first half of my $\mathrm{PhD}$.

My heartfelt thanks to Tomma Eisbein for being an enormous help with the cell culture experiments and for the times she took over the tedious task of embryo washing and buffer changes. I also want to acknowledge Anton Volkov, who helped me in setting up some cell culture assays as part of his lab rotation work.

I thank Gordon Dowe for sequencing my innumerable samples. For microinjections to generate transgenic flies I thank Iris Plischke, Tomma Eisbein and Ursula Jahns-Meier.

My special thanks to Ralf, Alf and Uli for the diverse and vast amount of technical help, the very fruitful discussions and helpful comments. To Ralf and Uli again and to Anu for the critical reading of this thesis.

For the friendly and conducive work atmosphere I wish to thank the past and present members of Lab5, Patrick, Sonja, Roland, Sebastian, Alexandra, Alexey and Tatyana.

I am grateful to Shruti, Anu and Rinki for being my sounding board for the past ten years, for seeing me through my every up and down and keeping their patience through my taciturn phases. You all managed to keep me sane :-). To Tina and Rebecca for being my home away from home.

And my deep and lasting gratitude to my family, Biji, Papa, Mama, Chetan and Chirantan for their unconditional love and support and belief in me. Without you I would have never managed to come this far. 


\section{Table of Contents}

Abbreviations _ 1

Abstract__ 3

1 Introduction $\quad 5$

1.1 Heparan Sulphate Proteoglycans (HSPGs) _ 5

1.2 Roles of HSPGs in Signalling __ 8

1.3 The Drosophila ventral midline___ 11

1.4 Slit/Robo signalling mediates axon guidance

1.5 Slit/Robo signalling mediates muscle patterning ___ 14

1.6 Syndecan regulates Slit/Robo signalling __ 15

1.7 Domain structure of Syndecan

1.7.1 Cytoplasmic domain of Syndecan__ 16

1.7.2 Transmembrane domain of Syndecan__ 17

1.7.3 Extracellular domain of Syndecan 18

1.8 Mechanistic analysis of Syndecan function in Slit/Robo signalling _ 19

2 Materials and Methods

2.1 Molecular Biology 20

2.1.1 Polymerase Chain Reaction _ 20

2.1.2 DNA Restriction 20

2.1.3 DNA extraction from agarose gel 20

2.1.4 Dephosphorylation of vector DNA_ 20

2.1.5 DNA Ligation 21

2.1.6 Preparation of electro-competent Escherichia coli (E.coli) cells __ 21

2.1.7 Preparation of chemical-competent E.coli cells 21

2.1.8 Transformation of electro-competent E.coli cells 22

2.1.9 Transformation of chemical-competent E.coli cells 22

2.1.10 Plasmid DNA purification 22

2.1.11 DNA Sequencing __ 23

2.1.12 Site-directed mutagenesis 23

2.1.13 DNA preparation for Embryo Injections __ 23

2.2 Fly techniques _ 24

2.2.1 Maintenance of flies _ 24

2.2.2 Generation of stable transgenic fly lines 24

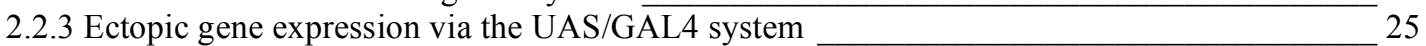

2.2.4 Fixation of embryos 25

2.2.5 Antibody $(\mathrm{Ab})$ staining of embryos _ 25

2.2.6 Fluorescence microscopy ___ 26

2.3 Cell culture based techniques _ 26

2.3.1 Maintenance of cells 26

$\begin{array}{lr}\text { 2.3.2 Transfection of cells } & 27\end{array}$

$\begin{array}{ll}2.3 .3 \text { Assay for protein secretion } & 27\end{array}$

$\begin{array}{ll}\text { 2.3.4 Assay for protein shedding } & 27\end{array}$

2.3.5 Enzymatic assays with glycosaminoglycan depolymerising enzymes __ 28 
2.3.6 Western blot for protein detection 28

2.4 List of oligonucleotides 29

2.5 List of plasmids 30

2.6 List of fly stocks generated for this study 32

2.7 List of other fly stocks used 35

2.8 List of primary antibodies 36

2.9 List of secondary antibodies 36

3 Results 37

3.1 Syndecan activity is required on the Slit target tissue 37

3.2 Identification of Syndecan protein domains essential for Slit/Robo signalling 39

3.2.1 Cytoplasmic domain of Syndecan is not required for its function in Slit/Robo signalling 39

3.2.2 The secreted form of Syndecan is not functional in Slit/Robo signalling

3.3 sdc $\triangle T C$-GFP codes for a protein that is secreted 41

$3.4 s d c \triangle T C$-GFP codes for a protein that carries high molecular weight modifications_46 3.5 Syndecan transmembrane domain serves as an inert anchor for the extracellular domain

3.6 Heparan sulphate glycosaminoglycan (HSGAG) attachment site mutants rescue the $s d c^{23}$ mutant phenotype

3.6.1 $\mathrm{sg} 5-$-GFP codes for a protein that bears high molecular weight modifications 47

3.6.2 Enzymatic depolymerisation of glycosaminoglycan (GAG) chains

3.7 Shedding of Sdc in cell culture by Drosophila Schneider 2 (S2) cells

3.8 No shedding of Sdc in vivo 52

3.9 Participation of Ttv in Slit/Robo signalling 55

3.10 Participation of Dlp in Slit/Robo signalling 56

Discussion 58

4.1 Syndecan is required specifically on the target tissue 60

4.2 Cytoplasmic domain of Syndecan is not required for function in Slit/Robo signalling 60 64

4.3 Syndecan has to be membrane anchored for its function in Slit/Robo signalling _ 65

4.4 The secreted form of Syndecan is modified 68

4.5 Heparan sulphate glycosaminoglycan attachment site mutant transgenes encode for proteins that carry high molecular weight modifications 69

4.6 Syndecan is shed in culture by Drosophila S2 cells _ 71

4.7 Shedding of Syndecan in vivo

4.8 Ttv and Slit/Robo signalling: participation of an additional HSPG in Slit/Robo signalling 73

4.9 Dlp: the second HSPG in Slit/Robo signalling 
Table of Contents

Summary and Conclusions __ 79

References _ 81

Curriculum vitae _ 92 


\section{List of Figures}

Figure 1: Biosynthesis of HSGAG chains in the Golgi apparatus.

Figure 2: Roles of HSPGs in signalling.

Figure 3: Axon guidance at the ventral midline.

Figure 4: Slit and Robo expression in the CNS and their mutant phenotypes.

Figure 5: Sdc expression in the CNS and mutant phenotypes.

Figure 6: Tissue specific rescue of $s d c^{23}$ mutant phenotypes. 38

Figure 7: Rescue of $s d c^{23}$ mutant phenotype with $s d c$ deletion transgene variants. 40

Figure 8: $\operatorname{Sdc} \triangle \mathrm{TC}-\mathrm{GFP}$ is secreted in the CNS and hindgut. 42

Figure 9: $\operatorname{Sdc} \Delta \mathrm{TC}-\mathrm{GFP}$ is secreted in the tracheal system. 44

Figure 10: Sdc-GFP fusion proteins are modified and $\operatorname{Sdc} \Delta \mathrm{TC}-\mathrm{GFP}$ is secreted in Drosophila $\mathrm{S} 2$ cells. 45

Figure 11: Rescue of $s d c^{23}$ mutant phenotype with a chimeric $s d c$ transgene variant. 47

Figure 12: Rescue of $s d c^{23}$ mutant phenotype with $s d c$ HSGAG attachment site mutant transgenes. 48

Figure 13: SG5-GFP carries high molecular weight modifications. 50

Figure 14: FLAG-SG5-GFP is modified. 51

Figure 15: Shedding of the Sdc protein variant: Sdc:D30. 53

Figure 16: Sdc shedding in Drosophila S2 cells is sensitive to a serine protease inhibitor.

Figure 17: Drosophila Sdc shedding is not detectable in vivo. 54

Figure 18: Ttv participates in Slit/Robo signalling. 55

Figure 19: Dlp participates in Slit/Robo signalling. 57

Figure 20: Models for the role of Sdc in Slit repellent signalling. 58

Figure 21: A model for combinatorial mode of action of Sdc and Dlp in Slit/Robo signalling. 75 


\section{Abbreviations}

$\mu \mathrm{g} \quad$ microgram

$\mu 1 \quad$ microlitre

$\mathrm{Ab} \quad$ Antibody

act-Gal4 actin5C-Gal4

ADAM A Disintegrin and Metalloprotease

BSA Bovine Serum Albumin

CNS Central Nervous System

CSGAG Chondroitin Sulphate Glycosaminoglycan

Dally Division abnormally delayed

DCC Deleted in Colorectal Cancer

Dlp Dally-like protein

DNA Deoxyribonucleic acid

Dpp Decapentaplegic

E.coli Escherichia coli

FGF Fibroblast Growth Factor

Fra Frazzled

GFP Green Fluorescent Protein

Gly Glycine

GPI Glycosylphosphatidylinositol

h hour

$\mathrm{Hh} \quad$ Hedgehog

HSGAG Heparan Sulphate Glycosaminoglycan

HSPG Heparan Sulphate Proteoglycan

kDa kilo Dalton

LB Luria Bertani

MAS Muscle Attachment Sites

NDST N-deacteylase/sulphotransferase

PBS Phosphate Buffered Saline 


$\begin{array}{ll}\text { PCR } & \text { Polymerase Chain Reaction } \\ \text { PNS } & \text { Peripheral Nervous System } \\ \text { Robo } & \text { Roundabout } \\ \text { rpm } & \text { revolutions per minute } \\ \text { S2 } & \text { Schneider } 2 \\ \text { Sdc } & \text { Syndecan } \\ \text { SDS-PAGE } & \text { Sodium Dodecyl Sulphate Polyacrylamide Gel Electrophoresis } \\ \text { Ser } & \text { Serine } \\ \text { Sfl } & \text { Sulfateless } \\ \text { Sgl } & \text { Sugarless } \\ \text { Ttv } & \text { Tout velu } \\ \text { UAS } & \text { Upstream Activating Sequence } \\ \text { WB } & \text { Wash Buffer } \\ \text { Wg } & \text { Wingless }\end{array}$




\section{Abstract}

Syndecan $(\mathrm{Sdc})$ is a type I transmembrane protein characterized by the presence of linear sugar chains called heparan sulphate glycosaminoglycans (HSGAGs) linked to its extracellular domain. Its cytoplasmic and transmembrane domains are conserved from invertebrates to vertebrates though the extracellular domain is highly sequence variable. Sdc was shown to be critical for the fidelity of Slit repellent signalling at the Drosophila midline where via its receptor Robo, Slit patterns the central nervous system (CNS) and the musculature. Embryos homozygous mutant for $s d c$, however, are weakly penetrant for the slit like phenotype and exhibit ventral midline crossing of ipsilateral axons and ventral muscles. These embryos die during embryogenesis.

This study aimed at shedding some light on how Sdc functions in Slit/Robo signalling. Employing the UAS/GAL4 system, different $s d c$ variants and chimeric transgenes were expressed in specific tissues in a $s d c$ mutant background and tested for their rescue capability. Rescue was scored by the absence of ventral midline crossing of ipsilateral axons and ventral muscles.

These experiments aimed at the identification of the tissue dependence of Sdc and its functional protein domains for Slit/Robo signaling. Tissue-specific rescue experiments were performed to identify the mechanism of Sdc action by its tissue specific requirement: in the ventral midline cells to test for a function in Slit secretion, in the intermediate tissue to test for a function in Slit transport and on the target tissue to test for a role in Slit reception. These experiments revealed that Sdc does not play any apparent role in the secretion of Slit or in its transport but is required specifically on the target tissue with the receptor Robo in a cis-cis configuration for the reception of Slit.

Earlier vertebrate Sdc studies had reported the cytoplasmic domain of Sdc to directly interact with and reorganize the actin cytoskeleton. The cytoplasmic domain had also been shown to be involved in receptor recycling and intracellular signalling. To ascertain if Drosophila Sdc might be acting in any of these processes with respect to Slit/Robo signalling, the rescue potential of a $s d c$ deletion transgene lacking the cytoplasmic domain was analyzed. Rescue of phenotype with this transgene indicated that Sdc does not direct the reorganization of the actin cytoskeleton in response to Slit nor does it participate directly in intracellular signalling. 
Vertebrate Sdc studies had also reported the transmembrane domain to mediate proteinprotein interactions in the plane of the plasma membrane. To determine if these interactions were functionally relevant and if the transmembrane domain has a sequence specific function, various transgenes were analyzed in $s d c$ rescue experiments. This analysis revealed that even though the transmembrane domain is important for function it only acts as an inert anchor for the extracellular domain and this mode of anchorage is functionally exchangeable for an alternate one.

Shedding, the proteolytic release of the extracellular domain, of vertebrate Sdc has been demonstrated to be essential for function in vivo. However, in vivo analysis of a doubletagged version of Sdc indicated that Sdc is not shed during embryogenesis. In contrast, cell culture based experiments showed that Drosophila Sdc might be proteolytically cleaved in vivo by a serine protease, which would be in contrast to vertebrate Sdcs that have been proposed to be cleaved by a metalloprotease.

Investigation for the participation of other HSPGs in Slit/Robo signalling by generating double mutants identified Dlp to be the second HSPG involved in the transduction of the Slit repellent signal.

In summary, the in vivo rescue experiments proved that Drosophila Sdc is specifically required on the target tissue where it functions as a coreceptor with Robo and that Sdc has no function in Slit secretion or transport nor does it have an independent intracellular signalling activity. Furthermore, the results also support a model in which shedding of Sdc though not required for the fidelity of Slit repellent signalling could occur by the proteolytic activity of a serine protease which might function as a negative feedback system or might be required for the recycling of Robo receptor. 


\section{Introduction}

Higher organisms are bilaterally symmetric. They efficiently coordinate the left and right sides of their body by integrating sensory input and exerting motor control. This is dependent on the formation of correct connections between neurons and their targets (reviewed in (Garbe and Bashaw, 2004; Kaprielian et al., 2000)). Therefore, patterning of the nervous system is a critical phase of embryonic development. This patterning process is controlled by attractive and repulsive cues emanating from the ventral midline cells that function as an organisation centre. Heparan sulphate proteoglycans (HSPGs) have been implicated in regulating axon guidance in invertebrates and vertebrates (reviewed in (Lee and Chien, 2004)). This work is aimed at elucidating the mechanism by which Drosophila Syndecan (Sdc), an HSPG, regulates Slit/Robo signalling, a key axon guidance signalling pathway at the ventral midline.

\subsection{Heparan Sulphate Proteoglycans (HSPGs)}

HSPGs are a diverse group of glycoproteins found on cell membranes and in the extracellular matrix, characterized by the presence of linear Heparan Sulphate Glycosaminoglycan (HSGAG) chains. There are two sources of diversity in HSPGs: the differentially modified HSGAGs, and the different core proteins to which HSGAGs can be attached (reviewed in (Lee and Chien, 2004)).

The family of HSPGs is comprised of four core proteins, namely Syndecans (Sdcs), Glypicans, Perlecans and Agrins (reviewed in (Bernfield et al., 1999)). Although Glypicans, Perlecans and Agrins exclusively bear HSGAG chains, Sdcs carry both HSGAG and Chondroitin Sulphate Glycosaminoglycan (CSGAG) chains. Agrins and Perlecans are large multi-domain proteins ( $\sim 2000$ and $\sim 4000$ amino acids, respectively) that are part of the extracellular matrix. Sdcs are small typeI transmembrane proteins (200-400 amino acids) with divergent extracellular domains but conserved transmembrane and cytoplasmic domains. Glypicans are larger proteins (550-600 amino acids) with globular extracellular domains that are folded by the formation of disulphide bridges between 14 conserved cysteine residues. Glypicans are linked to the plasma 
membrane via a glycosylphosphatidylinositol (GPI) anchor and their HSGAG chains are present close to the plasma membrane. In contrast Sdcs have an extended proline-rich extracellular domain and their HSGAG chains are located far from the plasma membrane (reviewed in (Lee and Chien, 2004)).

The Drosophila genome encodes for four HSPG homologs: a single syndecan ( $s d c)$ (Johnson et al., 2004; Spring et al., 1994; Steigemann et al., 2004), two Glypicans, encoded by division abnormally delayed (dally) and dally-like protein (dlp) (Baeg et al., 2001; Khare and Baumgartner, 2000; Nakato et al., 1995), and a Perlecan encoded by terribly reduced optic lobes (trol) (Park et al., 2003; Voigt et al., 2002).

All HSPGs have one to several HSGAG side chains. HSGAGs are covalently attached to serine residues of the core protein at a Serine-Glycine (Ser-Gly) motif. The HSGAG attachment sites and their surrounding amino acid sequences determine the number of HSGAG chains that attach to a specific HSPG core protein (reviewed in (Bernfield et al., 1999)). A cytoplasmic UDP-glucose dehydrogenase converts UDP-glucose to UDPacetyl glucosamine that is transferred to the Golgi where it is used for the synthesis of HSGAG chains. The HSGAG chain is synthesised by consecutive addition of single sugar residues to an initial tetrasaccharide composed of xylose-galactose-galactoseglucuronic acid that functions as a specific linker and is shared by all the HSGAGs (Fig. 1). The actual HSGAG side chain is made up of repeating disaccharide units of glucuronic acid and $\mathrm{N}$-acetyl glucosamine that are polymerised by an HSGAG polymerase. Each disaccharide unit is subject to a total of six possible modifications. The glucuronic acid residue can be epimerised at the fifth carbon by an epimerase to iduronic acid and the C2-hydroxyl can be 2-O-sulphated by 2-O-sulphotransferases. The other four modifications are of the glucosamine residue: $\mathrm{N}$-deacetylaion and $\mathrm{N}$-sulphation by $\mathrm{N}$-deacetylase/sulphotransferases, 3-O-sulphation by 3-O-sulphotransferases and 6-Osulphation by 6-O-sulphotransferases (Fig. 1) (reviewed in (Lee and Chien, 2004)).

In Drosophila the proteins responsible for some of the steps of HSGAG biosynthesis have been identified. sugarless $(s g l)$ encodes for the UDP-glucose dehydrogenase (Häcker et al., 1997), tout velu (ttv) encodes for an HSGAG polymerase (Bellaiche et al., 1998), sulfateless ( $s f l$ ) codes for an N-deacetylase/sulphotransferase (Lin et al., 1999), $h s 2 s t$ codes for a 2-O-sulphotransferase (Kamimura et al., 2006), hs3stB (Kamimura et 
al., 2004) codes for a 3-O-sulphotransferase and $h s 6 s t$ codes for a 6-O-sulphotransferase (Kamimura et al., 2006).

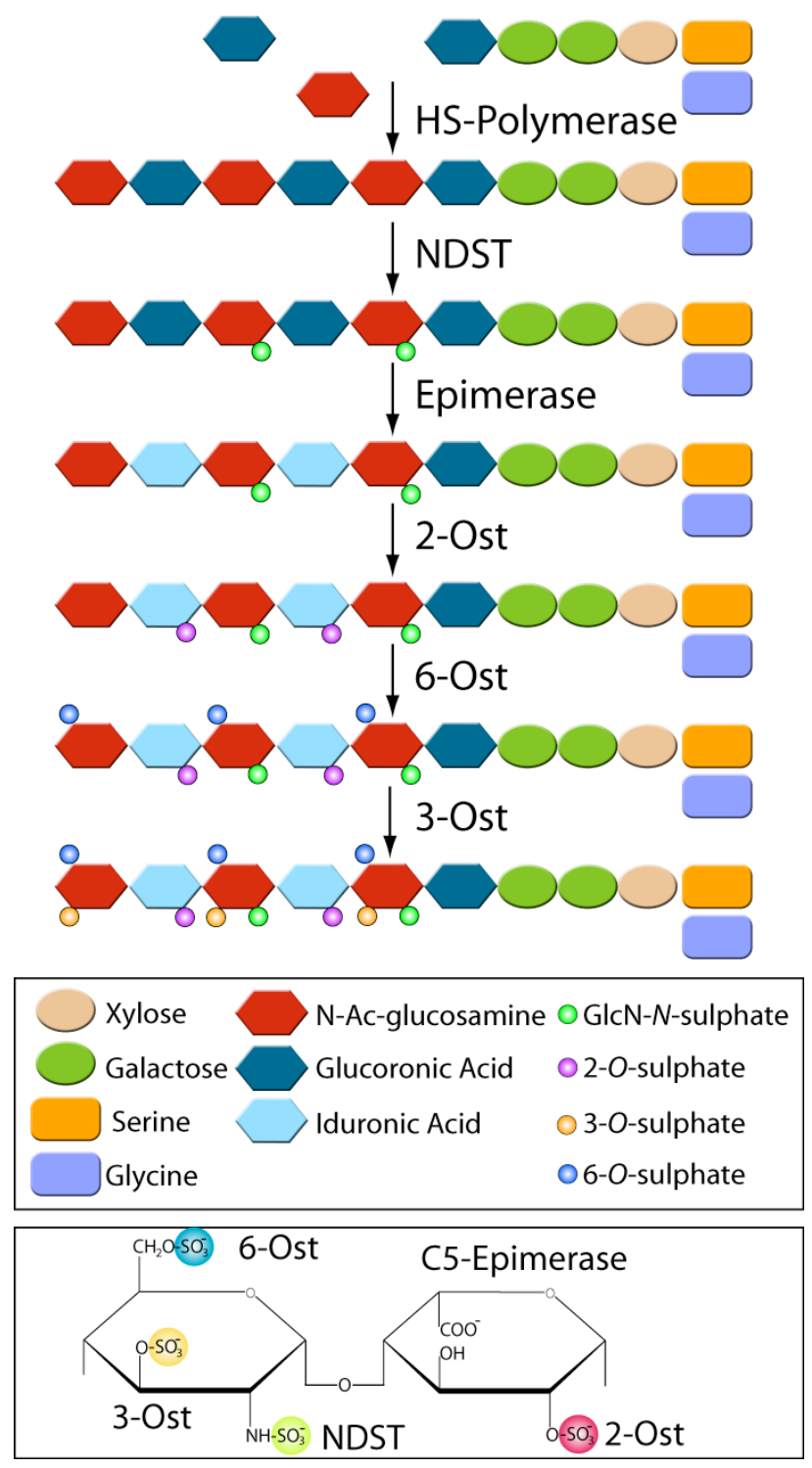

Figure 1: Biosynthesis of HSGAG chains in the Golgi apparatus. HSGAG chains are attached to a specific serine residue in the core protein via a tetrasaccharide (xylose-galactose-galactoseglucuronic acid) linker. Polymerisation of alternating $\mathrm{N}$-acetylglucosamine (GlcNAc) and glucuronic acid (GlcA) residues generates HSGAG chains. Successive modifications of Ndeacetylation, N-sulphation, epimerisation of GlcA to iduronic acid, 2-O-sulphation, 6-Osulphation and 3-O-sulphation results in mature HSGAG chains. In the bottom box the fully modified sugar moieties (left: N-acetyl-glucosamine, right: Iduronic Acid) and the enzymes required are shown. Abb.: NDST: N-deacetylase/sulphotransferase; 2-, 3- and 6-Ost: 2-, 3-, 6O-Sulphotransferases respectively (numbers refer to the position of the hydroxyl modified); C5-Epimerase: catalyses the epimerisation at the $\mathrm{C} 5$ position of glucuronic acid to yield iduronic acid. 
The pattern of modifications is complex: different moieties in the same HSGAG chain have different sets of modifications, and sequences of mostly sulphated residues alternate with sequences of unsulphated residues. This basic molecular design of spatially discrete sulphated domains is a unique characteristic of HSGAG and may confer distinctive physical and chemical properties on the glycan chains. The structurally variable core proteins carrying differentially modified HSGAG chains can interact specifically with a wide variety of molecules in the extracellular milieu (reviewed in (Cooper, 2002)). This heterogeneity therefore increases the repertoire of sequences available for specific interactions without an increase in the number of protein coding genes (reviewed in (Gallagher, 2001)).

The modifications of HSGAG chains from different cell types (Kato et al., 1994; Sanderson et al., 1994) and tissues (Friedl et al., 1997; Maccarana et al., 1996) vary reproducibly, owing to differences in the activity of cell type-specific isozymes (Rosenberg et al., 1997) and these tissue-specific glycanation patterns can modulate cell surface proteoglycan function. For example, Sdc1 shows cell type-specific HSGAG modifications which differentially affect its binding to collagen (Sanderson et al., 1994).

\subsection{Roles of HSPGs in Signalling}

HSPGs play a central role in the reception and modulation of signals by a wide range of growth factors like fibroblast growth factor (FGF) and morphogens like Wingless (Wg) and Hedgehog (Hh) (Fig. 2) (reviewed in (Kramer and Yost, 2003)). The long, flexible, polyanionic HSGAG chains of HSPGs are highly effective in capturing and concentrating ligands and restricting their diffusion to the quasi-2-dimensional network of polysaccharides around the cell surface. Infact, studies in Drosophila have shown that Dlp traps Wg outside of cells and seems to retard its movement (Baeg et al., 2001).

Cultured cells deficient in cell surface HSGAG usually fail to proliferate in the presence of HSGAG-dependent growth factors even if growth factor concentrations are high (Fannon and Nugent, 1996; Walker et al., 1994). This result supports a model in which the HSGAG chains have a function in addition to only increasing the probability of ligand-receptor binding. For example, FGF-2 binds to FGFRs expressed on HSGAG- 
depleted cells and elicits downstream signals, but these are short-lived in comparison to HSGAG-mediated signalling (Delehedde et al., 2000). This suggests that one of the functions of HSGAG is to stabilise the ligand-receptor complex, perhaps by a crossbridging mechanism. Also, two crystallographic studies of FGF bound to its receptor and HSGAG indicate that the two FGF molecules do not contact one another and might require HSGAG to form an active complex with FGFR (Pellegrini et al., 2000; Schlessinger et al., 2000). Infact, vertebrate Sdc has been shown to act as a coreceptor with bFGF receptor (Filla et al., 1998; Steinfeld et al., 1996).

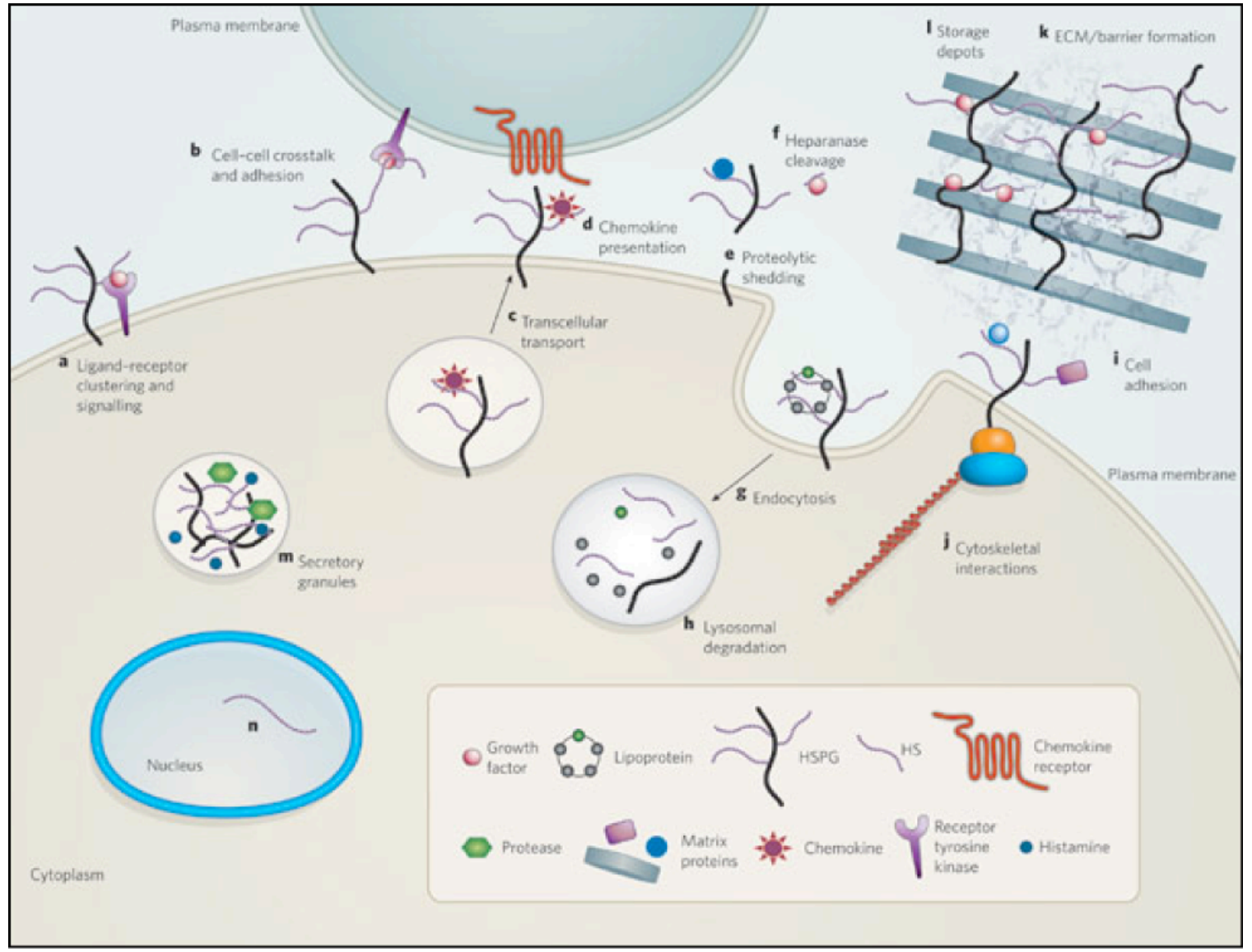

Figure 2: Roles of HSPGs in signalling (from (Bishop et al., 2007)). a) HSPGs function as coreceptors for growth factors, which are present either on the same cell or on adjacent cells (b). c) They transport molecules and present them at the cell surface (d). e) Proteolytic processing leads to the shedding of HSPGs from the cells surface to generate free ectodomainsfrom which bound ligands have been proposed to be subsequently released (f). g) Cell surface HSPGs can be internalised by endocytosis and degraded in lysosomes (h). i) HSPGs also facilitate cell adhesion to the extracellular matrix (ECM) by crosslinking it to the cellular cytoskeleton (j). k) Secreted HSPGs are components of the ECM and form physiological barriers (l). m) HSPGs have also been observed to colocalise with ligands in secretory vesicles. $n$ ) Importance of nuclear HSPGs is at present not known. 
HSPGs might also function to transport signalling molecules to their sites of action. This model is attractive because it has been shown that HSPGs such as Sdes and Glypicans can be shed from the cell surface either by proteolytic cleavage or by phospholipase action, respectively (Carey and Stahl, 1990; Kim et al., 1994; Spring et al., 1994). Thus, in this model an HSPG with its bound signalling ligands could diffuse away from the cell of origin to transport the ligand while protecting it against extracellular proteases. However in an alternative model, shedding could generate soluble HSPG ectodomains that sequester ligands thus diminishing cellular response.

It has also been established that GPI-linked molecules are capable of being transferred intact between the plasma membranes of cells that come into contact with one another (Kooyman et al., 1995). GPI-linked proteoglycans like the Glypicans could therefore provide a molecular mechanism for contact-mediated diffusion of growth factors by sliding with the ligand from cell to cell.

$\mathrm{Wg}$ has been reported to be transported in wing imaginal discs via vesicles called argosomes (Greco et al., 2001). Treatment of these discs with heparinase eliminated Wgcontaining vesicles but not argosomes (Eugster et al., 2007; Greco et al., 2001; Marois et al., 2006). This result suggested that HSPGs might be required for localisation of $\mathrm{Wg}$ to argosomes or that HSPGs are essential components of Wg-transport vesicles.

It is also possible that HSPGs regulate the distribution of the receptor between intracellular compartments and the cell surface (Zimmermann et al., 2005). The cell surface HSPGs can also direct ligands into the cell for degradation or recycling via both clathrin-coated pits and membrane lipid rafts associated caveolae. FGF-2 can be internalised on both Sdes and Glypicans via caveolae through an FGF receptorindependent mechanism (Gleizes et al., 1996). It is highly likely that the function of HSPGs in signalling is ligand and tissue specific. The protein core, the HSGAG chains or a combination of both can confer this specificity in function.

Genetic analysis of D.melanogaster, M.musculus, C.elegans and D.rerio mutants confirm the role of HSPGs in axon guidance as well (reviewed in (Lee and Chien, 2004)). Furthermore, in each of these systems, genes involved in HSGAG biosynthesis show genetic interactions with previously known axon guidance pathways. Also, specific patterns of HSGAG sugar modifications are important for ligand binding as indicated by 
the C.elegans HSGAG modification mutants in which each mutant shows specific axon guidance-phenotypes (Bülow and Hobert, 2004).

\subsection{The Drosophila ventral midline}

The formation of precise connections between neurons and their targets depends upon the ability of the leading edge of an axon termed the growth cone to navigate over long distances by identifying regulatory landmarks along highly stereotyped trajectories (reviewed in (Garbe and Bashaw, 2004; Kaprielian et al., 2000)). The guidance cues are either diffusible or cell surface-associated and regulate long-range and short-range guidance, respectively.
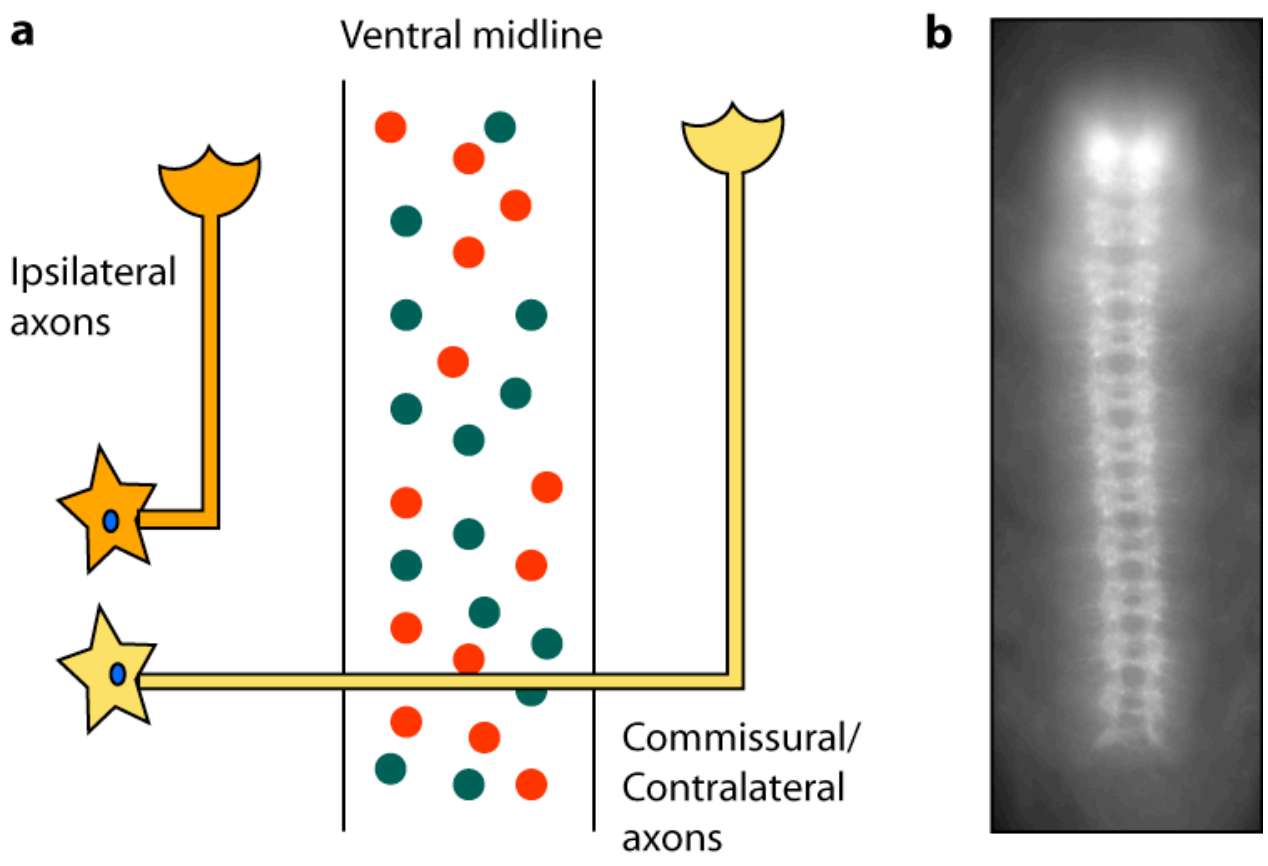

Figure 3: Axon guidance at the ventral midline. a) A schematic representation of the Drosophila ventral midline where attractive (green) and repulsive (red) cues regulate midline crossing of commissural and ipsilateral axons (anterior up). b) The characteristic orthogonal scaffold of CNS axons at the Drosophila ventral midline. Immunofluorescence detection with BP102 Ab that binds an unidentified factor on all CNS axons (stage 16 embryo, ventral view with anterior up).

The majority of neurons in the central nervous system (CNS) called commissural axons project across the ventral midline (Fig. 3a). Interestingly, these axons do not recross the midline. On the other hand, some neurons called ipsilateral axons remain on their own 
side of the CNS (Fig. 3a), without ever crossing the midline. Collectively, the population of commissural and ipsilateral neurons projecting along stereotypic trajectories form the characteristic orthogonal array that represents the Drosophila ventral nerve cord (Fig. 3b) (reviewed in (Tear, 1999)).

Specialised cells which reside at the ventral midline of the developing vertebrate spinal cord and the Drosophila ventral nerve cord physically separate the two halves of the CNS and play a critical role in allowing commissural axons to cross the midline once but prevent ipsilateral axons from entering the midline (reviewed in (Jacobs, 2000)). Many of the molecular mechanisms that control midline guidance are evolutionarily conserved (reviewed in (Chisholm and Tessier-Lavigne, 1999)). Additionally, the clearly defined sources of guidance cues at the midline and the relative ease of interpreting midline guidance defects has made the ventral midline of the invertebrates, C.elegans and Drosophila, and the spinal cord and optic chiasm of vertebrate species powerful systems for the study of axon guidance mechanisms.

\subsection{Slit/Robo signalling mediates axon guidance}

The ventral midline attraction is primarily dependent on Netrin mediated signalling (reviewed in (Cirulli and Yebra, 2007; Guthrie, 1997)). During embryonic CNS patterning Netrin is secreted by the ventral midline cells in Drosophila and C.elegans and by the floor plate of the spinal cord in vertebrates, where it attracts commissural axons towards the midline (Chan et al., 1996; Harris et al., 1996; Hedgecock et al., 1990; Keino-Masu et al., 1996; Kolodziej et al., 1996; Mitchell et al., 1996; Serafini et al., 1996). Members of the DCC (Deleted in Colorectal Cancer) family of Netrin receptors, which include C.elegans UNC-40, Drosophila Frazzled (Fra), and vertebrate DCC and Neogenin, have been shown to mediate Netrin attraction (Chan et al., 1996; Keino-Masu et al., 1996; Kolodziej et al., 1996).

The principal repellent guidance system operating at the ventral midline is Slit/Robo signalling. Roundabout (Robo), a transmembrane axon guidance receptor is expressed at high levels on ipsilateral axons but is upregulated on commissural axons only after they have crossed the midline (Fig. 4a) (Keleman et al., 2002; Kidd et al., 1998). robo 
mutants, as indicated by their name, have ipsilateral (Fig. 4d) and commissural axons that repeatedly circle the ventral midline, implying that Robo is a receptor for a midline repellent (Seeger et al., 1993).
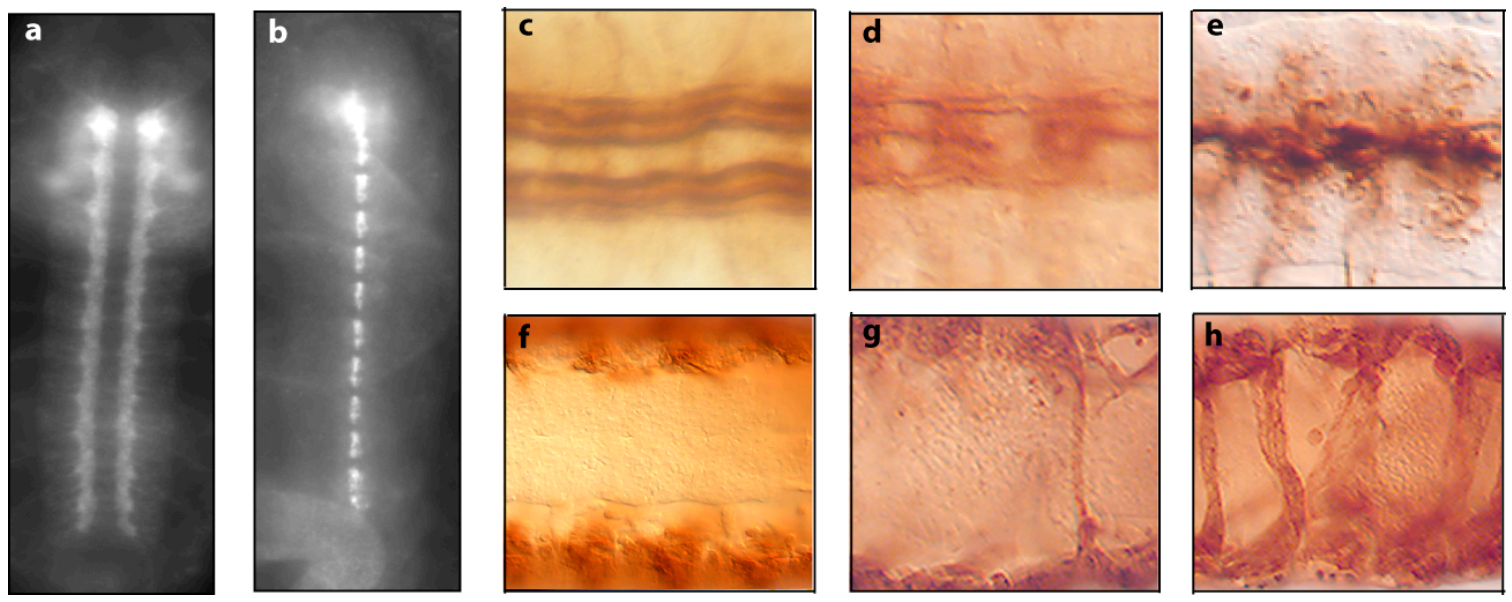

Figure 4: Slit and Robo expression in the CNS and their mutant phenotypes. $a$ and $b$ ) Immunofluorescence images of wild-type stage 16 embryos stained with (a) $\alpha$-Robo Ab and (b) $\alpha$-Slit Ab respectively (ventral view, anterior is up). a) Robo is detected on longitudinal CNS axon tracts but not on the commissures; b) Slit expression is detected in the ventral midline cells. c-e) Stage 16 embryos stained with $\alpha$-FASII Ab (close-up of ventral view, anterior is to the left). c) In wild-type embryos three parallel ipsilateral axon tracts are detected by the Ab on each side of the ventral midline. d) In robo homozygous mutant embryos axons inappropriately circle the ventral midline. e) In slit homozygous mutant embryos all the axon tracts collapse into a single longitudinal bundle at the ventral midline. f-h) Stage 14 embryos stained with $\alpha$-MHC Ab to label muscles (close-up of ventral view, anterior is to the left). f) Wild-type embryos do not show ventral midline crossing of muscles. g) In robo homozygous mutant embryos fewer ventral muscles cross the midline as compared to slit homozygous mutant embryos (h) in which most of the muscles cross the ventral midline. (Figures c-h are from (Steigemann et al., 2004)).

The Robo ligand was identified as Slit, an extracellular matrix protein secreted by midline glia (Fig. 4b) (Nüsslein-Volhard and Wieschaus, 1980; Rothberg et al., 1990). slit mutants are characterised by a collapsed axon scaffold as a result of axons entering the midline but being unable to leave it (Zinn and Sun, 1999) (Fig. 4e). This implicates Slit as a midline repellent. Slit was also demonstrated to function as a repellent by overexpressing it either at the midline or in stripes, which caused axons to turn away from these Slit-expressing regions (Battye et al., 1999).

There is a paradoxical difference in the mutant phenotypes of slit and robo. While a slit mutant is characterised by a collapsed axon scaffold (Nüsslein-Volhard and Wieschaus, 
1980) the robo mutant shows repeated circling of axons within an intact axon scaffold (Seeger et al., 1993). This difference was explained when it was found that there are three Robo receptors in Drosophila: Robo, Robo2 and Robo3 and all three receptors mediate repulsive guidance responses upon activation by Slit (Rajagopalan et al., 2000a; Simpson et al., 2000).

\subsection{Slit/Robo signalling mediates muscle patterning}

The role of Slit in the development of the musculature is complex. During embryogenesis muscle founder cells called myoblasts express receptors Robo and Robo2 (Kidd et al., 1999). As a consequence they are repelled from the ventral midline by Slit (Kramer et al., 2001). Myoblasts subsequently fuse to form myotubes that extend processes towards muscle attachment sites (MAS) in the epidermis (reviewed in (Schnorrer and Dickson, 2004; Volk, 1999)). This migration of myotubes towards the MAS is due to the attraction by Slit (Kramer et al., 2001) produced at the MAS (Rothberg et al., 1990).

Slit deficient Drosophila embryos have an aberrant musculature in which many muscles extend across the ventral midline to attach alongside the ventral longitudinal muscles due to the absence of the early ventral repellent activity of Slit (Kidd et al., 1999) (Fig. 3h). A nearly identical phenotype is seen in robo,robo2 double mutants (Rajagopalan et al., 2000a; Simpson et al., 2000).

The initial repulsion of myoblasts from the ventral midline can be rescued by expressing Slit at the ventral midline of slit-deficient Drosophila embryos. However, the muscles then attach at inappropriate sites in the epidermis (Kramer et al., 2001). Ectopic expression of Slit in the epidermis of slit mutant embryos results in the attachment of Robo and Robo2 expressing muscles to epidermal sites ectopically expressing Slit that is presumably caused by the later attractive function of Slit for muscle guidance (Kramer et al., 2001). Furthermore, driving expression of Robo or Robo2 in lateral muscles that do not normally express these receptors causes them to respond to the attractive Slit signal resulting in their ectopic attachment to MAS expressing Slit at the segment borders (Kramer et al., 2001).

Thus Slit plays diametrically opposite roles in the processes of mesodermal migration in Drosophila, acting to repel Robo and Robo2 expressing ventrally positioned myoblasts 
from the midline in early embryogenesis and later acting to attract syncytial myotubes to specific epidermal attachment sites. How this switch in responsiveness is attained is unknown.

\subsection{Syndecan regulates Slit/Robo signalling}

During Drosophila embryogenesis, $s d c$ transcripts are detected in the ventral furrow, the ventral nerve cord, the abdominal and the thoracic segments, the epidermis and the differentiating CNS (Kopczynski et al., 1998). Towards late embryogenesis, sdc is expressed in the lymph glands, the peripheral nervous system (PNS), the CNS (Fig. 5a), the gut epithelia, the mesoderm and the tracheal system (Spring et al., 1994; Steigemann et al., 2004). The vertebrate Sdcs comprise a family of four distinct genes (Sdc1 to Sdc4) and are expressed in a variety of tissues throughout development (reviewed in (Princivalle and de Agostini, 2002)).
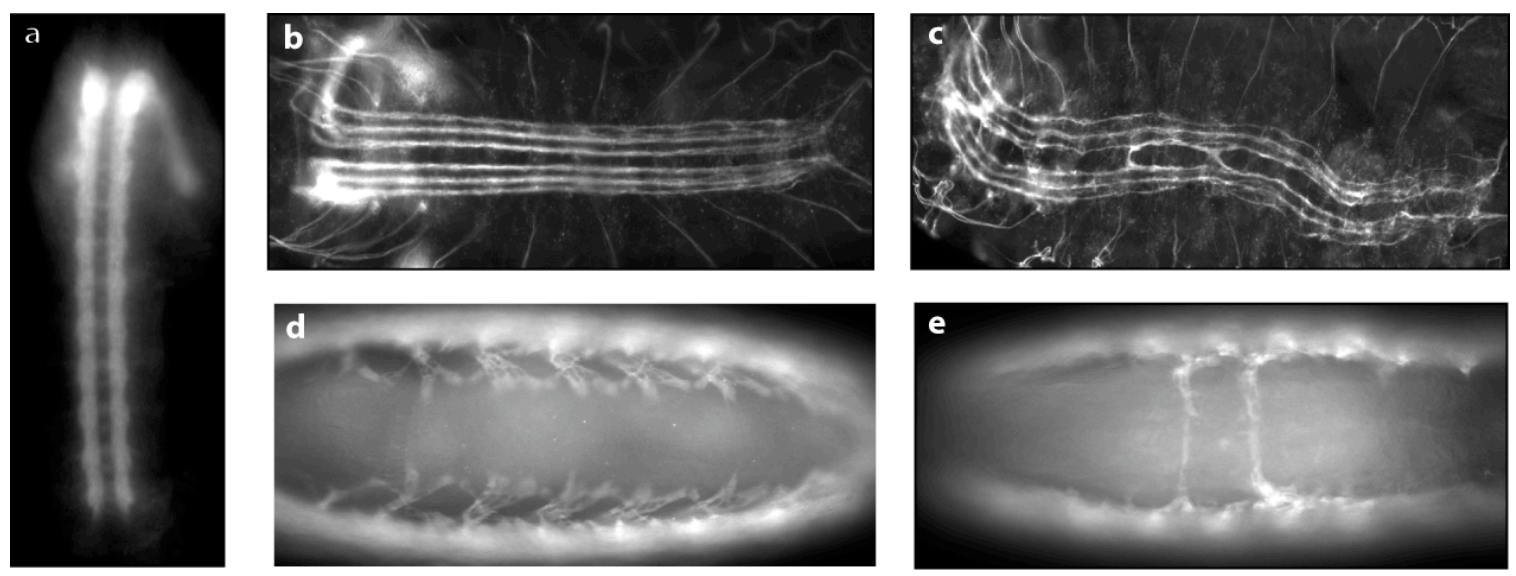

Figure 5: Sdc expression in the CNS and mutant phenotypes. a) Immunofluorescence image of a wild-type stage 16 embryo stained with $\alpha$-Sdc $\mathrm{Ab}$ (ventral view, anterior up). Sdc is expressed in the ventral nerve cord. $b$ and c) Immunofluorescence images of stage 16 embryos stained with $\alpha$-FASII Ab. b) In wild-type embryos three parallel ipsilateral axon tracts are present on each side of the ventral midline. c) In $s d c^{23}$ homozygous mutant embryos, the innermost axon tracts cross over the ventral midline; $d$ and e) Immunofluorescence images of stage 16 embryos stained with $\alpha$-MHC Ab. d) In wild-type embryos no muscle crosses the ventral midline. e) In $s d c^{23}$ homozygous mutant embryos ventral midline crossover of ventral muscles is observed. b-e: ventral view, anterior is to the left.

Drosophila $s d c$ null $\left(s d c^{23}\right)$ mutants, show partially penetrant midline crossing defects of both CNS ipsilateral axons and ventral muscles characteristic of defective Slit signalling 
(Fig. 5c and e) (Johnson et al., 2004; Steigemann et al., 2004). Furthermore, $s d c$ has been shown to interact genetically with slit and robo (Johnson et al., 2004; Steigemann et al., 2004). Coimmunoprecipitation experiments in cultured cells showed that both Slit and Robo form complexes with Sdc (Johnson et al., 2004). Although among all HSPGs, disruption of $s d c$ alone leads to axon guidance defects, neural over-expression of the Drosophila Glypican $d l p$ has been reported to significantly rescue the midline phenotype of the $s d c$ mutant (Johnson et al., 2004).

An essential role for cell surface heparan sulphate has also been demonstrated for the repulsive activity of vertebrate Slit2 and in enhancing Slit2/Robo1 interaction in cell culture (Hu, 2001). Infact the mammalian homologs of Slit have been reported to serve as ligands for Glypican1 (Liang et al., 1999). Furthermore, analysis of ext1 null brains (ext1 encodes the mammalian homolog of Drosophila HSGAG polymerase Ttv) from conditional knockout mice displayed severe guidance errors in major commissural tracts demonstrating that HSGAG is essential for mammalian brain development as well (Inatani et al., 2003).

\subsection{Domain structure of Syndecan}

Most of our knowledge regarding the structure, functions and modes of action of Sdcs, is derived from vertebrate studies. The analysis of $s d c 1$ knockout mice (Alexander et al., 2000) reveals an abnormality in repair of skin and corneal wounds (Stepp et al., 2002). Therefore, besides regulating CNS and muscle development, Sdc also maintains the integrity of simple epithelia by affecting the organisation of the actin cytoskeleton (Woods et al., 1986) and the expression of E-cadherin (Kato et al., 1995), the molecule responsible for epithelial intercellular adhesion (reviewed in (Miyoshi and Takai, 2005)).

\subsubsection{Cytoplasmic domain of Syndecan}

The short cytoplasmic domain of Sdc participates in specific intracellular signalling pathways and assembly of specific cellular structures that support cell adhesion (reviewed in (Kramer and Yost, 2003)). The cytoplasmic domain of Sdc has two conserved regions, a membrane proximal $\mathrm{C} 1$ region and a membrane distal $\mathrm{C} 2$ region, 
which are separated by a variable $\mathrm{V}$ region that is believed to confer specificity on each vertebrate Sdc subfamily (reviewed in (Bernfield et al., 1999; Couchman, 2003)).

The $\mathrm{C} 1$ domain of $\mathrm{Sdc} 3$ binds a protein complex from neuroblastoma cell extracts composed of the Src family kinases, the Src substrates and actin-binding proteins Cortactin and Tubulin (Kinnunen et al., 1998). Inhibitor studies also suggest that Src family kinases phosphorylate the Sdes, thus implicating Sde C1 region in intracellular signalling (Oh et al., 1997; Prasthofer et al., 1995). However the significance of these phosphorylation events are not known.

The $\mathrm{C} 2$ region has an EFYA sequence at its $\mathrm{C}$-terminus that can bind to PDZ domaincontaining proteins (Ethell and Yamaguchi, 1999). PDZ domains (named for PSD-95, Disc-large and Zonula occludens-1) bind specific C-terminal sequences to organise and assemble protein complexes at the inner face of the plasma membrane (Fanning and Anderson, 1996) and are thought to link membrane components to the underlying actin cytoskeleton (Bass and Humphries, 2002). This interaction may account for the variety of changes in actin filament organisation associated with the Sdcs, including binding of $\mathrm{Sdc} 1$ to a crude preparation of F-actin filaments, colocalisation of Sdc1 and F-actin at the basal surfaces of polarised mammary epithelial cells (reviewed in (Bernfield et al., 1999; Couchman, 2003)) and actin filament reorganisation upon binding of Sdes to an ECM ligand (Woods et al., 1986) or upon depletion of Sdc1 from epithelial cells (Kato et al., 1995). Furthermore, the distribution of clustered Sdc can be altered by cytochalasin treatment (Carey et al., 1994) that depolymerises actin filaments. These changes in distribution have been shown to be dependent on the cytoplasmic domain of Sdc (Carey et al., 1996). Clustering of cell surface Sdc1 with $\alpha$-Sdc antibodies, FGF2 or Collagen1coated beads also leads to recruitment of actin microfilaments (Carey, 1997).

\subsubsection{Transmembrane domain of Syndecan}

The conserved transmembrane domain of Sdc is responsible for its localisation to discrete membrane micro-domains: Sdc1 localises to the basolateral cell surface of epithelia, whereas Sdc4 localises to focal adhesions (Hayashi et al., 1987; Rapraeger et al., 1986; Woods and Couchman, 1994). The transmembrane domains may also interact within the plane of the membrane with proteins involved in cell spreading, because cells containing 
Sdc1 or Sdc4 devoid of their cytoplasmic domains can still attach and spread on substrata (Lebakken and Rapraeger, 1996; Yamashita et al., 1999). Additionally, transmembrane domain-induced oligomerisation is crucial for the functions of Sdc2 and Sdc4 (Choi et al., 2005).

\subsubsection{Extracellular domain of Syndecan}

Each mammalian Sdc and the single Drosophila Sdc is cleaved near the plasma membrane resulting in the release of their intact ectodomain in a process known as shedding (Kim et al., 1994; Spring et al., 1994). Shedding may occur as part of cell surface HSPG turn over (Yamagata et al., 1993), or might function to generate instant soluble intercellular regulators. Shedding of Sdc could produce agonists or antagonists that regulate its activity, render cells less responsive to their ligands and potentially generate an active fragment that remains membrane-associated or can become intracellular. Shedding of Sdc1 and Sdc4 is accelerated by cellular stress (mechanical, heat-shock, hyperosmolarity). Secreted products of certain bacterial pathogens also accelerate shedding (Park et al., 2001).

Shedding of vertebrate Sdc is inhibited by both peptide hydroxamate chelators of Zinc ions (Beckett et al., 1996) and tissue inhibitor of metalloprotease III (TIMP-3) (AnandApte et al., 1996). These findings suggest that the protease responsible for shedding is a member of the ADAM (A Disintegrin and Metalloprotease) family of cell surface proteases (Wolfsberg et al., 1995a; Wolfsberg et al., 1995b). The proteolytic cleavage site has been reported to be within 5 amino acids from the plasma membrane in the extracellular domain (Wang et al., 2005).

All Sdcs form sodium dodecyl sulphate (SDS) resistant oligomers (Saunders et al., 1989). That Sdcs form oligomers is surprising considering the molecular volume and negative charge of their HSGAG chains. Nevertheless, HSGAG chains can self-associate (Fransson et al., 1983) but it is not clear whether the HSGAG chains affect oligomerisation. Oligomers, however, are most readily demonstrated by Sdcs bearing relatively small HSGAG chains (as produced by keratinocytes) or by Sdcs devoid of HSGAG chains (Sanderson et al., 1992). Moreover, the shed ectodomains free of the 
transmembrane domain migrate similarly to the intact protein on polyacrylamide gel electrophoresis, suggesting that they form oligomers too (Subramanian et al., 1997).

\subsection{Mechanistic analysis of Syndecan function in Slit/Robo signalling}

The general regulatory mechanisms ranging from spatial and temporal regulation of transcription to post-translational trafficking of guidance cues and their receptors to ensure accurate reception of guidance signals (reviewed in (Garbe and Bashaw, 2004)) also apply to Slit/Robo signalling. However, another way to modulate signalling by secreted ligands such as Slit is to control their extracellular distribution and availability (reviewed in (Nguyen Ba-Charvet et al., 2001)). Based on the large number of vertebrate studies that examined the role of Sdc in various cellular processes several models can be proposed for the regulation of Slit/Robo signalling by Sdc. The present work is the first systematic approach to understand the mechanism by which an HSPG such as Sdc can regulate Slit/Robo signalling, the key repellent axon guidance system operating during embryogenesis. 


\section{Materials and Methods}

\subsection{Molecular Biology}

\subsubsection{Polymerase Chain Reaction}

The Polymerase Chain Reaction (PCR) allows for rapid amplification of DNA from minimal amounts of starting material (Higuchi et al., 1988). In this work it was used to generate DNA fragments for cloning. For cloning purposes, La Taq Kit (TAKARA) was used. The annealing temperature chosen was generally $5^{\circ} \mathrm{C}$ below the melting temperature of the primers used in the reaction. All PCRs were carried out in a Gene Amp 9700 PCR cycler (Applied Biosystems).

\subsubsection{DNA Restriction}

Restriction endonucleases (Fermentas) were used to prepare DNA fragments for cloning and as an analytical tool for clone confirmation. For analytical restriction, typically $1 \mu \mathrm{g}$ DNA was restricted for $1 \mathrm{hr}$ with $0.5 \mu \mathrm{l}$ of restriction enzyme in a $20 \mu \mathrm{l}$ volume using the appropriate restriction buffer and incubation temperature as indicated by the manufacturers. For preparative purposes, $10 \mu \mathrm{g}$ DNA was digested in a $100 \mu \mathrm{l}$ volume with $1.5 \mu \mathrm{l}$ of restriction enzyme for $4-16 \mathrm{hrs}$.

\subsubsection{DNA extraction from agarose gel}

To recover DNA from agarose gel, the desired DNA fragments were cut out with a scalpel. DNA was then extracted using the QIAquick Gel Extraction Kit (Qiagen), according to the manufacturer's protocol.

\subsubsection{Dephosphorylation of vector DNA}

Self-ligation of vector DNA was minimised by removing the 5' phosphate group with alkaline phosphatase treatment. The restricted vector DNA was incubated for 30 min with $1 \mu \mathrm{l}$ of shrimp alkaline phosphatase (SAP, USB) and the appropriate volume of 
dephosphorylation buffer (USB). Dephosphorylated DNA was purified using the QIAspin Nucleotide Removal Kit (Qiagen) according to the provided manual.

\subsubsection{DNA Ligation}

$100 \mathrm{ng}-1 \mu \mathrm{g}$ of restricted and dephosphorylated vector DNA was mixed with 3 molar excess of isolated DNA fragments, $1 \mu \mathrm{l}$ of T4-Ligase (Fermentas) and $1 \mu \mathrm{l}$ of 10X T4 Ligase buffer in a volume of $10 \mu \mathrm{l}$. The ligation reaction was incubated for 12-18 hrs at $16^{\mathrm{O}} \mathrm{C}$ or for $3 \mathrm{hrs}$ at room temperature. Direct subcloning of PCR products was done using the TOPO TA Cloning Kit (Invitrogen). For this, PCR fragments were gel-purified and ligated directly into pCRII-TOPO vector following the procedures described in the manual.

\subsubsection{Preparation of electro-competent Escherichia coli (E.coli) cells}

$50 \mathrm{ml} \mathrm{LB}$ medium was inoculated with a colony of E.coli and incubated overnight at $37^{\circ} \mathrm{C}$ at $180 \mathrm{rpm}$. Next day, $10 \mathrm{ml}$ of fresh culture was inoculated in $500 \mathrm{ml}$ of LB medium and incubated at $37^{\circ} \mathrm{C}$ at $180 \mathrm{rpm}$ until the culture was grown to an $\mathrm{OD}_{600}$ of 0.5-0.6. Once the appropriate cell density was reached, the cells were transferred to $4^{\mathrm{O}} \mathrm{C}$ for the following steps. The cells were centrifuged down at 5,000 rpm for $12 \mathrm{~min}$. The cell-pellet was resuspended in $250 \mathrm{ml}$ of sterile $10 \%$ glycerol solution. The cells were again centrifuged and the pellet resuspended in $125 \mathrm{ml}$ of $10 \%$ glycerol. The cells were subsequently centrifuged and the pellet resuspended in $5 \mathrm{ml}$ of $10 \%$ glycerol. Finally the cells were centrifuged and the pellet resuspended in $2 \mathrm{ml}$ of $10 \%$ glycerol. Aliquots of cells were prepared and flash frozen in liquid nitrogen before long-term storage at $-80^{\circ} \mathrm{C}$.

\subsubsection{Preparation of chemical-competent E.coli cells}

A single E.coli colony was inoculated in $100 \mathrm{ml} \mathrm{LB}$ medium and incubated overnight at $37^{\circ} \mathrm{C}$ at $180 \mathrm{rpm}$. Next day, $3 \mathrm{ml}$ of fresh culture was inoculated in $250 \mathrm{ml}$ of LB medium and incubated at $37^{\circ} \mathrm{C}$ at $180 \mathrm{rpm}$ until an $\mathrm{OD}_{600}$ of 0.5-0.6 was reached. The cells were then transferred to $4^{\circ} \mathrm{C}$ for further steps. The cells were centrifuged at $3,500 \mathrm{rpm}$ for 10 min and the pellet resuspended in $10 \mathrm{ml} \mathrm{TB}\left(10 \mathrm{mM}\right.$ Pipes, $15 \mathrm{mM} \mathrm{CaCl}_{2}, 250 \mathrm{mM} \mathrm{KCl}$, 
$\mathrm{pH}$ adjusted to 6.7 and then added $55 \mathrm{mM} \mathrm{MnCl}_{2}$ ). Then $70 \mathrm{ml}$ more TB was added. The cells were incubated on ice for $10 \mathrm{~min}$ and then centrifuged at 3,500 rpm for another 10 min. The cell pellet was resuspended in $20 \mathrm{ml}$ TB and 7\% DMSO was added to it. The cells were left on ice for $10 \mathrm{~min}$ and then aliquoted. The aliquots were flash frozen in liquid nitrogen before long-term storage at $-80^{\circ} \mathrm{C}$.

\subsubsection{Transformation of electro-competent E.coli cells}

Transformation of bacteria was done by high-voltage electroporation or by heat-shock of chemical-competent cells (Section 2.1.9). For electroporation, electro-competent cells were thawed on ice, mixed with 1-2 $\mu \mathrm{l}$ of ligation reaction and transferred to a gene pulser cuvette (Biorad). Electroporation was done in a Gene Pulser (Biorad) using the following settings: $25 \mu \mathrm{FD}, 1.8 \mathrm{kV}$ and $200 \mathrm{~W}$. After the pulse, bacteria were recovered in $1 \mathrm{ml} \mathrm{LB}$ medium and incubated on a shaker at $37^{\circ} \mathrm{C}$ for $1 \mathrm{hr}$. Afterwards, the cells were pelleted by centrifugation at 3,500 rpm, resuspended in $100 \mu \mathrm{LB}$ medium and plated on LB-agar plates containing ampicillin at a final concentration of $100 \mu \mathrm{g} / \mathrm{ml}$. Plates were incubated overnight at $37^{\circ} \mathrm{C}$.

\subsubsection{Transformation of chemical-competent E.coli cells}

To thawed chemical-competent cells, 1-5 $\mu 1$ of ligation reaction was added and incubated on ice for $30 \mathrm{~min}$. The cells were then heat-shocked at $42^{\circ} \mathrm{C}$ for $90 \mathrm{sec}$ and transferred to ice for $3 \mathrm{~min} .800 \mu \mathrm{LB}$ was added for recovery at $37^{\circ} \mathrm{C}$ at $180 \mathrm{rpm}$ for $1 \mathrm{hr}$. The cells were then centrifuged and resuspended in $200 \mu \mathrm{LB}$ before plating on LB-agar plates supplemented with ampicillin at a final concentration of $100 \mu \mathrm{g} / \mathrm{ml}$.

\subsubsection{Plasmid DNA purification}

Plasmid DNA purification was done using the QIAspin Plasmid Midi kit (Qiagen) or QIAPrep Spin Miniprep Kit (Qiagen) according to the manufacturer's protocol. Single colonies of transformed bacteria were used to inoculate $80-100 \mathrm{ml}$ or $5 \mathrm{ml}$ of LB medium supplemented with ampicillin $(100 \mu \mathrm{g} / \mathrm{ml})$ and grown overnight at $37^{\circ} \mathrm{C}$ at $180 \mathrm{rpm}$. 
Bacteria were harvested by centrifugation at $6,000 \mathrm{rpm}$ for $15 \mathrm{~min}$ or at $3,000 \mathrm{rpm}$ for 10 min. The rest of the purification was done following the procedure in the manual.

\subsubsection{DNA Sequencing}

DNA sequencing was done either by, Gordon Dowe on an ABI Prism 377 DNA sequencer (Applied Biosystems) in the Max-Planck-Institute for Biophysical Chemistry, Göttingen or at the MWG Sequencing facility (MWG-Biotech).

\subsubsection{Site-directed mutagenesis}

Site-directed mutagenesis was done to sequentially mutate the putative HSGAG attachment sites on Sdc. The mutations were introduced in the primers, which spanned the desired region in both directions. These primers were used in combination with primers specific for the 5' and 3' ends of $s d c$ to generate two overlapping fragments, both containing the desired point mutation. These overlapping fragments were then used as templates in a single PCR reaction in which only the 5' and 3' end-specific primers were used for amplification, thus generating a full-length $s d c$ transgene having a single point mutation. This transgene was then used as template to introduce a second-site point mutation. This cycle was continued until all 5 putative sites were mutated.

\subsubsection{DNA preparation for Embryo Injections}

Plasmid DNA for P-element mediated germline transformation of Drosophila was purified by phenol-chloroform extraction and then coprecipitated with carrier DNA that expresses the P-element transposase. For phenol-chloroform extraction, $40 \mu \mathrm{g}$ plasmid DNA (in $300 \mu \mathrm{l}$ water) was mixed with $300 \mu 1$ phenol-chloroform-isoamylalcohol mix (Ambion), vortexed and transferred to a PhaseLock ${ }^{\mathrm{TM}}$ tube (Eppendorf) and centrifuged for $3 \mathrm{~min}$ at 13,000 rpm in a tabletop centrifuge. The aqueous phase was transferred to a new tube, mixed with $30 \mu \mathrm{l} 3 \mathrm{M} \mathrm{NaAc}(\mathrm{pH}$ 5.2) and $750 \mu \mathrm{l} 100 \%$ ethanol and then centrifuged for $30 \mathrm{~min}$ at $13,000 \mathrm{rpm}$. The DNA pellet was washed twice with $500 \mu \mathrm{l}$ $70 \%$ ethanol, dried and resuspended in $20 \mu \mathrm{l}$ water. DNA concentration was determined spectrophotometrically. For coprecipitation with carrier DNA, $12 \mu \mathrm{l}$ of purified plasmid 
DNA was mixed with $4 \mu \mathrm{g}$ carrier DNA in $200 \mu \mathrm{l}$ water, $20 \mu 13 \mathrm{M} \mathrm{NaAc}(\mathrm{pH}$ 5.2) and $500 \mu 1100 \%$ ethanol. The DNA was precipitated by centrifugation for $30 \mathrm{~min}$ at 13,000 rpm, washed twice with $500 \mu 170 \%$ ethanol, dried and resuspended in $20 \mu 1$ water by incubation at $60^{\circ} \mathrm{C}$ for $5 \mathrm{~min}$. To remove insoluble fragments, DNA was centrifuged for $5 \mathrm{~min}$ at $13,000 \mathrm{rpm}$. DNA concentration was determined by spectrophotometry. For injection, concentration of the plasmid/carrier DNA mixture was adjusted to $400 \mathrm{ng} / \mu \mathrm{l}$. DNA was injected by Iris Plischke, Tomma Eisbein or Ursula Jahns-Meier at MaxPlanck-Institute for Biophysical Chemistry. Alternatively, $20 \mu \mathrm{g}$ of phenol-chloroform purified plasmid DNA was sent to the injection service at Oslo.

\subsection{Fly techniques}

\subsubsection{Maintenance of flies}

All flies were propagated on a complex corn flour-soya flour-molasses medium supplemented with dry yeast at $25^{\mathrm{O}} \mathrm{C}$ and $20-30 \%$ humidity.

\subsubsection{Generation of stable transgenic fly lines}

Transgenic flies were generated by P-element-mediated germline transformation (Rubin and Spradling, 1982; Spradling and Rubin, 1982). Plasmid DNA for injection was prepared as described in Section 2.1.13. $w^{118}$ embryos (BL8164, Section 2.7) were injected by Iris Plischke, Tomma Eisbein or Ursula Jahns-Meyer at the Max-PlanckInstitute for Biophysical Chemistry, Göttingen or alternatively it was sent to the injection facility at Oslo. Each hatched fly was back-crossed to a $w^{118}$ fly. In the next generation germline-transformed flies were identified by their red eye colour, which is due to the mini- $w^{+}$marker gene in the P-element vector. The transformed chromosome was identified and stabilised by crossing the flies with "balancer" flies using $w^{*}$; $\operatorname{amos}^{T f t} / C y O, P\{h b-l a c Z\}$ for the second chromosome and $w^{*} ; \operatorname{croc}^{59} e^{* / T M 3, P}\{u b x$ $\operatorname{lac} Z\}, S b^{l}$ for the third chromosome, respectively. For each experiment atleast two independent transgenic fly lines were used. 


\subsubsection{Ectopic gene expression via the UAS/GAL4 system}

The UAS/GAL4 system allows for ectopic induction of genes in a spatially and temporally controlled fashion. This two-component system is borrowed from yeast where the transcription factor GAL4 binds to its target Upstream Activating Sequence (UAS) to activate transcription (Brand and Perrimon, 1993). A transgenic fly line carrying a specific enhancer element upstream of the gal4 gene when mated with a transgenic fly line carrying a coding sequence fused downstream of the UAS, results in progeny, which express the UAS-coding region in a manner directed by the enhancer element upstream of GAL4.

\subsubsection{Fixation of embryos}

Appropriately staged embryos were collected from apple-juice agar plates, washed well with water and dechorinated with $50 \%$ bleach. The bleach was removed with extensive washing with water and embryos were fixed for $20 \mathrm{~min}$ with a mixture of $8 \mathrm{ml}$ hepatne and $1 \mathrm{ml}$ fix solution (100 mM HEPES pH 6.9, $2 \mathrm{mM} \mathrm{MgSO}_{4}, 1 \mathrm{mM}$ EGTA, 37\% formaldehyde) on a rocking platform. Fix solution was removed and the embryos were devitellinised by adding $10 \mathrm{ml}$ methanol and vortexing for $15 \mathrm{sec}$. Devitellinised embryos sank to the bottom and were washed 3 times with methanol and afterwards stored at $-20^{\circ} \mathrm{C}$.

\subsubsection{Antibody (Ab) staining of embryos}

All steps were at room temperature on a rotator unless mentioned otherwise. Fixed embryos were washed 3 times for 5 min with Phosphate Buffered Saline-Triton X-100 (PBS-T: 8.0 gm NaCl, 0.2 gm KCl, 1.4 gm Na $\mathrm{HPO}_{4}$, 0.2 gm $\mathrm{KH}_{2} \mathrm{PO}_{4}$ with volume made up to $1 \mathrm{~L}, \mathrm{pH} 7.4$ and supplemented with $0.1 \%$ Triton $\mathrm{X}-100$ ) to remove methanol. Embryos were blocked with $10 \%$ goat serum for $1 \mathrm{hr}$ and incubated overnight with $1^{\mathrm{O}} \mathrm{Ab}$ at $4^{\mathrm{O}} \mathrm{C}$. Next day embryos were washed 3 times 20 minutes with PBS-T. In case staining was done with FLAG-M2 $1^{\mathrm{O}} \mathrm{Ab}$, there was an additional step of washing with PBS-T containing 500mM NaCl, 6 times for $20 \mathrm{~min}$. Embryos were then incubated for $2 \mathrm{hrs}$ with the appropriate $2^{\mathrm{O}} \mathrm{Ab}$. After $2^{\mathrm{O}} \mathrm{Ab}$ incubation, embryos were washed 3 times 20 min with 
PBS-T. If the $2^{\mathrm{O}} \mathrm{Ab}$ used was not labelled with a fluorophore, staining was developed using the ABC Elite PK6100 Kit (Vectastain). In brief, a mix of sol A (10 $\mu \mathrm{l})$ and sol B (10 $\mu 1)$ in $500 \mu \mathrm{l}$ PBS-T was incubated for 30 min without shaking and then added to embryos and incubated for 30 min more on a rotator. Embryos were then washed 3 times for $15 \mathrm{~min}$ and staining was developed using the TSA Fluorescein System (Perkin Elmer) by incubating with TSA-coupled dye for $5 \mathrm{~min}$. Reaction was terminated by washing vigorously with PBS-T, 3 times for $10 \mathrm{~min}$ and in the end heating at $70^{\circ} \mathrm{C}$ for $10 \mathrm{~min}$. For a sequential antibody staining, biotin from the $1^{\text {st }} \mathrm{Ab}$ development was blocked by using the Avidin/Biotin Blocking Kit (Vector Labs). Blocking was done after washing the $2^{\text {nd }}$ $1^{\mathrm{O}} \mathrm{Ab}$ by incubating with each blocking solution for $15 \mathrm{~min}$ and rinsing 3 times with PBS$\mathrm{T}$ before continuing with $2^{\text {nd }} 2^{\mathrm{O}} \mathrm{Ab}$ incubation. After staining, embryos were either mounted in a glycerol based mounting medium (7 gm glycerol, $500 \mu 1$ 10X PBS, $500 \mu 11$ M Tris-HCl, pH 9.5, $100 \mathrm{mg}$ propyl gallate, $250 \mu \mathrm{l}$ 1,4-phenylene diamine $(20 \mathrm{mg} / \mathrm{ml})$ with volume made up to $10 \mathrm{ml}$ double-distilled water) for quantification of phenotype or dehydrated and mounted in BB medium (benzylbenzoate:benzylalcohol::2:1) for qualitative analysis.

\subsubsection{Fluorescence microscopy}

For quantification of phenotype, stained embryos were analysed on a Leica epifluorescence microscope. The other stainings were analysed using a Leica TCS SP2 LSM confocal microscope.

\subsection{Cell culture based techniques}

\subsubsection{Maintenance of cells}

Drosophila S2 cells were grown and maintained in Gibco's Drosophila medium supplemented with $10 \%$ fetal calf serum (Sigma Aldrich) and streptomycin (PAA Labs) at a concentration of $100 \mu \mathrm{g} / \mathrm{ml}$ at $25^{\circ} \mathrm{C}$. 


\subsubsection{Transfection of cells}

Confluent cells were split and seeded at a concentration of $1 \times 10^{5} \mathrm{cells} / \mathrm{ml}, 3 \mathrm{ml} / \mathrm{well}$ in 6-well plates. The cells were allowed to settle and grow for 1 day before transfection. Transfection was done using the Qiagen Effectene Transfection Kit (Qiagen). The manufacturer's protocol was modified for Drosophila S2 cells. The volumes used per well were: $20 \mu \mathrm{l}$ enhancer, $200 \mu \mathrm{l}$ of DNA in buffer EC and $16 \mu \mathrm{l}$ of effectene. $1 \mu \mathrm{g}$ of actinG4 plasmid was cotransfected with $1 \mu \mathrm{g}$ of UAS-transgene plasmid. The final effectene-DNA mix was added drop-wise on cells. After 1 day the medium on the cells was changed. The supernatant and cells were harvested 2 days later for analysis. Cell extracts were prepared in $3 \mathrm{X}$ sample buffer $(150 \mathrm{mM}$ Tris, $\mathrm{pH} 6.8,6 \%$ SDS, $0.3 \%$ bromophenol blue, 30\% glycerol with $100 \mathrm{mM}$ DTT added fresh before loading) while the supernatants were flash frozen in liquid nitrogen and stored at $-80^{\circ} \mathrm{C}$ for later analysis.

\subsubsection{Assay for protein secretion}

To test if a protein was secreted or not, cells were seeded, transfected and harvested as discussed in Section 2.3.2. Then, $300 \mu$ of harvested supernatant was concentrated 10 times using a Vivaspin-500 columns (Viva Science). One-third of the concentrate was loaded and run on an $8 \%$ Sodium Dodecyl Sulphate-Polyacrylamide Gel (SDS-PAGE) and analysed further by western blot (Section 2.3.6).

\subsubsection{Assay for protein shedding}

To check if a protein is shed in cell culture, cells were seeded, transfected and harvested as discussed in Section 2.3.2. Following that, the harvested supernatant was incubated overnight with $2 \mathrm{ml}$ DEAE-Sepharose Fast Flow (Amersham) at $4^{\mathrm{O}} \mathrm{C}$ on a shaker. The DEAE-Sepharose beads had been washed previously, twice with $10 \mathrm{ml}$ of wash buffer 1 (WB1: $2 \mathrm{M}$ urea, $150 \mathrm{mM} \mathrm{NaCl}, 50 \mathrm{mM} \mathrm{NaAc}, \mathrm{pH} \mathrm{4.5,} \mathrm{0.1 \%} \mathrm{Triton} \mathrm{X-100).} \mathrm{After}$ overnight incubation, the mix was loaded into an empty column and the flow through was allowed to pass. The column was then washed twice with $10 \mathrm{ml}$ WB1 and once with WB2 (150 mM NaCl, $50 \mathrm{mM} \mathrm{NaAc}, \mathrm{pH} 4.5,0.1 \%$ Triton X-100). Protein was eluted 
using a step-elution gradient of $\mathrm{NaCl}(0.2,0.4,0.6,0.8$ and $1 \mathrm{M})$ in $\mathrm{WB} 2$ in $1 \mathrm{ml}$ volumes. The protein in the eluted fractions was precipitated by adding 3 volumes of ethanol and $1.3 \%$ potassium acetate and incubating overnight at $-20^{\circ} \mathrm{C}$. Next day, samples were centrifuged at 11,000 rpm for $30 \mathrm{~min}$, dried and the protein resuspended in $10 \mu \mathrm{l}$ Tris-HCl, pH 7.2 (100 mM Tris-HCl, 5 mM EDTA, 1mM PMSF). These fractions were then analysed by WB (Section 2.3.6) or used for enzymatic assays (Section 2.3.5). Also, protease sensitivity of shedding was determined by adding a protease inhibitor cocktail (Complete Mini, Roche), serine protease inhibitor (4-(2-aminoethyl)benzenesulphonyl fluoride, Sigma Aldrich) or a metalloprotease inhibitor (bestatin hydrochloride, Sigma Aldrich), at a concentration of $10 \mu \mathrm{g} / \mathrm{ml}, 24 \mathrm{hrs}$ after transfection. The cell supernatants were harvested and analysed as mentioned above.

\subsubsection{Enzymatic assays with glycosaminoglycan depolymerising enzymes}

Enzymatic assays with heparinase II (HS depolymerising enzyme, Sigma Aldrich) and chondroitinase ABC (CS depolymerising enzyme, Sigma Aldrich) were used to test the nature of modifications present on the shed ectodomains, which were purified as described in Section 2.3.4. $10 \mu$ of the purified sample was digested either with heparinase II $(1.75 \mathrm{U} / \mathrm{ml})$ or chondroitinase $\mathrm{ABC}(1.5 \mathrm{U} / \mathrm{ml})$ at $37^{\mathrm{O}} \mathrm{C}$ for $2 \mathrm{hrs}$. The samples were then analysed by western blot.

\subsubsection{Western blot for protein detection}

All steps were at room temperature on a shaker unless mentioned otherwise. The samples were mixed with appropriate amounts of $3 \mathrm{X}$ sample buffer, boiled for $5 \mathrm{~min}$ at $95^{\circ} \mathrm{C}$ and centrifuged at 13,000 $\mathrm{rpm}$ for $5 \mathrm{~min}$ before running along with a protein marker (Precision Plus, Biorad) on an 8\% SDS-PAGE (Mini Protean II System, Biorad) at 15 mAmp in SDS-running buffer (3.0 gm Tris, 18.7 gm glycine, $1 \mathrm{ml}$ 10\% SDS with volume made up to $1 \mathrm{~L}$ ). The gel was then blotted on a nitrocellulose membrane (Schleicher and Schuell) for $1 \mathrm{hr} 30 \mathrm{~min}$ at $150 \mathrm{mAmp}$ in transfer buffer (3.0 gm Tris, 18.7 gm glycine, $200 \mathrm{ml}$ methanol with volume made up to $1 \mathrm{~L}$ ). After blotting the membrane was washed 
three times 20 min with PBS-T, and incubated overnight in 5\% Bovine Serum Albumin (BSA) at $4^{\mathrm{O}} \mathrm{C}$. Next day, the membrane was washed three times 20 min with PBS-T and incubated with $1^{\mathrm{O}} \mathrm{Ab}$ in $2.5 \% \mathrm{BSA}$ for $2 \mathrm{hr}$. The membrane was subsequently washed three times 20 min with PBS-T and then incubated for 45 min with HRP-coupled $2^{\mathrm{O}} \mathrm{Ab}$ in $2.5 \%$ BSA. The blot was finally washed three times 20 min with PBS-T and then developed using Pierce ECL Western Blotting Substrate (Pierce) according to the protocol provided with the kit. If required, blots were stripped with Restore Western Blot Stripping Buffer (Pierce) according to the provided manual and reprobed.

\subsection{List of oligonucleotides}

\begin{tabular}{|c|l|c|}
\hline $\begin{array}{c}\text { Oligonucleotide } \\
\text { number }\end{array}$ & \multicolumn{1}{|c|}{ Sequence (5'-3') } & $\begin{array}{l}\text { Restriction } \\
\text { site }\end{array}$ \\
\hline BCO1 & CTCGAGATGAAGCCAAAGCAGAAGATTTC & XhoI \\
\hline BCO2 & GGTACCTCGGCGTAGAACTCGCGGTTAT & KpnI \\
\hline BCO3 & GGTACCAAGTACACGATGAACATGACCACG & KpnI \\
\hline BCO4 & GGTACCAATCCGGGCTGCGAGAAGAAGC & KpnI \\
\hline BCO5 & CCGCCGCGTCCGCCGGCTCCCTCGA & KpnI \\
\hline BCO6 & TCGAGGGAGCCGGCGGACGCGGCGG & \\
\hline BCO7 & GGTACCTCAGGCGTAGAACTCGCGGTT & SpeI \\
\hline BCO8 & ATCGGGTCCAAAGCCGGCGCCAGCATAGTCC & \\
\hline BCO9 & GGACTATGCTGGCGCCGGCTTTGGACCCGAT & \\
\hline BCO10 & AGCTGTGTTTATGCCGGCGTTGCTGCTCTG & EcoRI \\
\hline BCO11 & CAGAGCAGCAACGCCGGCATAAACACAGCT & \\
\hline BCO12 & ATCGATGCCATCGCCGGCGGACTCCGTATC & \\
\hline BCO13 & GATACGGAGTCCGCCGGCGATGGCATCGAT & \\
\hline BCO14 & GAATTCATGAAGCCAAAGCAGAAGATTTC & \\
\hline BCO15 & ACTAGTATCGTGATCCTTGTAATCCCGAGAAGC & \\
\hline TGCTGCTGATGG & ACTAGTGATTACAAGGATCACGATCCCCATGAT & \\
\hline GAAATCTATATC & \\
\hline
\end{tabular}


Materials and Methods

\begin{tabular}{|l|l|l|}
\hline BCO17 & CTCGAGGTCGGAGGGCTGGCTATTCACGTT & KpnI \\
\hline BCO18 & CCTGAGTCCGGGCTGCGAGAAGAAGC & Xhol \\
\hline BCO19 & CTCGAGGACCAAGATCACACC & Xhol \\
\hline BCO20 & GGTACCTCACAGCAAATCGGCGCAGA & KpnI \\
\hline BCO21 & AGATCTTTGAGCGTGGGTGGC & BglII \\
\hline BCO22 & GAGAGAAGATCTATGGTGAGCAAGGGC & BglII \\
\hline BCO23 & ATAAGAATCGCGGCCGCCTTGTACAGCTCGTC & XbaI \\
\hline BCO24 & GCGGCCGCGGATCAGAAATCGGTG & XbaI \\
\hline BCO25 & CTCGAGGGCGTAGAACTCGCG & XhoI \\
\hline BCO26 & CTCGAGATGGTGAGCAAGGGC & Xhol \\
\hline BCO27 & TCTAGATTACTTGTACAGCTC & KpnI \\
\hline BCO28 & CTCGAGAAGTACACGATGAACATGACCACG & Xhol \\
\hline BCO29 & CTCGAGATTCTGGCTGCTGTCATTGG & Xhol \\
\hline
\end{tabular}

\subsection{List of plasmids}

\begin{tabular}{|c|l|l|l|}
\hline $\begin{array}{l}\text { Plasmid } \\
\text { number }\end{array}$ & Insert name & Vector & Insert preparation \\
\hline $\mathrm{BCP} 1$ & $s d c$ cDNA & pCRII-Topo & PCR with BCO1/BCO2 on cDNA \\
\hline BCP2 & $s d c$ cDNA & pUAST-GFP & BCP1 cut with XhoI/KpnI \\
\hline BCP3 & $s d c \Delta C$ & pCRII-Topo & PCR with BC1/BC3 on BCP1 \\
\hline BCP4 & $s d c \Delta C$ & pUAST-GFP & BCP3 cut with XhoI/KpnI \\
\hline BCP5 & $s d c \Delta T C$ & pCRII-Topo & PCR with BCO1/BCO4 on BCP1 \\
\hline BCP6 & $s d c \Delta T C$ & pUAST-GFP & BCP5 cut with XhoI/KpnI \\
\hline BCP7 & $\begin{array}{l}\text { SG1: with } \\
\text { stop codon }\end{array}$ & pCRII-Topo & $\begin{array}{l}\text { Overlapping fragments amplified by } \\
\text { BCO1/BCO5 and BCO6/BCO7 on BCP1 } \\
\text { used as templates with BCO1/BCO7 }\end{array}$ \\
\hline BCP8 & $\begin{array}{l}\text { SG3: with } \\
\text { stop codon }\end{array}$ & pCRII-Topo & $\begin{array}{l}\text { Overlapping fragments amplified by } \\
\text { BCO1/BCO8 and BCO9/BCO7 on BCP7 } \\
\text { used as templates with BCO1/BCO7 }\end{array}$ \\
\hline
\end{tabular}




\begin{tabular}{|c|c|c|c|}
\hline ВСР9 & $\begin{array}{l}\text { SG4: with } \\
\text { stop codon }\end{array}$ & pCRII-Topo & $\begin{array}{l}\text { Overlapping fragments amplified by } \\
\mathrm{BCO} 1 / \mathrm{BCO} 10 \text { and } \mathrm{BCO} 11 / \mathrm{BCO} 7 \text { on } \mathrm{BCP} 8 \\
\text { used as templates with } \mathrm{BCO} 1 / \mathrm{BCO} 7\end{array}$ \\
\hline ВCP 10 & $\begin{array}{l}\text { SG5: with } \\
\text { stop codon }\end{array}$ & pCRII-Topo & $\begin{array}{l}\text { Overlapping fragments amplified by } \\
\mathrm{BCO} 1 / \mathrm{BCO} 12 \text { and } \mathrm{BCO} 13 / \mathrm{BCO} 7 \text { on } \mathrm{BCP} 9 \\
\text { used as templates with } \mathrm{BCO} 1 / \mathrm{BCO} 7\end{array}$ \\
\hline BCP11 & SG1 & pCRII-Topo & PCR with $\mathrm{BCO} 1 / \mathrm{BCO} 2$ on $\mathrm{BCP} 7$ \\
\hline BCP12 & SG3 & pCRII-Topo & PCR with $\mathrm{BCO} 1 / \mathrm{BCO} 2$ on $\mathrm{BCP} 8$ \\
\hline BCP13 & SG4 & pCRII-Topo & PCR with $\mathrm{BCO} 1 / \mathrm{BCO} 2$ on $\mathrm{BCP} 9$ \\
\hline BCP14 & SG5 & pCRII-Topo & $\mathrm{PCR}$ with $\mathrm{BCO} 1 / \mathrm{BCo} 2$ on $\mathrm{BCP} 10$ \\
\hline BCP15 & SG1 & pUAST-GFP & BCP11 cut with XhoI/KpnI \\
\hline BCP16 & SG3 & pUAST-GFP & BCP12 cut with $\mathrm{XhoI} / \mathrm{KpnI}$ \\
\hline ВCP17 & SG4 & pUAST-GFP & BCP13 cut with XhoI/KpnI \\
\hline ВCP18 & SG5 & pUAST-GFP & BCP14 cut with Xhol/KpnI \\
\hline ВСР19 & $\begin{array}{l}s d c- \\
s p+\mathrm{FLAG}\end{array}$ & pCRII-Topo & PCR with BCO1/BCO15 on BCP1 \\
\hline ВСР20 & $\begin{array}{l}\text { sdc-FLAG(- } \\
\text { sp) }\end{array}$ & pCRII-Topo & PCR with $\mathrm{BCO} 16 / \mathrm{BCO} 2$ on $\mathrm{BCP} 1$ \\
\hline BCP21 & FLAG-sdc & pUAST-GFP & $\begin{array}{l}\text { Clone insert from BCP20 with } \mathrm{Xhol} / \mathrm{KpnI} \text {, } \\
\text { then, cut BCP19 and new vector with } \\
\text { XhoI/SpeI }\end{array}$ \\
\hline BCP22 & $s d c-\operatorname{ext} \mathrm{D} 30$ & pCRII-Topo & PCR with BCO14/BCO17 on BCP21 \\
\hline BCP23 & $s d c-t m-c y t$ & pCRII-Topo & PCR with $\mathrm{BCO} 29 / \mathrm{BCO} 2$ on $\mathrm{BCP} 1$ \\
\hline ВСР24 & $s d c-\mathrm{D} 30$ & pUAST-GFP & $\begin{array}{l}\text { inserts from BCP22 cut with EcoRI/XhoI } \\
\text { and } \mathrm{BCP} 23 \text { cut with XhoI/KpnI }\end{array}$ \\
\hline ВСР25 & $\begin{array}{l}\text { FLAG- } \\
s d c \Delta C\end{array}$ & pCRII-Topo & PCR with $\mathrm{BC} 1 / \mathrm{BC} 3$ on $\mathrm{BCP} 21$ \\
\hline ВСР26 & $\begin{array}{l}\text { FLAG- } \\
s d c \Delta C\end{array}$ & pUAST-GFP & BCP25 cut with XhoI/KpnI \\
\hline BCP27 & $s d c-e x t$ & pCRII-Topo & PCR with BCO14/BCO18 on BCP21 \\
\hline
\end{tabular}




\begin{tabular}{|c|c|c|c|}
\hline BCP28 & $d l p-G P I$ & pCRII-Topo & $\begin{array}{l}\text { PCR with BCO19/BCO20 on Drosophila } \\
\text { cDNA library }\end{array}$ \\
\hline ВСР29 & $\begin{array}{l}\text { sdc-ext+dlp- } \\
G P I\end{array}$ & pUAST & $\begin{array}{l}\text { inserts from BCP25 cut with EcoRI/XhoI } \\
\text { and BCP } 26 \text { cut with } \mathrm{XhoI} / \mathrm{KpnI}\end{array}$ \\
\hline BCP30 & $s d c-s p$ & pCRII-Topo & PCR with BCO14/BCO21 on BCP1 \\
\hline BCP31 & $e G F P$ & pCRII-Topo & $\begin{array}{l}\text { PCR with BCO22/BCO23 on EGFP (from } \\
\text { Clontech) }\end{array}$ \\
\hline BCP32 & $s d c(-s p)$ & pCRII-Topo & PCR with $\mathrm{BCO} 24 / \mathrm{BCO} 25$ on $\mathrm{BCP} 1$ \\
\hline ВCP33 & mCherry & pCRII-Topo & $\begin{array}{l}\text { PCR with BCO26/BCO27 on pmCherry-N1 } \\
\text { (Clontech) }\end{array}$ \\
\hline BCP34 & $\begin{array}{l}\text { eGFP-sdc- } \\
\text { mCherry }\end{array}$ & pUAST & $\begin{array}{l}\text { insert from BCP28 cut with EcoRI/BglII, } \\
\text { BCP29 cut with BglII/XbaI and BCP31 cut } \\
\text { with XhoI/KpnI were cloned in first. Lastly, } \\
\text { insert from BCP30 cut with XbaI/XhoI was } \\
\text { cloned }\end{array}$ \\
\hline BCP35 & $\begin{array}{l}e G F P- \\
s d c \triangle C\end{array}$ & pCRII-Topo & PCR with BCO24/BCO28 on BCP32 \\
\hline ВCР36 & $\begin{array}{l}e G F P- \\
s d c \Delta C- \\
m C h e r r y\end{array}$ & pUAST & $\begin{array}{l}\text { BCP33 cut with } \mathrm{XbaI} / \mathrm{XhoI} \text {, cloned in } \\
\text { BCP32 cut with } \mathrm{XbaI} / \mathrm{XhoI}\end{array}$ \\
\hline
\end{tabular}

\subsection{List of fly stocks generated for this study}

\begin{tabular}{|c|l|l|}
\hline $\begin{array}{c}\text { Stock } \\
\text { number }\end{array}$ & Genotype & Description \\
\hline BCF1 & $\begin{array}{l}w^{*} ; ; P\{w[+m C] U A S T-s d c-e G F P\} / T M 3, P\{u b x- \\
l a c Z\}, S b^{1} \text { floating }\end{array}$ & $\begin{array}{l}\text { stock carrying transgene } \\
\text { BCP1, P. Steigemann }\end{array}$ \\
\hline BCF2 & $\begin{array}{l}w^{*} ; s d c^{23} / C y O, P\{f t z-l a c Z\} / P\{w[+m C] U A S T- \\
s d c-e G F P\} / T M 3, P\{f t z-l a c Z\}, S b^{1} \text { floating }\end{array}$ & $\begin{array}{l}\text { transgene BCP1 in } s d c^{23} \\
\text { mutant background, P. } \\
\text { Steigemann }\end{array}$ \\
\hline
\end{tabular}


Materials and Methods

\begin{tabular}{|c|c|c|}
\hline $\mathrm{BCF} 3$ & $\begin{array}{l}w^{*} ; P\{w[+m C] U A S T-s d c \Delta C- \\
e G F P\} / T M 3, P\{u b x-l a c Z\}, S b^{l} \text { floating }\end{array}$ & $\begin{array}{l}\text { stock carrying transgene } \\
\text { BCP4, P. Steigemann }\end{array}$ \\
\hline $\mathrm{BCF} 4$ & $\begin{array}{l}w^{*} ; s d c^{23} / C y O, P\{f t z-l a c Z\} ; P\{w[+m C] U A S T- \\
s d c \Delta C-e G F P\} / T M 3, P\{f t z-l a c Z\}, S b^{1} \text { floating }\end{array}$ & $\begin{array}{l}\text { transgene } \mathrm{BCP} 4 \text { in } s d c^{23} \\
\text { mutant background, } \mathrm{P} \text {. } \\
\text { Steigemann }\end{array}$ \\
\hline BCF5 & $\begin{array}{l}w^{*} ; P\{w[+m C] U A S T-s d c \Delta T C-e G F P\} / \\
T M 3, P\{u b x-l a c Z\}, S b^{l} \text { floating }\end{array}$ & $\begin{array}{l}\text { stock transformed with } \\
\text { BCP6, P. Steigemann }\end{array}$ \\
\hline BCF6 & $\begin{array}{l}w^{*} ; s d c^{23} / C y O, P\{f t z-l a c Z\} ; P\{w[+m C] U A S T- \\
s d c \Delta T C-e G F P\} / T M 3, P\{f t z-l a c Z\}, S b^{1} \text { floating }\end{array}$ & $\begin{array}{l}\text { transgene BCP6 in } s d c^{23} \\
\text { mutant background, } \mathrm{P} \text {. } \\
\text { Steigemann }\end{array}$ \\
\hline BCF7 & $\begin{array}{l}w^{*} ; P\{w[+m C] U A S T-s d c: s g 1- \\
e G F P\} / C y O, P\{h b \text {-lacZ }\} \text { floating }\end{array}$ & $\begin{array}{l}\text { stock carrying transgene } \\
\text { BCP15 }\end{array}$ \\
\hline BCF8 & $\begin{array}{l}w^{*} ; P\{w[+m C] U A S T-s d c: s g 1- \\
e G F P\}, s d c^{23} / C y O, f t z-l a c Z\end{array}$ & $\begin{array}{l}\text { transgene } \mathrm{BCP} 15 \text { in } s d c^{23} \\
\text { mutant background }\end{array}$ \\
\hline BCF9 & $\begin{array}{l}w^{*} ; P\{w[+m C] U A S T-s d c: s g 3- \\
e G F P\} / T M 3, P\{u b x-l a c Z\}, S b^{1} \text { floating }\end{array}$ & $\begin{array}{l}\text { stock carrying transgene } \\
\text { BCP16 }\end{array}$ \\
\hline BCF10 & $\begin{array}{l}w^{*} ; s d c^{23} / C y O, P\{f t z-l a c Z\} ; P\{w[+m C] U A S T- \\
\text { sdc:sg3-eGFP }\} / T M 3, P\{u b x-l a c Z\}, S b^{1} \text { floating }\end{array}$ & $\begin{array}{l}\text { transgene BCP16 in } s d c^{23} \\
\text { mutant background }\end{array}$ \\
\hline BCF11 & $\begin{array}{l}w^{*} ; P\{w[+m C] U A S T-s d c: s g 4- \\
e G F P\} / C y O, P\{h b \text {-lacZ }\} \text { floating }\end{array}$ & stock carrying BCP17 \\
\hline BCF12 & $\begin{array}{l}w^{*} ; P\{w[+m C] U A S T-s d c: s g 4- \\
e G F P\}, s d c^{23} / C y O, P\{f t z-l a c Z\}\end{array}$ & $\begin{array}{l}\text { transgene BCP17 in } s d c^{23} \\
\text { mutant background }\end{array}$ \\
\hline BCF13 & $\begin{array}{l}w^{*} ; P\{w[+m C] U A S T-s d c: s g 5- \\
e G F P\} / C y O, P\{h b-l a c Z\} \text { floating }\end{array}$ & stock carrying BCP18 \\
\hline BCF14 & $\begin{array}{l}w^{*} ; P\{w[+m C] U A S T-s d c: s g 5- \\
e G F P\}, s d c^{23} / C y O, P\{f t z-l a c Z\}\end{array}$ & $\begin{array}{l}\text { transgene BCP18 in } s d c^{23} \\
\text { mutant background }\end{array}$ \\
\hline BCF15 & $\begin{array}{l}w^{*} ; P\{w[+m C] U A S T-F L A G-s d c-e G F P\} / \\
T M 3, P\{u b x-l a c Z\}, S b^{l} \text { floating }\end{array}$ & $\begin{array}{l}\text { stock transformed with } \\
\text { BCP21 }\end{array}$ \\
\hline
\end{tabular}


Materials and Methods

\begin{tabular}{|c|c|c|}
\hline BCF 16 & $\begin{array}{l}w^{*} ; P\{w[+m C] U A S T-F L A G-s d c: \Delta C- \\
e G F P\} / C y O, P\{h b-l a c Z\} \text { floating }\end{array}$ & $\begin{array}{l}\text { stock transformed with } \\
\text { BCP26 }\end{array}$ \\
\hline BCF 17 & $\begin{array}{l}w^{*} ; P\{w[+m C] U A S T-F L A G-s d c: D 30-e G F P\} / \\
T M 3, P\{u b x-l a c Z\}, S b^{l} \text { floating }\end{array}$ & $\begin{array}{l}\text { stock transformed with } \\
\text { BCP24 }\end{array}$ \\
\hline BC18 & $\begin{array}{l}w^{*} ; s d c^{23} / C y O, P\{f t z-l a c Z\} ; P\{w[+m C] U A S T- \\
F L A G-s d c: D 30-e G F P\} / T M 3, P\{u b x-l a c Z\}, S b^{l} \\
\text { floating }\end{array}$ & $\begin{array}{l}\text { transgene } \mathrm{BCP} 24 \text { in } s d c^{23} \\
\text { mutant background }\end{array}$ \\
\hline BCF19 & $\begin{array}{l}w^{*} ; P\{w[+m C] U A S T-F L A G-s d c-e x t+d l p- \\
G P I\} / T M 3, P\{u b x-l a c Z\}, S b^{l} \text { floating }\end{array}$ & $\begin{array}{l}\text { stock transformed with } \\
\text { BCP29 }\end{array}$ \\
\hline BCF 20 & $\begin{array}{l}w^{*} ; s d c^{23} / C y O, P\{f t z-l a c Z\} ; P\{w[+m C] U A S T- \\
F L A G-s d c-e x t+d l p-G P I\} / T M 3, P\{u b x-l a c Z\}, S b^{1} \\
\text { floating }\end{array}$ & $\begin{array}{l}\text { transgene } \mathrm{BCP} 27 \text { in } s d c^{23} \\
\text { mutant background }\end{array}$ \\
\hline BCF21 & $w^{*} ; s d c^{23}, t t v^{00681 b} / C y O, P\{f t z-l a c Z\}$ & $\begin{array}{l}\text { double mutant of } s d c \text { and } \\
\text { ttv }\end{array}$ \\
\hline BCF22 & $\begin{array}{l}w^{*} ; s d c^{23} / C y O, P\{a c t-G F P\} \\
d l p^{A 187} / T M 3, P\{a c t-G F P\}, S e r^{1}\end{array}$ & $\begin{array}{l}\text { double mutant of } s d c \text { and } \\
d l p\end{array}$ \\
\hline BCF 23 & $\begin{array}{l}w^{*} ; s d c^{23} / C y O, P\{f t z-l a c Z\} ; P\{e l a v- \\
G A L 4\} / T M 3, P\{f t z-l a c Z\}, S b^{1} \text { floating }\end{array}$ & $\begin{array}{l}\text { elavG4 in the } s d c^{23} \text { mutant } \\
\text { background, } \mathrm{P} \text {. } \\
\text { Steigemann }\end{array}$ \\
\hline BCF24 & $\begin{array}{l}w^{*} ; s d c^{23} / C y O, P\{f t z-l a c Z\} ; P\{\text { elav- } \\
G A L 4\} / T M 3, P\{u b x-l a c Z\}, S b^{1} \text { floating }\end{array}$ & $\begin{array}{l}\text { elavG4 in the } s d c^{23} \text { mutant } \\
\text { background }\end{array}$ \\
\hline BCF25 & $w^{*} ; s d c^{23}, P\{m e f 2-G A L 4\} / C y O, P\{f t z-l a c Z\}$ & $\begin{array}{l}\text { mef2G4 in the } s d c^{23} \\
\text { mutant background, P. } \\
\text { Steigemann }\end{array}$ \\
\hline BCF26 & $\begin{array}{l}w^{*} ; s d c^{23} / C y O, P\{f t z-l a c Z\} ; P\{G A L 4- \\
\text { repo }\} / T M 3, P\{f t z-l a c Z\}, S b^{1} \text { floating }\end{array}$ & $\begin{array}{l}\text { repoG4 in } s d c^{23} \text { mutant } \\
\text { background }\end{array}$ \\
\hline BCF27 & $\begin{array}{l}w^{*} ; s d c^{23} / C y O, P\{f t z-l a c Z\} ; P\{G A L 4- \\
\left.\operatorname{sim}^{3.7}\right\} / T M 3, P\{f t z-l a c Z\}, S b^{1} \text { floating }\end{array}$ & $\begin{array}{l}\operatorname{sim} G 4 \text { in } s d c^{23} \text { mutant } \\
\text { background, } \mathrm{P} \text {. } \\
\text { Steigemann }\end{array}$ \\
\hline
\end{tabular}


2.7 List of other fly stocks used

\begin{tabular}{|c|c|c|}
\hline $\begin{array}{l}\text { Stock } \\
\text { number }\end{array}$ & Genotype & Source \\
\hline GÖ734 & $w^{*} ; w g^{S p l} / C y o, P\{f t z-l a c Z\} ; D^{*} / T M 3, P\{f t z-l a c Z\}, S b^{l}$ & $\begin{array}{l}\text { Department } \\
\text { stock }\end{array}$ \\
\hline GÖ1277 & $w^{*}$, trol $^{\text {null }}, P\left\{F R T\left(w^{h s}\right)\right\} 101 / F M 7 i, P\{a c t-G F P\}$ & $\begin{array}{l}\text { Department } \\
\text { stock }\end{array}$ \\
\hline GÖ1051 & $w^{*} ; ; P\{$ elav-GAL4\} & $\begin{array}{l}\text { Department } \\
\text { stock }\end{array}$ \\
\hline 9150 & $w^{*} ; P\{$ sim-GAL4 $\} / C y O ; P\{$ sim-GAL4 $\} / P\{$ sim-GAL4 $\}$ & Bloomington \\
\hline 8164 & $w^{118}$ & Bloomington \\
\hline 7415 & $w^{118} ; ; P\left\{\right.$ repo-GAL4\}/TM3,Sb ${ }^{1}$ & Bloomington \\
\hline 5460 & $w^{*} ; ; P\{d a-G A L 4\} / P\{d a-G A L 4\}$ & Bloomington \\
\hline 5400 & $m w h^{I}, s g l^{A 3 I}$, red $^{I}, e^{I} / T M 6 b, T b^{I}$ & Bloomington \\
\hline \multirow[t]{12}{*}{10949} & $c n^{I}, P\{P Z\} C y t-b 5^{00681 a}, P\{P Z\} t t v^{00681 b} / C y O ; r y^{506}$ & Bloomington \\
\hline & $w^{*} ; w g^{S p l} / C y o, P\{f t z-l a c Z\} ; D^{*} / T M 3, P\{u b x-l a c Z\}, S b^{I}$ & A. Herzig \\
\hline & $w^{*} ; w^{S p l} / C y o, P\{a c t-G F P\} ; D r^{*} / T M 3, P\{a c t-G F P\}, S e r^{I}$ & A. Michelson \\
\hline & $\begin{array}{l}w^{*} ; P\{a p-G A L 4\} / C y O ; P\{U A S-C D 8:: G F P\} / P\{U A S- \\
C D 8:: G F P\}\end{array}$ & B. Dickson \\
\hline & $w^{*} ; P\{a p-G A L 4\} / C y O$ & B. Dickson \\
\hline & $w^{*} ; ;$ dally $^{80} / T M 6 b, P\{a c t-G F P\}, e^{I}$ & C. Han \\
\hline & $w^{*} ; ; d l p^{A 187} / T M 6 b, P\{a c t-G F P\}, e^{I}$ & C. Han \\
\hline & $w^{*} ; \operatorname{amos}^{T f t} / C y O, P\{h b-l a c Z\}$ & Lab stock \\
\hline & $w^{*} ; \operatorname{croc}^{59}, e / T M 3, P\{u b x-l a c Z\}, S b^{I}$ & Lab stock \\
\hline & $w^{*} ; P\{m e f 2-G A L 4\} / C y O$ & M. Taylor \\
\hline & $w^{*} ; ; s f l^{9 B 4}, P\{w=F R T 21\} / T M 6 b, T b^{I}$ & N. Perrimon \\
\hline & $w^{I 18} ; s d c^{23} / C y O, P\{f t z-l a c Z\}$ & P. Steigemann \\
\hline
\end{tabular}


2.8 List of primary antibodies

\begin{tabular}{|c|c|c|c|c|}
\hline Antibody & Animal & Source & $\begin{array}{l}\text { Epitope } \\
\text { detected }\end{array}$ & Dilution \\
\hline$\beta$-galactosidase & Mouse & Promega & $\beta$-galactosidase & $1: 1000$ \\
\hline$\beta$-galactosidase & Rabbit & Cappel & $\beta$-galactosidase & $1: 1000$ \\
\hline $13 \mathrm{C} 9$ & Mouse & Iowa Hybridoma Bank & Robo & $1: 50$ \\
\hline $1 \mathrm{D} 4$ & Mouse & Iowa Hybridoma Bank & FAS II & $1: 15$ \\
\hline $2 \mathrm{~A} 12$ & Mouse & Iowa Hybridoma Bank & Tracheal system & $1: 5$ \\
\hline ab290 & Rabbit & ABCam (for immunoblot) & GFP & $1: 2000$ \\
\hline BP102 & Mouse & Iowa Hybridoma Bank & CNS axons & $1: 100$ \\
\hline C555.6 & Mouse & Iowa Hybridoma Bank & Slit & $1: 25$ \\
\hline $\mathrm{Cq} 4$ & Mouse & Iowa Hybridoma Bank & Crumbs & $1: 1000$ \\
\hline FLAG M2 & Mouse & Sigma Aldrich & FLAG & $1: 1000$ \\
\hline GFP & Rabbit & $\begin{array}{l}\text { Synaptic Systems (for } \\
\text { immunohistochemistry) }\end{array}$ & GFP & $1: 1000$ \\
\hline MHC & Rabbit & D. Kiehart & $\mathrm{MHC}$ & $1: 2000$ \\
\hline Sdc31605 & Rabbit & G. Vorbrüggen & Syndecan & $1: 200$ \\
\hline
\end{tabular}

2.9 List of secondary antibodies

\begin{tabular}{|c|l|l|l|l|}
\hline Epitope detected & Animal & Source & Label & Dilution \\
\hline Mouse IgG & Goat & Molecular Probes & Alexa 488 & $1: 400$ \\
\hline Mouse IgG & Goat & Molecular Probes & Alexa 568 & $1: 400$ \\
\hline Mouse IgG & Goat & Pierce & HPR & $1: 1000$ \\
\hline Mouse IgG & Horse & Vector Labs & biotinylated & $1: 500$ \\
\hline Mouse IgM & Donkey & Jackson Labs & Cy3 & $1: 400$ \\
\hline Rabbit IgG & Goat & Molecular Probes & Alexa 488 & $1: 400$ \\
\hline Rabbit IgG & Goat & Molecular Probes & Alexa 568 & $1: 400$ \\
\hline Rabbit IgG & Goat & Pierce & HRP & $1: 1000$ \\
\hline Rabbit IgG & Horse & Vector Labs & biotinylated & $1: 500$ \\
\hline
\end{tabular}




\section{Results}

\subsection{Syndecan activity is required on the Slit target tissue}

Syndecan $(\mathrm{Sdc})$ is critical for the fidelity of Slit repellent signalling emanating from the ventral midline of the Drosophila embryo (Section 1.6) (Johnson et al., 2004; Steigemann et al., 2004). In $s d c$ null embryos CNS ipsilateral axons (detected by staining with monoclonal antibody (Ab) that detects Fascilin II (FASII)) and ventral muscles (stained for myosin heavy chain (MHC)) cross the ventral midline. The penetrance of the phenotype is quantifiable as the number of crossovers of CNS ipsilateral axons and muscles per embryo can be counted (Steigemann et al., 2004) (Fig. 5c and e). However, although $s d c$ null mutant embryos display a slit like phenotype and genetic interaction studies prove a role for Sdc in Slit/Robo signalling the mechanism of Sdc function is not well understood. To decipher this mechanism a systematic approach employing tissue specific rescue experiments as well as rescue experiments using Sdc protein variants was adopted in this study.

Sdc is expressed in the Drosophila ventral nerve cord (Kopczynski et al., 1998) where the Slit ligand is secreted (Nüsslein-Volhard and Wieschaus, 1980; Rothberg et al., 1990) and specifically on the CNS axons (Fig. 5a) (Spring et al., 1994; Steigemann et al., 2004) that express the Slit receptor Robo. In addition, Sdc has been reported to be shed from the cell surface (Kim et al., 1994; Spring et al., 1994) to release a soluble form of the extracellular domain. Therefore, Sdc might be acting to facilitate Slit secretion, Slit transport and/or Slit reception. To identify the tissue in which Sdc activity is required, the UAS/GAL4 system (Brand and Perrimon, 1993) (Section 2.2.3) was employed to express a $s d c-G F P$ transgene ( $s d c$ open reading frame (ORF) with a fused carboxyl-terminal (Cterminal) GFP ORF) in the $s d c^{23}$ mutant background specifically in different tissues to rescue the CNS and ventral muscle phenotypes. Rescue was scored by the absence of ventral midline crossing of both the CNS ipsilateral axons and of the ventral muscles.

In brief, the $s d c-G F P$ transgene was expressed in the $s d c^{23}$ mutant background either at the source of Slit: the ventral midline cells using a single-mindedG4 (simG4) driver line, or in the intermediate tissue: the glia cells (for axonal rescue) using repoG4 and in the CNS (for muscle rescue) using elavG4 or in the target tissue: the axons (for axonal 
rescue) using elavG4 and muscles (for muscle rescue) using mef2G4 (summarised in

Table 1). The results from this tissue specific rescue experiment are summarised in Fig. 6.

\begin{tabular}{|l|c|c|c|c|}
\hline \multirow{2}{*}{ Ligand source } & \multicolumn{2}{|c|}{ Rescue of CNS phenotype } & \multicolumn{2}{l|}{ Rescue of muscle phenotype } \\
\cline { 2 - 5 } & Tissue expression & Driver line & Tissue expression & Driver line \\
\hline Intermediate tissue & Midline cells & $\operatorname{sim} G 4$ & Midline cells & $\operatorname{sim} G 4$ \\
\hline Target tissue & Glia & repoG4 & CNS & elavG4 \\
\hline
\end{tabular}

Table 1: GAL4 driver lines used for tissue-specific rescue of $s d c^{23}$ mutant phenotypes.
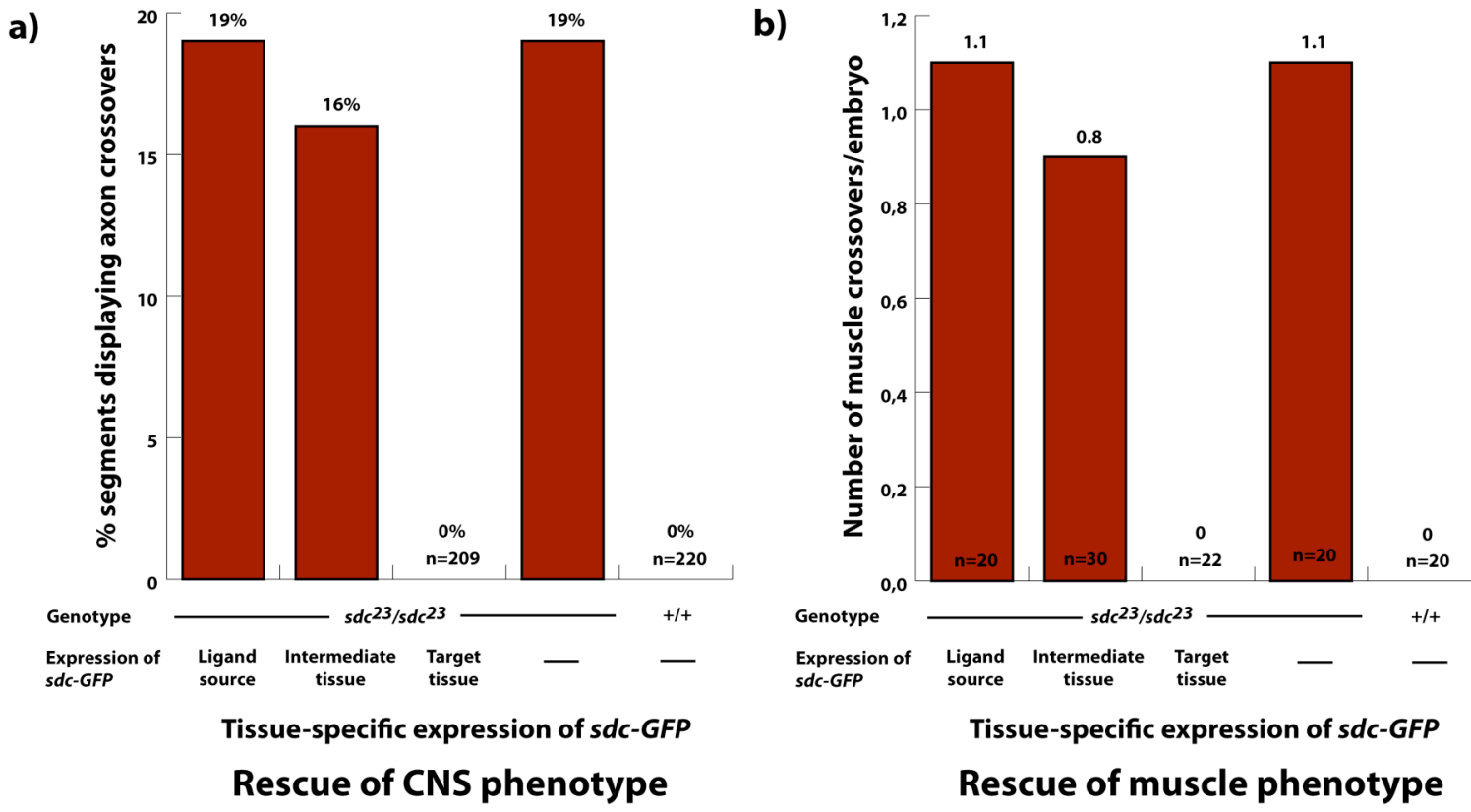

Figure 6: Tissue specific rescue of $s d c^{23}$ mutant phenotypes. A $s d c-G F P$ transgene was expressed in the $s d c^{23}$ mutant background specifically at the source of ligand, in the intermediate tissue or at the target tissue (The tissue-specific GAL4 driver lines are summarised in Table 1). Rescue of the CNS (a, $\mathrm{n}=$ number of segments) and muscle (b, $\mathrm{n}=$ number of embryos) phenotypes was determined by counting the number of crossovers of CNS ipsilateral axons and ventral muscles respectively in comparison to $s d c^{23}$ homozygous mutant and wild-type control embryos. The ipsilateral CNS axons and muscles were stained with $\alpha$-FASII and $\alpha$-MHC Abs respectively. a) For the rescue of CNS phenotype, $s d c-G F P$ expression in the target tissue alone is sufficient to prevent ventral midline crossover of CNS ipsilateral axons. Crossovers by CNS ipsilateral axons are still observed when $s d c-G F P$ is expressed either at the ligand source $(19 \%)$ or in the intermediate tissue (16\%). b) Similarly, expressing $s d c-G F P$ in the target tissue prevents the atypical ventral midline crossing of muscles and rescues the muscle phenotype completely. However, no rescue is observed when $s d c-G F P$ is expressed at the ligand source (1.1 muscle crossover per embryo) or in the intermediate tissue ( 0.8 muscle crossover per embryo). 
In $s d c^{23}$ homozygous mutant embryos, $19 \%$ of the counted segments show ventral midline crossovers of CNS ipsilateral axons. A similar percentage of segments (19\%) still showed midline crossovers of CNS ipsilateral axons when a $s d c-G F P$ transgene is expressed in the midline cells (ligand source) and in the glia (16\%) (intermediate tissue) but the phenotype is completely rescued when $s d c-G F P$ is expressed in the axons (target tissue) (Fig. 6a). An analogous phenomenon is observed in the case of rescue of the muscle phenotype. $s d c^{23}$ homozygous mutant embryos show 1.1 muscle crossover per embryo and this phenotype is rescued by expressing $s d c-G F P$ in the muscles (target tissue) but not when it is expressed in the midline cells (ligand source) (1.1 muscle crossovers per embryo) or in the CNS (intermediate tissue) (0.8 muscle crossover per embryo) (Fig. 6b). Based on the results of the tissue-specific rescue experiments for both the muscle and axonal phenotype, Sdc activity is exclusively required in the target tissue and not at the source of Slit ligand or in the intermediate tissue through which Slit has to diffuse or be transported.

\subsection{Identification of Syndecan protein domains essential for Slit/Robo signalling}

Since the ventral muscle phenotype of $s d c^{23}$ homozygous mutant embryos is very poorly penetrant (1.1 muscle crossover per embryo) and would have made interpretation difficult in cases of partial rescue, further functional characterisation was done by testing only the rescue of the CNS phenotype by expressing the transgenes in the CNS axons using the elavG4 driver line. To determine which domain of Sdc functions in Slit/Robo signalling, $s d c-G F P$ deletion transgenes were constructed and analysed for their ability to rescue the $s d c^{23}$ mutant phenotype.

\subsubsection{Cytoplasmic domain of Syndecan is not required for its function in Slit/Robo signalling}

Sdc, a typeI transmembrane protein, has a highly conserved short cytoplasmic domain, which has been shown to interact with a wide variety of proteins in vertebrates (reviewed in (Kramer and Yost, 2003)). These protein-protein interactions are required for Sdc 
mediated changes in actin cytoskeleton (Woods et al., 1986), intracellular signalling (Kinnunen et al., 1998) and receptor recycling (Zimmermann et al., 2005). To investigate if Drosophila Sdc activity in Slit/Robo signalling is based on such similar functions, a $s d c$ deletion transgene called $s d c \Delta C-G F P$ (Fig. 7a) was constructed which lacks the coding region for the cytoplasmic domain of Sdc. This deletion transgene was used to rescue the $s d c^{23}$ mutant phenotype. It was observed that the Sdc protein lacking its cytoplasmic domain could fully rescue the $s d c^{23}$ mutant phenotype (Fig. 7b). Based on the complete rescue activity of the $s d c$ deletion transgene that codes for a protein that cannot interact with cytoplasmic proteins, the requirement of an active intracellular signalling activity of Sdc could be excluded for Slit/Robo signalling.

a)

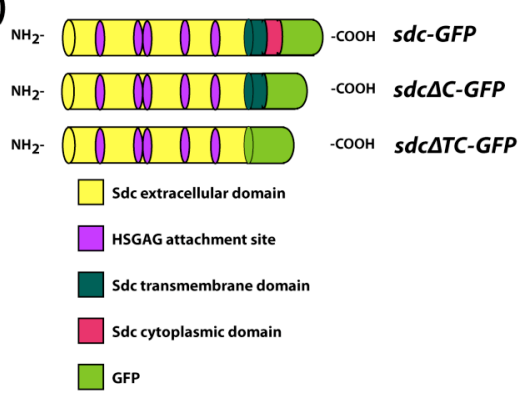

b)

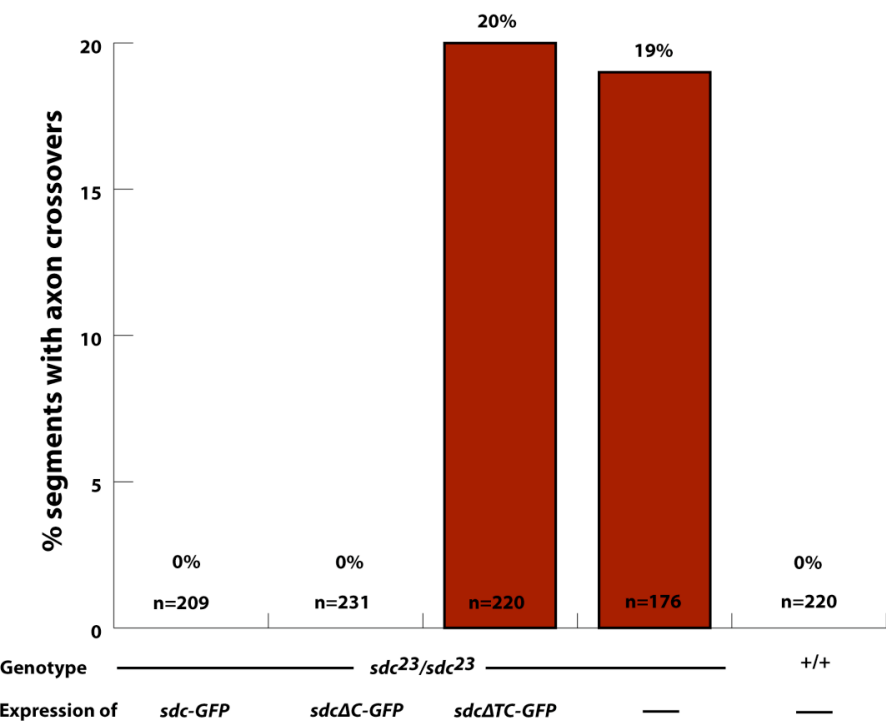

Rescue with sdc transgene variants

Figure 7: Rescue of $s d c^{23}$ mutant phenotype with $s d c$ deletion transgene variants. a) A schematic representation of $s d c$ transgene deletion variants used to rescue the $s d c^{23}$ mutant phenotype. b) Percentage of segments displaying ventral midline crossover of CNS ipsilateral axons was determined in $s d c^{23}$ homozygous mutant embryos rescued with $s d c-G F P$, $s d c \Delta C-G F P$ and $s d c \Delta T C-G F P$ in comparison to control $s d c^{23}$ homozygous mutant and wild-type embryos $(\mathrm{n}=$ number of segments). The CNS ipsilateral axons were stained with $\alpha$-FASII Ab. While $s d c-G F P$ and $s d c \Delta C-G F P$ rescued the phenotype completely, $s d c^{23}$ homozygous mutant embryos rescued with $s d c \triangle T C-G F P$ still had $20 \%$ of the counted segments displaying ventral midline crossover of CNS ipsilateral axons. 


\subsubsection{The secreted form of Syndecan is not functional in Slit/Robo signalling}

Vertebrate studies have reported the shed ectodomain of Sdc to be functionally active (Park et al., 2001). To investigate if Drosophila Sdc also has to be released from the cell surface to be functional, a $s d c$ transgene, $s d c \Delta T C-G F P$, was constructed which lacked the coding region for both the cytoplasmic domain and the transmembrane domain of Sdc (Fig. 7a). This potentially secreted form of the extracellular domain of Sdc was tested for its ability to rescue the $s d c^{23}$ mutant phenotype. This $s d c$ deletion transgene, $s d c \Delta T C$ $G F P$, however was not able to rescue the $s d c^{23}$ mutant phenotype as $20 \%$ of counted segments showed ventral midline crossover of CNS ipsilateral axons (Fig. 7b). This result proves that a secreted form of Drosophila Sdc is not functional in Slit/Robo signalling. As the cytoplasmic domain of Sdc is not essential as well, this result indicated that either Sdc has to be attached to the cell surface or that the highly conserved transmembrane domain has a significant role in conferring specificity to the function of Sdc in Slit/Robo signalling.

\section{3 sdc $\Delta T C-G F P$ codes for a protein that is secreted}

To confirm that the protein encoded by $s d c \triangle T C-G F P$ is secreted in the Drosophila embryo in vivo, the localisation of the fusion protein $\mathrm{Sdc} \Delta \mathrm{TC}-\mathrm{GFP}$ (Sdc extracellular domain with a C-terminal GFP) was analyzed by two independent approaches. In the first approach, localisation of Sdc $\Delta \mathrm{TC}-\mathrm{GFP}$ protein was determined in the embryo while the second approach tested for the presence of secreted Sdc $\Delta \mathrm{TC}-\mathrm{GFP}$ protein in the supernatant of $s d c \triangle T C-G F P$ transfected Drosophila Schneider 2 (S2) cells.

Employing the first approach, $s d c-G F P$, $s d c \Delta C-G F P$ and $s d c \triangle T C-G F P$ transgenes (Fig. 8a) were expressed in the CNS using the elavG4 driver line (Fig. 8b-d). Localisation of the respective proteins was determined by epifluorescence of the C-terminal GFP. SdcGFP (Fig. 8b) and Sdc $\Delta$ C-GFP (Fig. 8c) were localised to the axon bundles of the CNS while Sdc $\Delta$ TC-GFP (Fig. 8d) was expressed in a diffuse manner in the entire CNS with no specific localisation to the axon bundles. This diffuse localisation of Sdc $\Delta T C-G F P$ indicated that it is secreted from the cell bodies of post-mitotic neurons. However, since 
a) sdc-GFP
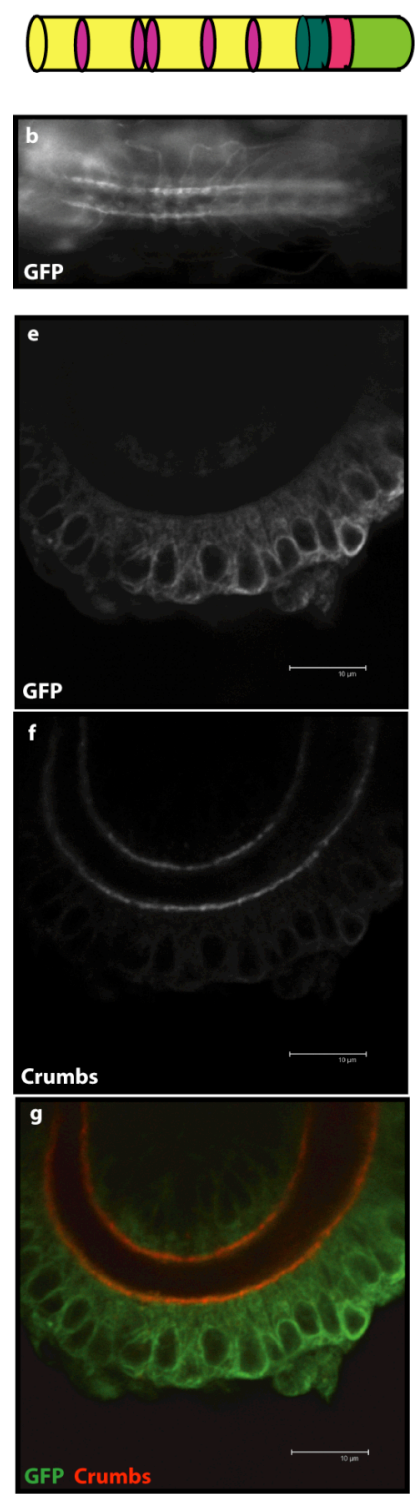

sdc $\Delta$ C-GFP
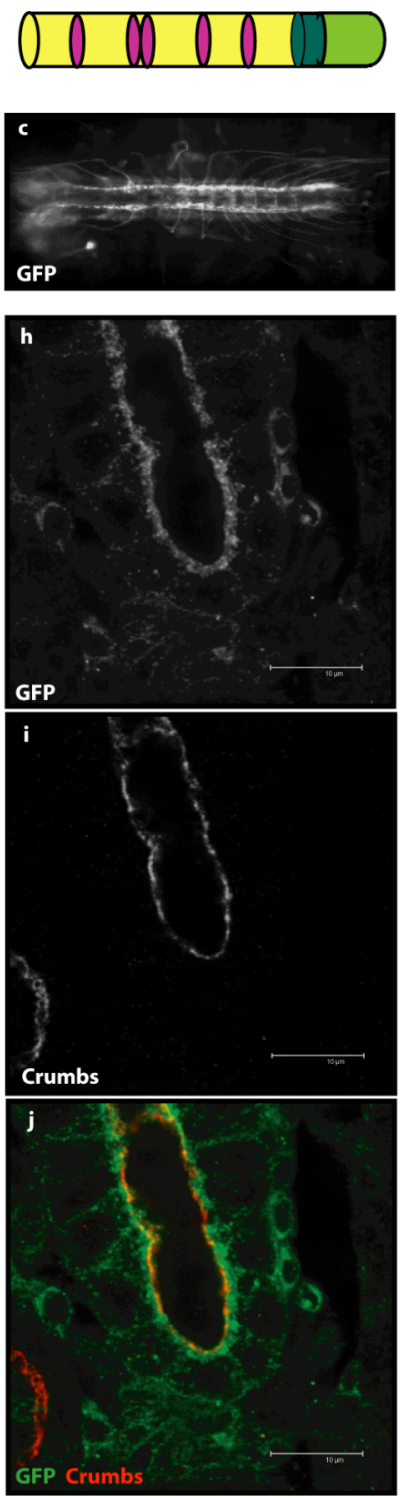

sdc $\Delta T C-G F P$
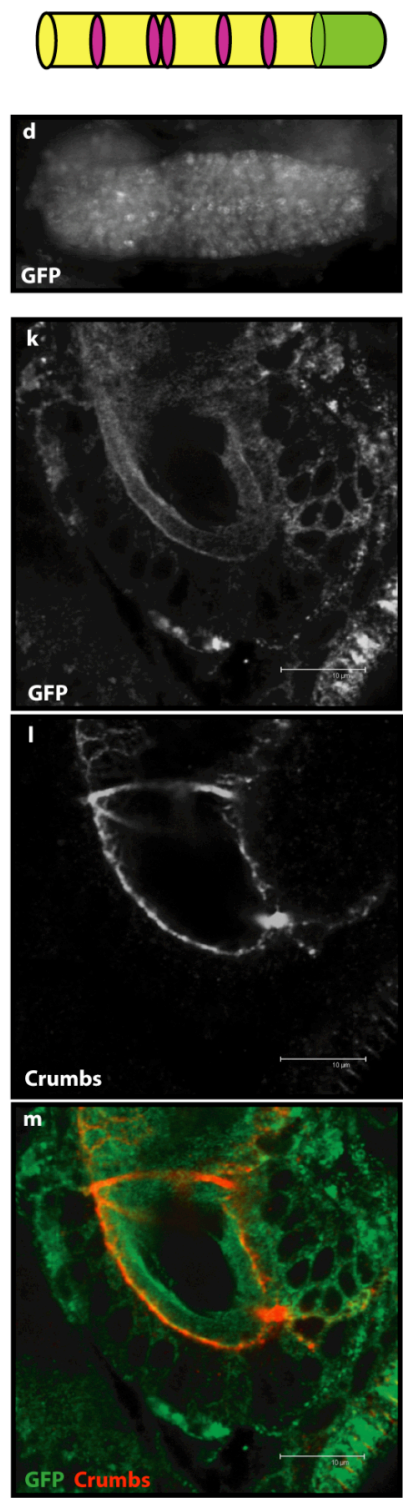

Figure 8: Sdc $\Delta$ TC-GFP is secreted in the CNS and hindgut. a) A schematic representation of $s d c$ transgene variants used in this protein localisation study. b-d) GFP epifluorescence images of stage 16 embryos, ventral view anterior is to the left. The proteins Sdc-GFP (b), Sdc $\Delta C$-GFP (c) and Sdc $\Delta$ TC-GFP (d) are expressed in the CNS. Sdc-GFP (b) and Sdc $\Delta$ C-GFP (c) are localised to the axon tracts in the CNS while Sdc $\Delta$ TC-GFP (d) is expressed in a diffused manner in the CNS. e-m) Scale bar: $10 \mu \mathrm{m}$. Optical transverse sections of the hindgut of stage 16 embryos ubiquitously expressing $s d c-G F P(\mathrm{e}-\mathrm{g}), s d c \Delta C-G F P(\mathrm{~h}-\mathrm{j})$ or $s d c \Delta T C-G F P(\mathrm{k}-\mathrm{m})$. Proteins were detected by staining for their C-terminal GFP. Ab against the Crumbs protein was used to mark the apical membrane of epithelial cells that border the hindgut lumen. (e) Sdc-GFP is expressed in the hindgut epithelia but is not secreted in the lumen demarcated by Crumbs (f) and localises to the basal membrane showing no colocalisation with Crumbs (g), h) Sdc $\Delta$ C-GFP is expressed in the hindgut epithelia but is not secreted in the lumen demarcated by Crumbs (i) and localises to the apical membrane with Crumbs (j), k) Sdc $\Delta$ TC-GFP is expressed in the hindgut epithelia and is secreted in the lumen demarcated by Crumbs (l) where GFP signal is detectable (m). 
the complex morphology of the CNS did not allow for examination of secretion in more detail two tissues in the embryo were analysed for the detection of secreted protein.

The $s d c-G F P, s d c \Delta C$-GFP and $s d c \Delta T C-G F P$ transgenes were expressed ubiquitously in the embryo using the $d a G 4$ driver line. Protein localization in both the hindgut (Fig. 8em) and the dorsal trunk of the trachea (Fig. 9b-j) were analysed. These two tissues were specifically selected as they have wide well defined lumens that are bounded by apical membranes of large epithelial cells. Therefore, a secreted protein would be easily visible in these wide lumens contrary to the extracellular space of any other tissue where the secreted protein would be enmeshed in the little but dense extracellular matrix, making analysis difficult.

First the expression in the hindgut was analysed by detecting the ectopically expressed proteins with an $\mathrm{Ab}$ directed against their C-terminal GFP. The apical membrane, which borders the hindgut lumen was labelled by staining for the apically localised membrane protein Crumbs (Tepass et al., 1990). It was observed that the proteins Sdc-GFP (Fig. 8e) and Sdc $\Delta$ C-GFP (Fig. 8h) were expressed in the hindgut epithelial cells but not secreted as ascertained by the absence of staining in the hindgut lumen demarcated by Crumbs (Fig. 8f and i). Additionally it was seen that $\operatorname{Sdc} \Delta \mathrm{C}$-GFP localised to the apical domain of the hindgut epithelium (Fig. 8h) as it overlaps with Crumbs expression (Fig. 8i) as seen in the overlay (Fig. 8j) in contrast to Sdc-GFP (Fig. 8e), which preferentially localises to the basal domain of the hindgut epithelium and does not colocalise with Crumbs (Fig. 8f) as seen in the overlay (Fig. 8g). In contrast the protein encoded by $s d c \Delta T C-G F P$ (Fig. 8k) was expressed in the hindgut epithelial cells and secreted into the lumen demarcated by Crumbs (Fig. 81) as seen in the overlay (Fig. 8m).

For analysis of protein localisation in the tracheal system the ubiquitously expressed proteins were detected by using an Ab directed against their C-terminal GFP while the tracheal lumen was labelled with the monoclonal 2A12 $\mathrm{Ab}$ that binds an unidentified factor. The subcellular localisation of Sdc-GFP (Fig. 9b) and Sdc $\Delta$ C-GFP (Fig. 9e) did not show any overlap with the lumen marker 2A12 (Fig. 9c and f) indicating that these proteins are not secreted as seen in the overlay (Fig. 9d and g). In contrast embryos ubiquitously expressing $s d c \Delta T C-G F P$, showed a colocalisation of $\operatorname{Sdc} \Delta$ TC-GFP (Fig. 9h) 
a) sdc-GFP
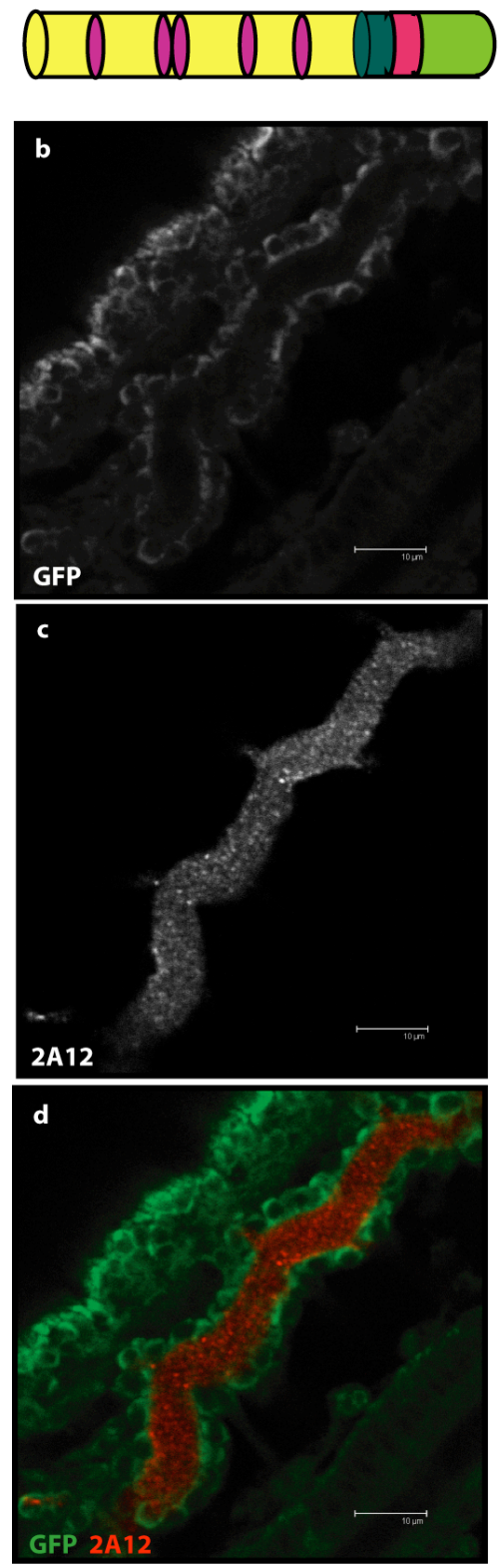

sdc $\Delta$ C-GFP
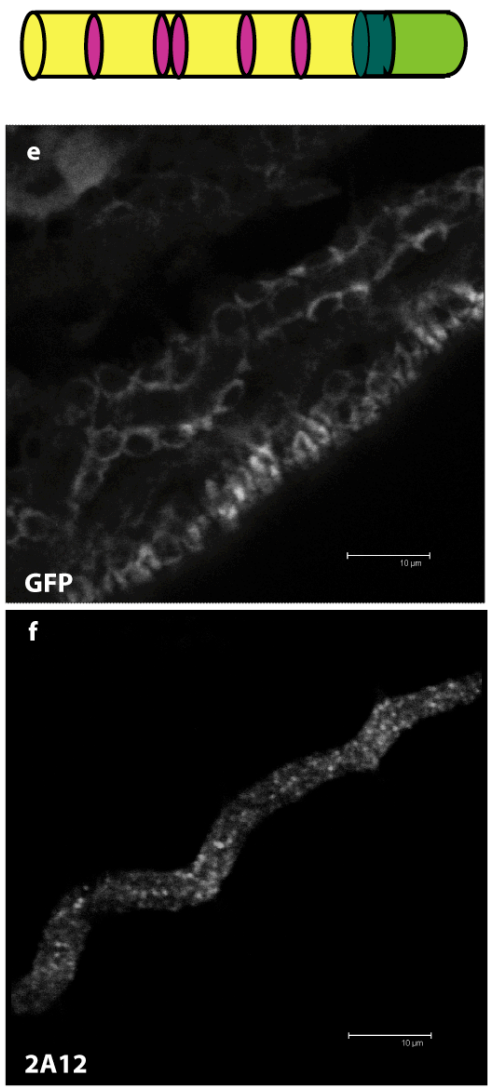

g

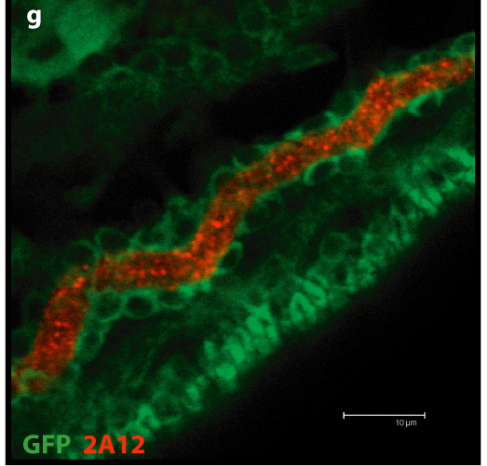

sdc $\Delta T C-G F P$
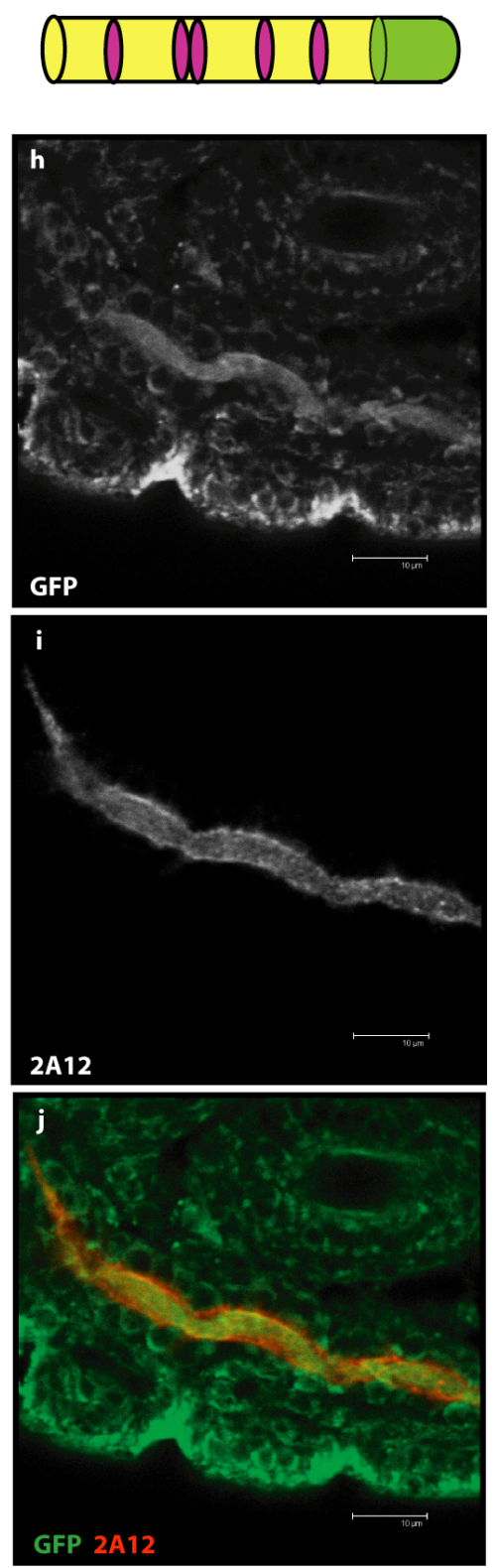

Figure 9: Sdc $\Delta$ TC-GFP is secreted in the tracheal system. a) A schematic representation of $s d c$ transgene variants used in this protein localisation study. b-j) Optical transverse sections of the dorsal tracheal trunk of stage 16 embryos ubiquitously expressing $s d c-G F P(\mathrm{~b}-\mathrm{d}), s d c \Delta C$ $G F P(\mathrm{e}-\mathrm{g})$ or $s d c \triangle T C-G F P(\mathrm{~h}-\mathrm{j})$. Proteins were detected by staining for their C-terminal GFP. The tracheal lumen was labelled by using the $2 \mathrm{~A} 12 \mathrm{Ab}$. Scale bar: $10 \mu \mathrm{m}$. b) Sdc-GFP is expressed in the tracheal system but not secreted into the tracheal lumen as seen by absence of colocalisation with $2 \mathrm{~A} 12$ (c) in the overlay (d), e) Sdc $\Delta$ C-GFP is expressed in the tracheal system but not secreted into the tracheal lumen as seen by absence of colocalisation with $2 \mathrm{~A} 12$ (f) in the overlay $(\mathrm{g}), \mathrm{h}) \mathrm{Sdc} \Delta \mathrm{TC}$-GFP is expressed in the tracheal system and is secreted into the tracheal lumen labelled with $2 \mathrm{~A} 12$ (i) as seen in the overlay (j). 
protein with the lumen marker 2A12 (Fig. 9i) in their dorsal tracheal trunk (Fig. 9j) providing proof that $\operatorname{Sdc} \Delta \mathrm{TC}-\mathrm{GFP}$ is secreted out of the cells.

To prove the secretion of $\operatorname{Sdc} \Delta \mathrm{TC}$-GFP protein in an independent approach, the localisation of the protein was determined in cell culture. For this, Drosophila S2 cells were transfected (Section 2.3.2) with $s d c-G F P$, $s d c \Delta C-G F P$ or $s d c \Delta T C-G F P$. The transfected cells and their supernatants were harvested and processed as described in Section 2.3.3. Western blot analysis using an Ab directed against the C-terminal GFP, clearly showed that the transfected cells synthesise the proteins Sdc-GFP, Sdc $\Delta$ C-GFP or Sdc $\Delta$ TC-GFP (Fig. 10b) but only Sdc $\Delta$ TC-GFP is secreted into the supernatant (Fig. 10c).

a)

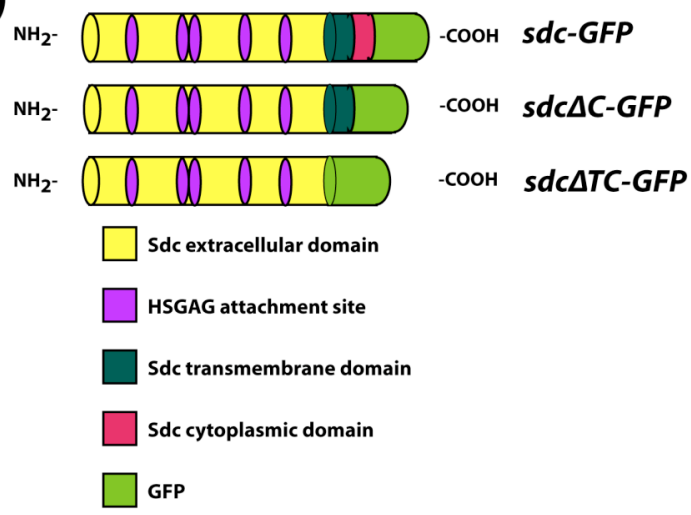

b)

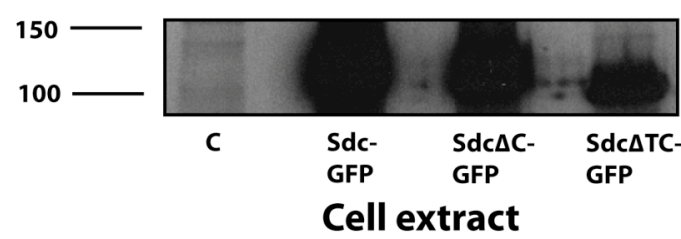

c)

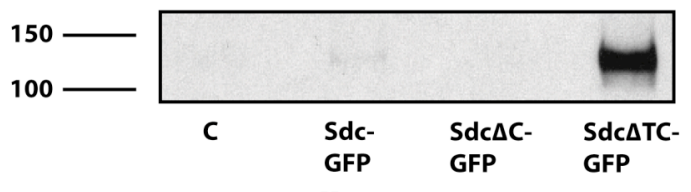

Cell supernatant

Figure 10: Sdc-GFP fusion proteins are modified and Sdc $\Delta$ TC-GFP is secreted in Drosophila S2 cells. a) A schematic representation of $s d c$ transgene variants used in this experiment. $b$ and c) Western blots using $\alpha$-GFP Ab to detect Sdc-GFP, Sdc $\Delta C$-GFP and $\mathrm{Sdc} \triangle \mathrm{TC}-\mathrm{GFP}$ proteins in cell extracts (b) and supernatant (c) of S2 cells mock transfected (C, control) or transfected with $s d c-G F P, s d c \triangle C-G F P$ and $s d c \triangle T C-G F P$ respectively. b) Sdc-GFP, $\mathrm{Sdc} \Delta \mathrm{C}-\mathrm{GFP}$ and $\mathrm{Sdc} \Delta \mathrm{TC}$-GFP are expressed and modified by Drosophila S2 cells but only $\operatorname{Sdc} \Delta \mathrm{TC}-\mathrm{GFP}$ is secreted into the supernatant (c).

Taken together the protein localisation studies in the embryo and cell culture experiments provide concrete proof that the protein Sdc $\Delta$ TC-GFP is secreted. Furthermore, these experiments show that the Sdc $\Delta \mathrm{TC}-\mathrm{GFP}$ protein is expressed thereby excluding nonexpression of the transgene as a possible explanation for the failure in its ability to rescue the $s d c^{23}$ mutant phenotype (Section 3.2.2). 


\section{4 sdc $\Delta T C-G F P$ codes for a protein that carries high molecular weight modifications}

Since the $s d c \triangle T C-G F P$ transgene did not rescue the $s d c^{23}$ mutant phenotype, it was not only essential to show that the protein was secreted but also that it was modified like a wild-type Sde in vivo as HSGAG modifications influence ligand binding (Sanderson et al., 1994). Modification of Sdc with HSGAG chains causes it to migrate as a highmolecular weight broad band on SDS-PAGE (Spring et al., 1994). To determine if Sdc $\Delta$ TC-GFP was modified, Drosophila S2 cells were transfected with $s d c-G F P, s d c \Delta C$ $G F P$ or $s d c \triangle T C-G F P$. Cell extracts were prepared three days after transfection (Section 2.3.2) and western blot analysis using an $\mathrm{Ab}$ directed against the $\mathrm{C}$-terminal GFP (Section 2.3.3) revealed that the protein encoded by the $s d c \triangle T C-G F P$ transgene migrated as a high molecular weight band similar to Sdc-GFP and Sdc $\Delta$ C-GFP proteins (Fig. 10b) thereby indicating that the protein encoded by $s d c \triangle T C-G F P$ is modified like a wild-type Sdc in vivo. Its secretion was also demonstrated both in the embryo and in cell culture experiments (section 3.2.2.1). This secreted form of Sdc that mimics the active shed form of vertebrate Sdcs does not rescue the $s d c^{23}$ mutant phenotype. This data clearly proves that a secreted form of Sdc, analogous to the shed form of Sdc protein, is not functional in Slit/Robo signalling in Drosophila. Furthermore, these results indicate that either the highly conserved transmembrane domain of Sdc is essential for its function in Slit/Robo signalling or that the Sdc extracellular domain has to be membrane attached to be functional.

\subsection{Syndecan transmembrane domain serves as an inert anchor for the extracellular domain}

To determine whether the Sdc transmembrane domain has a sequence specific function or just serves as an inert anchor, a chimeric transgene, FLAG-sdc-ext+dlp-GPI (Fig. 11a), was constructed. This transgene codes for a chimeric protein that has the extracellular domain of Sdc fused to the GPI anchor sequence from Dlp. Such a protein therefore, would not span the membrane but would be anchored via a lipid moiety, specifically a GPI molecule. Also, this protein would be unable to participate in the formation of any functional complexes, which are supposed to be mediated by the transmembrane domain 
(Lebakken and Rapraeger, 1996; Yamashita et al., 1999). This chimeric transgene almost completely rescued the $s d c^{23}$ mutant phenotype (Fig. 11b) providing clear proof that the transmembrane domain of Sdc serves exclusively as an inert anchor for the extracellular domain, which is the functional moiety. Additionally, in light of the fact that a secreted form of Sdc is not functional in Slit/Robo signalling this result indicates that the extracellular domain has to be membrane anchored to be functional and that this mode of attachment is exchangeable.
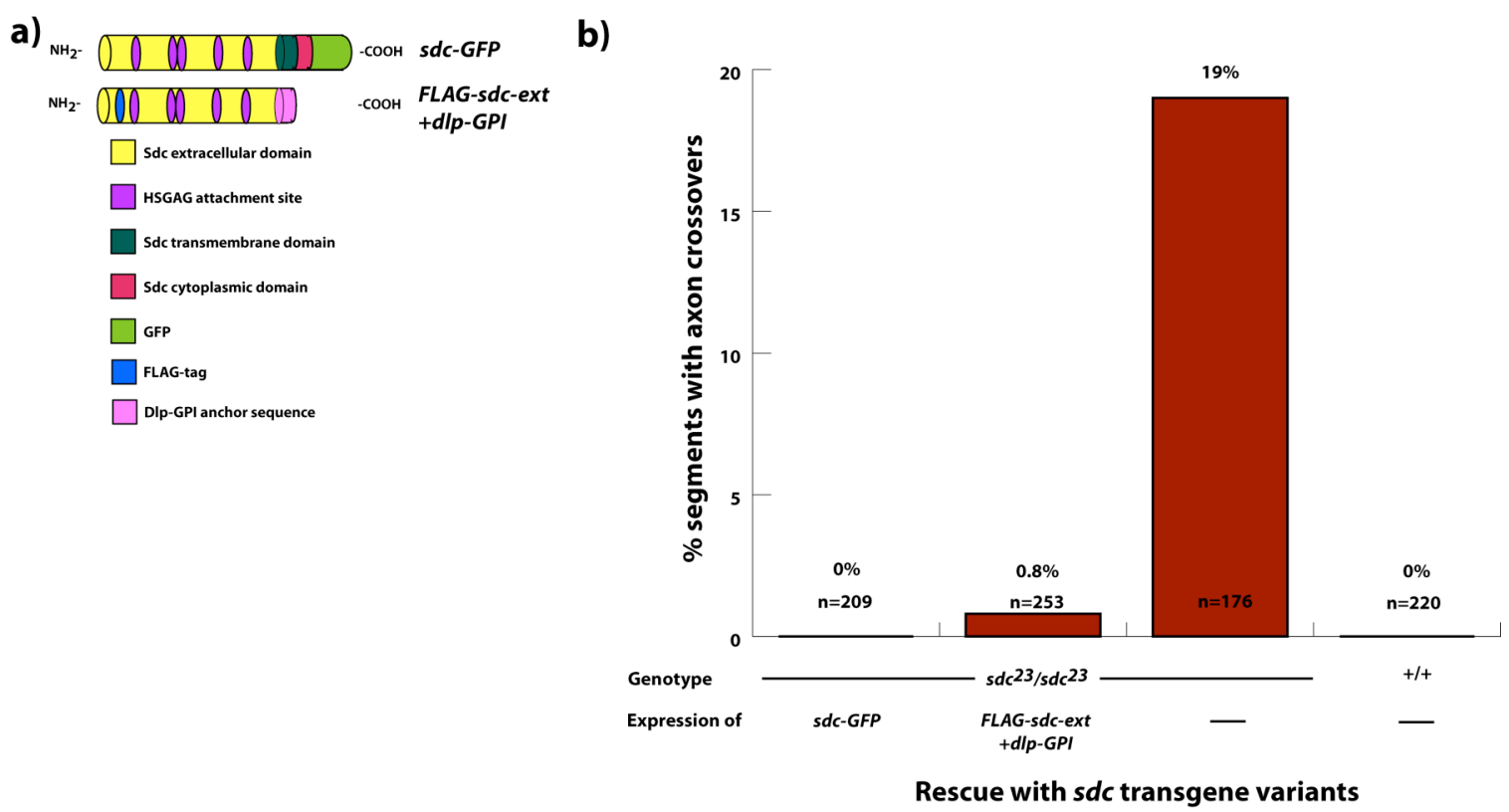

Figure 11: Rescue of $s d c^{23}$ mutant phenotype with a chimeric $s d c$ transgene variant. a) A schematic representation of $s d c$ transgene variants used to rescue the $s d c^{23}$ mutant phenotype. The full-length $s d c$ transgene was labelled with a C-terminal GFP while the chimeric $s d c$ transgene was labelled with a FLAG-tag C-terminal to the signal peptide sequence. b) Percentage of segments displaying ventral midline crossover of CNS ipsilateral axons was determined in $s d c^{23}$ homozygous mutant embryos rescued with $s d c-G F P$ or FLAG-sdc+ext $+d l p-G P I$ and compared to control $s d c^{23}$ homozygous mutant and wild-type embryos ( $\mathrm{n}=$ number of segments). The CNS ipsilateral axons were stained with $\alpha$-FASII $\mathrm{Ab}$. While $s d c-G F P$ rescued the phenotype completely, $s d c^{23}$ homozygous mutant embryos rescued with FLAG-sdc-ext+dlp-GPI still had $0.8 \%$ of counted segments displaying ventral midline crossover of CNS ipsilateral axons.

\subsection{Heparan sulphate glycosaminoglycan (HSGAG) attachment site mutants rescue the $s d c^{23}$ mutant phenotype}

Considering that the cytoplasmic domain and the transmembrane domain did not contribute to the function of Sdc in Slit/Robo signalling, the role of the extracellular 
domain was examined. The extracellular domain of Sdc has two distinct components: the core protein sequence and the HSGAG chains that are attached to it. In order to dissect the function of these two components independently of each other, the core protein sequence was analysed to identify putative HSGAG attachment sites. HSGAG chains are attached to specific Serine (Ser) residues in the protein that are followed by a Glycine (Gly) (Section 1.1). This analysis revealed five putative Ser-Gly motifs. By introducing single base changes (see Section 2.1.12) the putative HSGAG attachment sites were sequentially mutated by converting the codon for Ser of the Ser-Gly motif to a codon for Alanine (Ala). In this manner, four new $s d c$ transgenes were constructed: $s g 1-G F P$ (lacking one putative HSGAG attachment site), sg3-GFP (lacking three putative HSGAG attachment sites), sg4-GFP (lacking four putative HSGAG attachment sites) and sg5GFP (lacking all five putative HSGAG attachment sites) (Fig. 12a). The proteins encoded
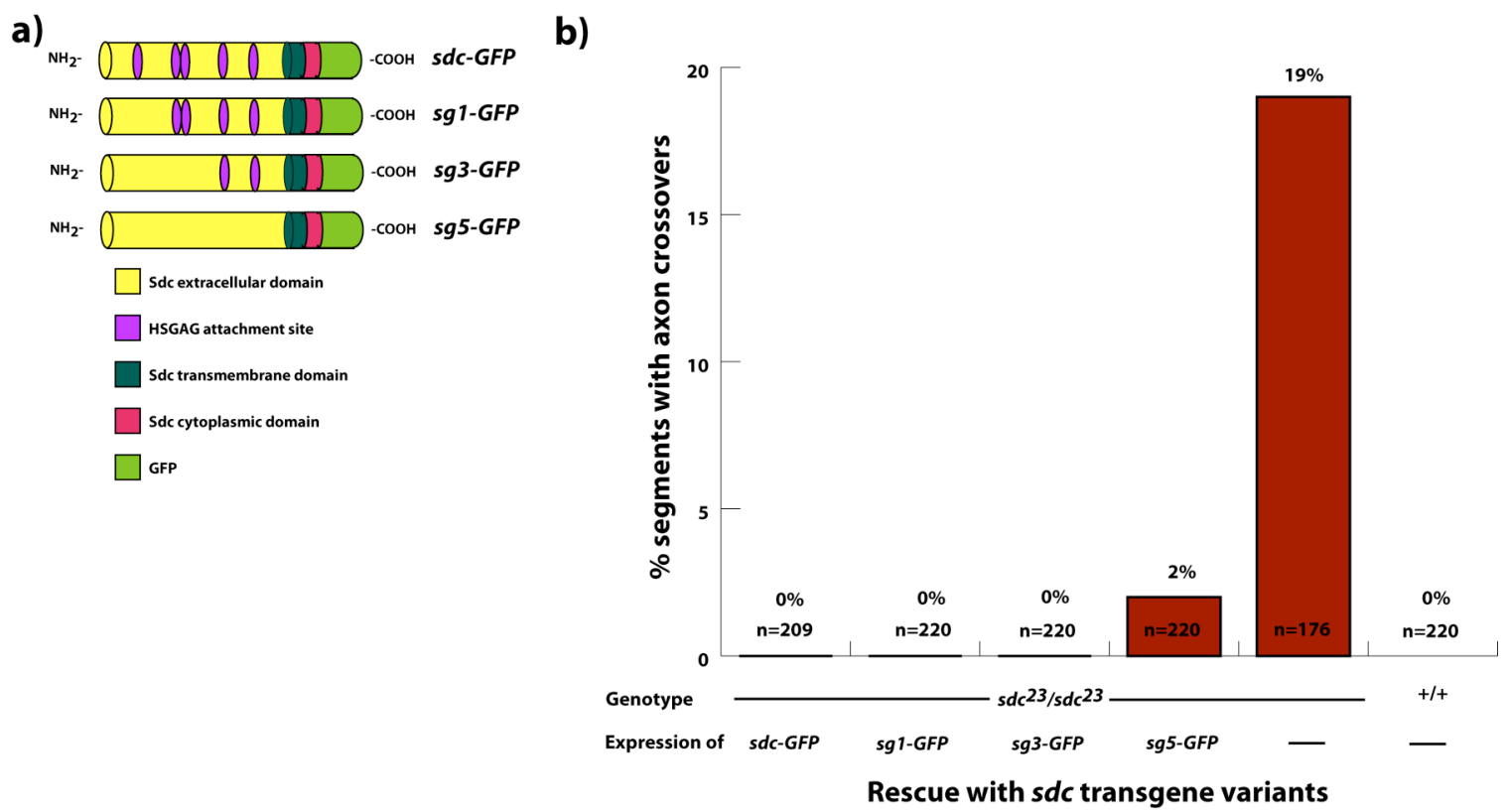

Figure 12: Rescue of $s d c^{23}$ mutant phenotype with $s d c$ HSGAG attachment site mutant transgenes. a) A schematic representation of $s d c$ transgene variants used to rescue the $s d c^{23}$ mutant phenotype. b) Percentage of segments displaying ventral midline crossover of CNS ipsilateral axons was determined in $s d c^{23}$ homozygous mutant embryos rescued with $s d c-G F P$, $s g 1-G F P$, sg3-GFP and sg5-GFP and compared to control $s d c^{23}$ homozygous mutant and wildtype embryos ( $\mathrm{n}=$ number of segments). The CNS ipsilateral axons were stained with $\alpha$-FASII Ab. While $s d c-G F P, s g 1-G F P$ and $s g 3-G F P$ rescued the phenotype completely, $s d c^{23}$ homozygous mutant embryos rescued with $s g 5-G F P$ still had $2 \%$ of counted segments displaying ventral midline crossover of CNS ipsilateral axons. 
by these transgenes should carry a decreasing number of HSGAG chains because of fewer putative HSGAG attachment sites with the $s g 5-G F P$ transgene coding for a protein devoid of any HSGAG chains. The results of the rescue experiment with these transgenes is summarised in Fig. 12b. $s g 1-G F P$ and $s g 3-G F P$ transgenes were able to rescue the $s d c^{23}$ mutant phenotype completely while the sg5-GFP transgene rescued almost completely leaving $2 \%$ of segments with ventral midline crossover of CNS ipsilateral axons in comparison to $s d c^{23}$ homozygous mutant embryos where $19 \%$ of segments had ventral midline crossover of CNS ipsilateral axons. These results indicate that the core protein of Sdc is the functional part required for Slit/Robo signalling. Since this result is contrary to the academic opinion, which supposes HSGAG chains to be the functional part of Sdc, it had to be clarified that the protein variants tested are HSGAG mutants in vivo. Furthermore, these results have to be interpreted with caution, as the consensus sequence for HSGAG attachment sites is not well defined. Additionally, the modification of Ser in a Ser-Gly motif cannot be the sole criteria for HSGAG attachment otherwise a large number of proteins would be HSGAG modified. In further confirmation is the fact that Drosophila has only four HSPGs: Sdc, Dlp, Dally and Perlecan. This points to the requirement of additional sequences and/or motifs that define an HSGAG attachment site. Based on this argument it had to be analyzed if mutation of the Ser codon to an Ala codon in the proposed HSGAG attachment sites was sufficient to block modification.

\subsection{1 sg5-GFP codes for a protein that bears high molecular weight modifications}

The rescue experiment performed on the assumption that HSGAG attachment site mutants would carry a decreasing number of HSGAG chains had indicated that the HSGAG chains are not required for the activity of Sdc. Therefore it was essential to confirm that the protein encoded by sg5-GFP was indeed without modifications. An unmodified Sdc protein should migrate as a lower molecular weight band as compared to modified Sdc. To resolve the issue of modification state of SG5-GFP, Drosophila S2 cells were transfected with either $s d c-G F P$ or with $s g 5-G F P$ and the cells harvested as described in Section 2.3.2. Western blot analysis of the cell extracts, using an Ab directed against the C-terminal GFP, revealed that the protein encoded by $s g 5-G F P$ migrates 
similarly to the one encoded by $s d c-G F P$ (Fig. 13b), implying that the protein, SG5-GFP, carries high molecular weight modifications like wild-type Sdc. Since the apparent molecular weight is not linearly dependent on the number of HSGAG chains this result only proves that the protein SG5-GFP is modified and not that SG5-GFP and Sdc-GFP have the same number of HSGAG chains. Furthermore, Sdc is modified with both HSGAG and CSGAG chains. Therefore, this result did not exclude the possibility that the SG5-GFP variant of Sdc is modified by CSGAG chains only.

a)

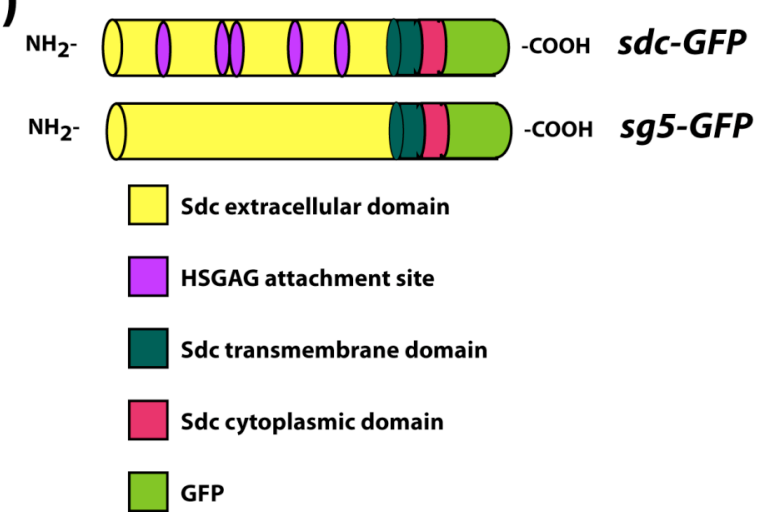

b)

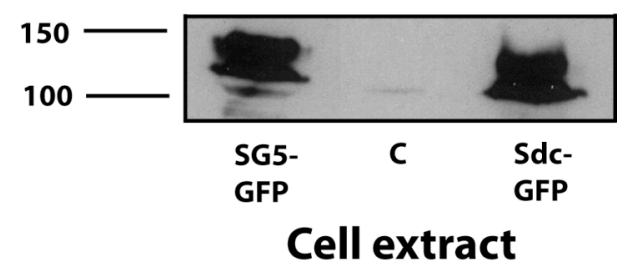

Figure 13: SG5-GFP carries high molecular weight modifications. a) A schematic representation of $s d c$ transgene variants used in this experiment. b) Western blot using $\alpha$-GFP Ab to detect Sdc-GFP and SG5-GFP in cell extracts of Drosophila S2 cells transfected with $s d c-G F P$ or sg5-GFP respectively. Mock transfected cells served as control (labelled C in the blot). Both Sdc-GFP and SG5-GFP are expressed by Drosophila S2 cells and migrate similarly indicating that SG5-GFP carries high molecular weight modifications.

\subsubsection{Enzymatic depolymerisation of glycosaminoglycan (GAG) chains}

Drosophila Sdc is modified with both HSGAG and CSGAG chains because of which it migrates as a high molecular weight band on SDS-PAGE (Spring et al., 1994). Since the protein encoded by sg5-GFP also migrated as a high molecular weight band inspite of mutating all five putative HSGAG attachment sites, it was necessary to determine if CSGAG modifications were compensating for the lack of HSGAG or cryptic HSGAG attachment sites were being modified. To assess the nature of modifications present on the protein encoded by $s g 5-G F P$, heparinase II and chondroitinase ABC enzymes were used to enzymatically depolymerise HSGAG and CSGAG, respectively. Loss of 
modifications should result in a change in the mobility of the protein in comparison to untreated protein sample, which should be detectable by SDS-PAGE.

Because the transmembrane nature of the proteins precluded the possibility of purifying sufficient amounts of Sdc-GFP and Sg5-GFP from cell extracts for enzymatic assays, an alternative strategy was employed to purify the shed ectodomains of these proteins from the supernatant of Drosophila S2 cells transfected with their respective plasmids. In order to be able to detect the ectodomains with western blotting, a FLAG tag sequence was introduced C-terminal to the signal peptide sequence in $s d c-G F P$ and $s g 5-G F P$ transgenes to generate FLAG-sdc-GFP and FLAG-sg5-GFP, respectively (Fig. 14a).

a)

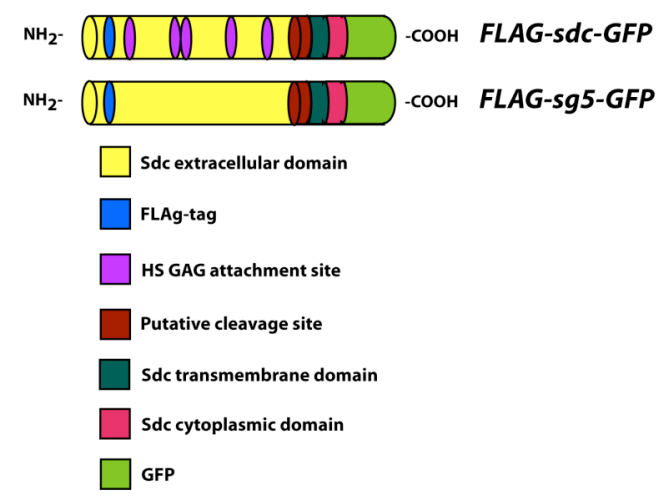

c)

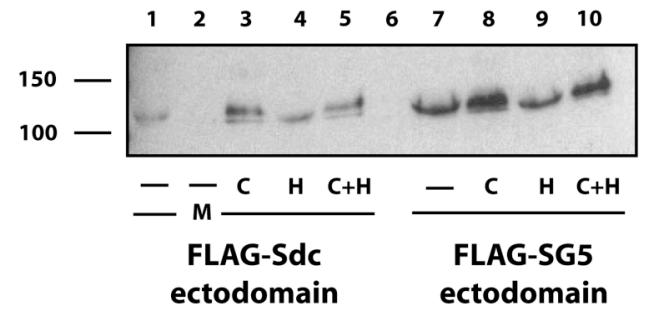

b)

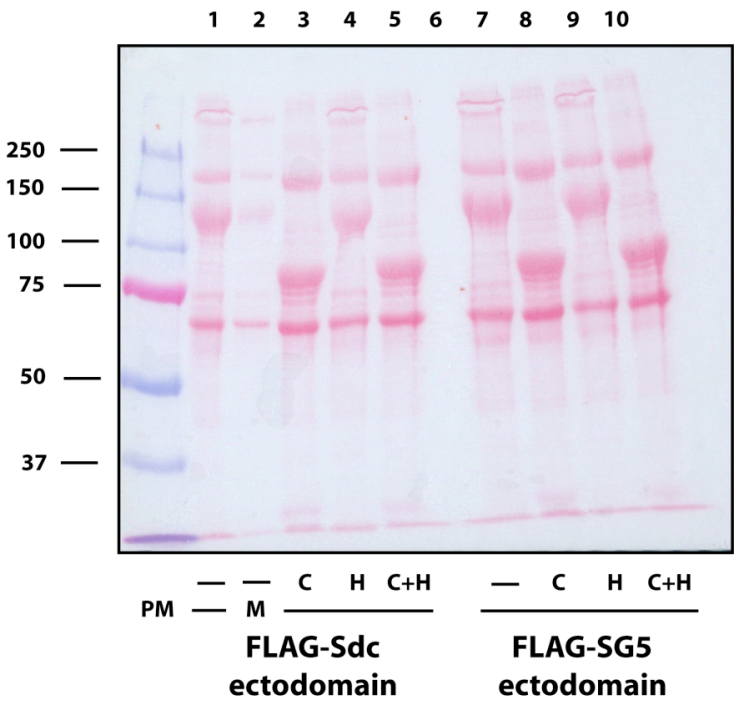

Figure 14: FLAG-SG5-GFP is modified. a) A schematic representation of $s d c$ transgene variants used in this experiment. b) Ponceau S stained membrane. PM: Protein Marker. Lane 1: purified cell supernatant from FLAG-sdc-GFP transfected Drosophila S2 cells. Lane 2: purified cell supernatant from mock (M) transfected Drosophila S2 cells. Lane 3-5: purified cell supernatant from FLAG-sdc-GFP transfected Drosophila S2 cells treated with chondroitinase ABC $(\mathrm{C})$, heparinase II $(\mathrm{H})$ and both chondroitinase $\mathrm{ABC}$ and heparinase II $(\mathrm{C}+\mathrm{H})$ respectively. Lane 6 is empty. Lane 7-10: purified cell supernatant from FLAG-sg5-GFP transfected Drosophila $\mathrm{S} 2$ cells untreated and treated with $\mathrm{C}, \mathrm{H}$ and $\mathrm{C}+\mathrm{H}$ respectively. c) Western blot using $\alpha$-FLAG M2 Ab of the Ponceau S stained membrane in (b) to detect the ectodomains of FLAGSdc-GFP and FLAG-SG5-GFP. Lane 1-10 are as described in (b). No change in the mobility of FLAG-Sdc ectodomain and FLAG-SG5 ectodomain is observed upon treatment with chondroitinase $\mathrm{ABC}$, heparinase II or both chondroitinase $\mathrm{ABC}$ and heparinase II in comparison to untreated FLAG-Sdc ectodomain and FLAG-SG5 ectodomain respectively. 
In brief, cells were transfected with $F L A G$-sdc-GFP or FLAG-sg5-GFP and supernatants processed to purify the shed ectodomains of the proteins as described in Section 2.3.4. The purified protein samples were then treated with heparinase II, chondroitinase $\mathrm{ABC}$ or with both heparinase II and chondroitinase $\mathrm{ABC}$ as described in Section 2.3.5. The enzymatically treated samples were separated by SDS-PAGE and blotted onto a nitrocellulose membrane, which was Ponceau S stained (Fig. 14b). On the Ponceau S stained membrane a dramatic shift in the molecular weight of a protein was visible when the samples had been treated with chondroitinase $\mathrm{ABC}$ as compared to untreated and only heparinase II treated samples in case of both FLAG-Sdc-GFP and FLAG-SG5-GFP. This proved that chondroitinase $\mathrm{ABC}$ is active under the conditions used for the enzymatic assay. This membrane was analysed further by western blot (Fig. 14c). Detection with antibody against the FLAG epitope revealed no mobility shifts of the treated samples in comparison to untreated ones, indicating that the enzymatic treatment was unsuccessful (Fig. 14c). However, Ponceau S staining of the membrane had provided proof of chondroitinase $\mathrm{ABC}$ activity. Taken together, it indicated that the enzymatic assay conditions for heparinase II needed further standardisation. It was therefore not possible to conclude if the protein encoded by FLAG-sg5-GFP was only CSGAG modified or still carried HSGAG chains on unknown cryptic HSGAG attachment sites.

\subsection{Shedding of Sdc in cell culture by Drosophila Schneider 2 (S2) cells}

The intact ectodomains of each mammalian Sdc and the single Drosophila Sdc are constitutively shed into the conditioned media of cultured cells (Kim et al., 1994; Spring et al., 1994). For mammalian Sdc, it has been shown that shedding of the Sdc protein is a key regulatory step for processes such as wound repair and microbial pathogenesis (Park

et al., 2001). To test if the shedding of Drosophila Sdc was also required for it to be functional in Slit/Robo signalling, a putative non-sheddable Sdc variant was constructed. Based on vertebrate Sdc studies, which suggested that the cleavage site is within five amino acids of the membrane proximal region of the extracellular domain a $s d c$ transgene called FLAG-sdc:D30-GFP was constructed (Fig. 15a), which lacks 30 amino acids of the membrane proximal region of the extracellular domain and therefore does not have 
the putative protease cleavage site. This deletion transgene was employed in a cell culture based shedding assay to verify that it is indeed not shed before using it for an in vivo rescue experiment. Drosophila S2 cells were transfected with either FLAG-sdc-GFP or FLAG-sdc:D30-GFP. The supernatants from transfected cells were harvested and processed as described in Section 2.3.4 and further analysed by western blot to detect the shed ectodomains of the respective proteins by probing for the FLAG epitope (Fig. 15b). This analysis revealed that FLAG-Sdc:D30-GFP ectodomain was shed in cell culture like the ectodomain of FLAG-Sdc-GFP (Fig. 15b). As a control, these blots were stripped and reprobed with $\alpha$-GFP Ab to exclude the possibility that the supernatant was contaminated by cell debris, which would contain full-length FLAG-Sdc-GFP or FLAG-Sdc:D30-GFP respectively. Absence of a signal with $\alpha$-GFP Ab proved that there was no contamination of the supernatant with full-length FLAG-Sdc-GFP and FLAG-Sdc:D30-GFP respectively. Since a non-sheddable form of Sdc could not be identified or generated, it was not possible to address the importance of Sdc shedding in vivo with a rescue experiment and thus further confirm the results obtained with the secreted form of Sdc (Section 3.2.2).

a)

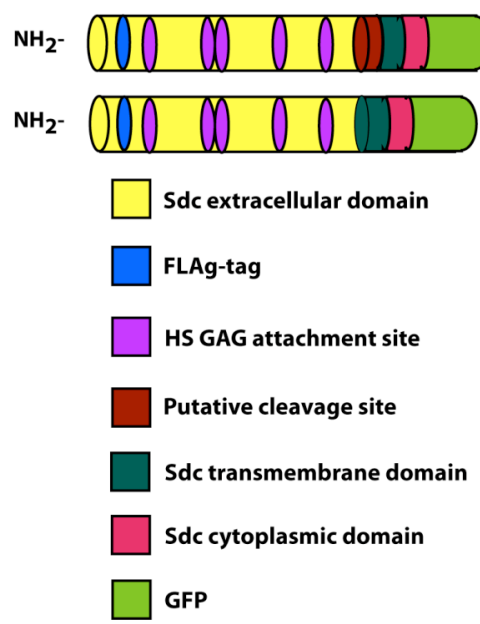

b)

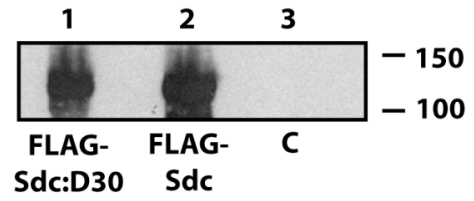

Figure 15: Shedding of the Sdc protein variant: Sdc:D30. a) A schematic representation of $s d c$ transgene variants used in this experiment. FLAG-Sdc:D30-GFP lacks 30 amino acids from the membrane proximal region of the extracellular domain that includes the putative protease cleavage site. b) Western blot to detect the shed ectodomains FLAG-Sdc and FLAG-Sdc:D30. Abs against the FLAG tag were used to detect the shed ectodomains FLAG-Sdc (lane 2) and FLAG-Sdc:D30 (lane 3) in the supernatant of Drosophila S2 cells transfected with their respective plasmids while no such band is apparent in the supernatant of mock transfected Drosophila S2 cells (lane 3) that serve as control (C). 
a)

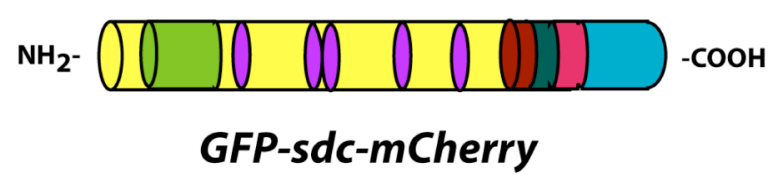

Sdc extracellular domain

GFP

HS GAG attachment site

Putative cleavage site

Sdc transmembrane domain

Sdc cytoplasmic domain

mCherry b)

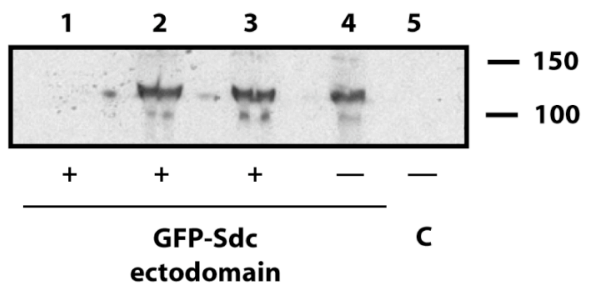

Figure 16: Sdc shedding in Drosophila $\mathbf{S 2}$ cells is sensitive to a serine protease inhibitor. a) A schematic representation of the double-tagged $s d c$ transgene used to determine protease inhibitor sensitivity of shedding. $b$ ) Western blot using $\alpha$-GFP Ab to detect the shed ectodomain of GFPSdc-mCherry. Lane 1-4: purified cell supernatant of Drosophila S2 cells transfected with GFP$s d c-m C h e r r y$ and cultured in media supplemented with a serine protease inhibitor (4-(2aminoethyl)benzene-sulphonyl fluoride, $10 \mu \mathrm{g} / \mathrm{ml}$ ), a metalloprotease inhibitor (bestatin hydrochloride, $10 \mu \mathrm{g} / \mathrm{ml}$ ), a protease inhibitor cocktail (Roche Complete Mini, 1 X) and no inhibitor respectively. Lane 5: purified cell supernatant of mock-transfected cells. Sdc shedding is inhibited in the presence of serine protease inhibitor (lane 1). Shed ectodomains are detectable in the supernatant of cells cultured in the presence of metalloprotease inhibitor (lane 2), protease inhibitor cocktail (lane 3) and no inhibitor (lane 4). No shed ectodomain is detectable in the supernatant of mock-transfected Drosophila S2 cells (lane 5).

Vertebrate Sdc studies imply that the protease responsible for shedding of Sdc is a TIMP3 sensitive metalloprotease (Anand-Apte et al., 1996) and that ectodomain shedding can be inhibited by addition of peptide hydroxamate chelators of $\mathrm{Zn}$ ions (Beckett et al., 1996). To determine if Drosophila Sdc shedding in cell culture was also sensitive to an inhibitor, a protease inhibitor cocktail, a metalloprotease inhibitor and a serine protease inhibitor were added to Drosophila S2 cells transfected with GFP-sdc-mCherry (Fig. 16a). Western blot analysis with an $\alpha$-GFP Ab to detect the shed ectodomains in the supernatant of transfected cells showed Drosophila Sdc shedding to be inhibited only in the presence of a serine protease inhibitor (Fig. 16b) indicating that the protease responsible for shedding is a serine protease. This is in contrast to vertebrate Sdc 
shedding, which is inhibited by peptide hydroxamate chelators of Zinc ions (Beckett et al., 1996) and metalloprotease inhibitor III (Anand-Apte et al., 1996).

\subsection{No shedding of Sdc in vivo}

Based on the results of the rescue experiments that showed a secreted form of Sdc to be inactive in Slit/Robo signalling and the cell culture based experiments that indicated shedding to be specific, an attempt was made to investigate if shedding of Sdc occurs in the embryo as well. Towards this aim a Sdc protein variant with an N-terminal FLAG-tag and a C-terminal GFP (Fig. 17a) was expressed in embryos using the apterousG4 driver line, which drives expression specifically in two parallel ipsilateral axon tracts one on each side of the ventral midline (Lundgren et al., 1995). CD8::GFP was expressed as a control in wild-type embryos (Fig. 17b). The localisation of the extracellular domain and the cytoplasmic domain of FLAG-Sdc-GFP was analysed independently of each other by
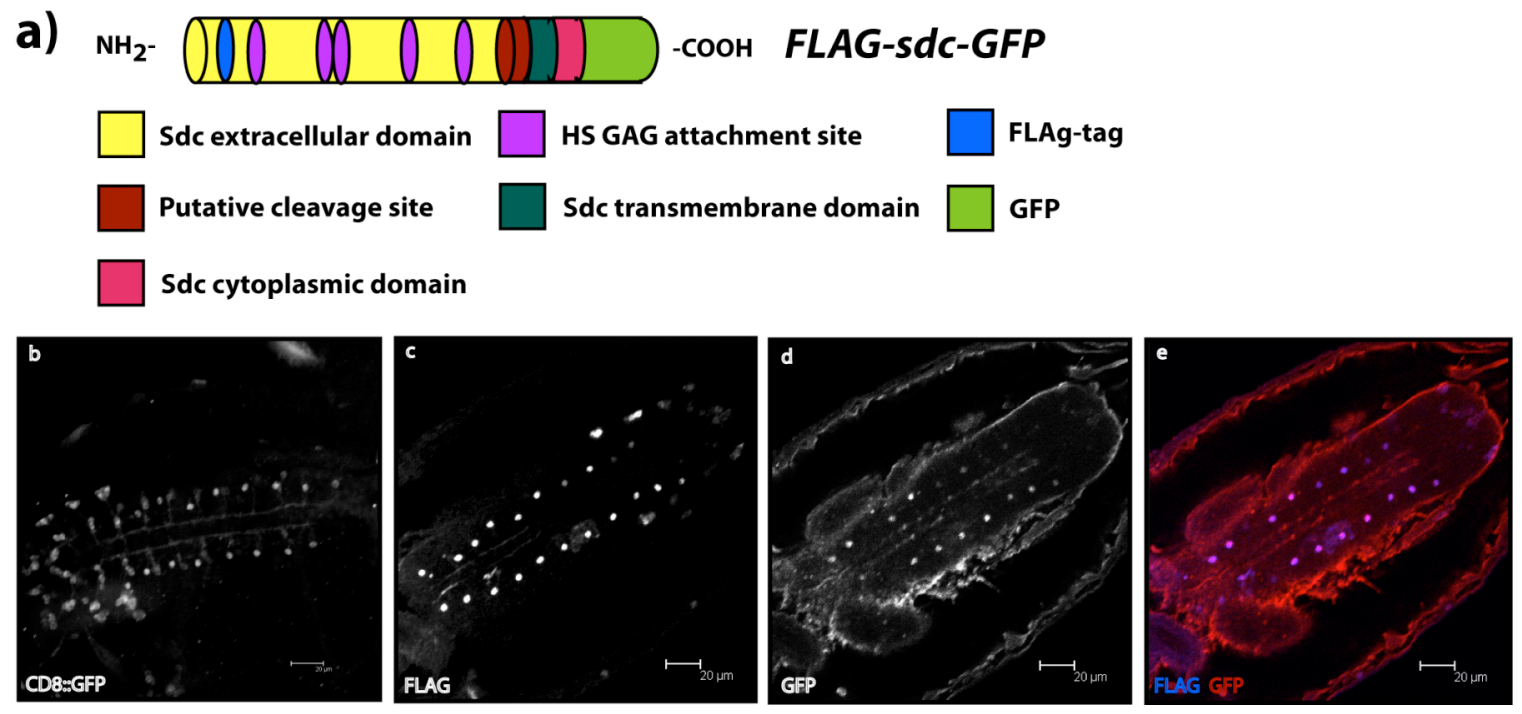

Figure 17: Drosophila Sde shedding is not detectable in vivo. a) A schematic representation of double-tagged $s d c$ transgene used for the in vivo localisation study. b-e) Optical transverse sections of stage 16 embryos. Scale bar: $20 \mu \mathrm{m}$. apterous 64 was used to express (b) UAS$C D 8:: G F P$ as control and (c-e) UAS-FLAG-sdc-GFP in wild-type embryos. b) CD8::GFP, detected with an $\alpha$-GFP $A b$, is localised to two ipsilateral axon tracts, one on each side of the ventral midline. c-e) Localisation of $\mathrm{N}$ - and C-termini of FLAG-Sdc-GFP were determined independently of each other by staining for the (c) FLAG epitope and (d) GFP epitope respectively. The $\mathrm{N}$ - and $\mathrm{C}$-termini colocalised on the two CNS ipsilateral axon tracts as seen in the overlay (e). No shed FLAG-Sdc ectodomain was discernible. 
detecting simultaneously both the FLAG tag (Fig. 17c) and the GFP tag (Fig. 17d). These results clearly show that both the FLAG-tag and the GFP signals colocalise (Fig. 17e). This is in accordance with the idea that no shedding of the Sdc protein occurs in vivo. However, this experiment does not exclude that shedding of Sdc occurs locally in the tissue and in amounts that are below detection level. But these results strongly suggest that the ectodomain is not shed in large amounts to function as an active form of Sdc as reported in some vertebrate processes like wound healing and microbial pathogenesis (Park et al., 2001).

\subsection{Participation of Ttv in Slit/Robo signalling}

The weak penetrance of $s d c^{23}$ mutant phenotype could be due to either (i) a partial rescue by the maternally provided $s d c$ transcripts or (ii) Robo receptor does not have an absolute dependence on Sdc for its activity or (iii) a combinatorial mode of function involving Sdc and additional HSPGs which compensates for the loss of Sdc. Analysis of $s d c^{23}$ mutant germline clones did not show an increase in the penetrance of the phenotype (P. Steigemann, unpublished data) excluding partial rescue by the maternally deposited $s d c$ transcripts. In order to distinguish between the other two possibilities, the role of other HSPG biosynthetic and modification enzymes was tested in Slit repellent signalling. Zygotic mutants of sugarless (sgl) (Häcker et al., 1997), tout velu (ttv) (Bellaiche et al., 1998) and sulfateless ( $s f l$ (Lin et al., 1999), were analysed for a slit like phenotype ( $s g l$ and $t t v$ are HSGAG biosynthetic enzymes while $s f l$ is an HSGAG modification enzyme, Section 1.1). Ventral midline crossing of CNS ipsilateral axons and ventral muscles was not observed in zygotic mutant embryos of $s g l$, $s f l$ (data not shown) and ttv (Fig. 18a and b). The mRNAs for these enzymes are maternally deposited in the oocyte so the phenotype could have been rescued by the maternal contribution. However, based on the essential role of these enzymes for Wingless (Wg), Hedgehog (Hh), Decapentaplegic (Dpp) and FGF signalling (Bellaiche et al., 1998; Häcker et al., 1997; Lin et al., 1999) it was not possible to analyze for a slit like phenotype in the germline clones of these mutants as the CNS is dramatically disrupted under the experimental conditions. Therefore, the function of these genes was analysed in a sensitized background by 
generating double mutants in combination with the $s d c^{23}$ mutant allele. The $s d c^{23} ; s g l$ and $s d c^{23} ; s f l$ double mutants had very low viability and were not amenable to further analysis. The $s d c^{23}, t t v^{00681 b}$ double mutant however is viable and fertile in the heterozygous mutant state. Analysis of the $s d c^{23}, t t v^{00681 b}$ double mutant homozygous embryos revealed an increase in the penetrance of the CNS phenotype, from $19 \%$ of counted segments in $s d c^{23}$ homozygous mutant embryos to $39 \%$ of counted segments in the homozygous double mutant embryos showing ventral midline crossover of CNS ipsilateral axons (Fig. 18a). The $s d c^{23}, t t v^{00681 b}$ double mutant homozygous embryos also showed a small increase in the penetrance of muscle phenotype with 1.3 muscle crossover per embryo as compared to the $s d c^{23}$ homozygous mutant embryos where 1.1 muscle crossover per embryo was observed (Fig. 18b) but this increase was not significant. This experiment clearly indicates that a second HSGAG modified protein participate with Sde in Slit/Robo signalling.

a)

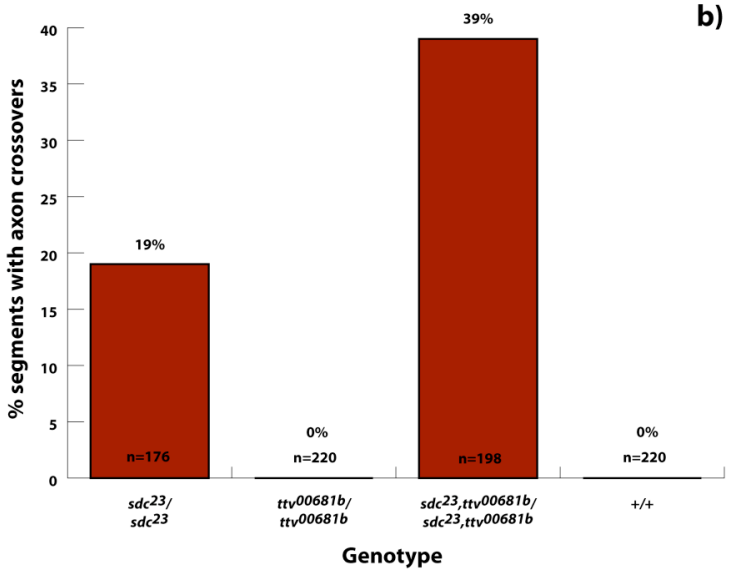

b)

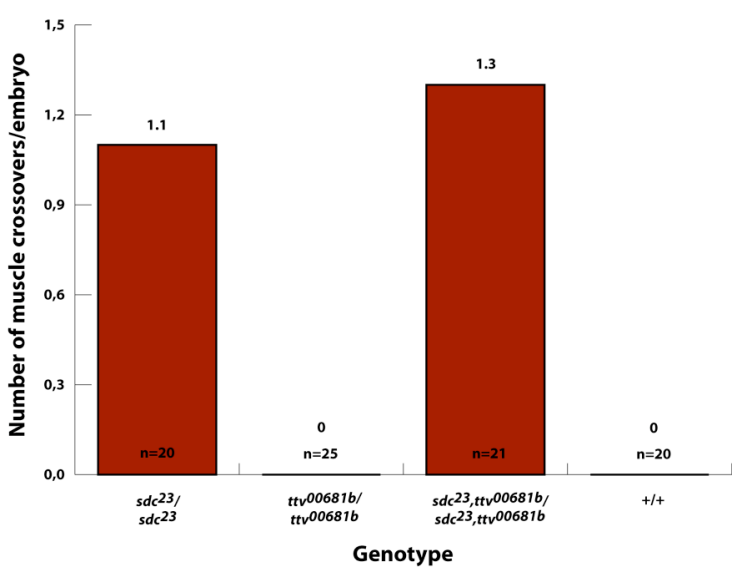

Figure 18: Ttv participates in Slit/Robo signalling. a) Percentage of segments displaying ventral midline crossing of CNS ipsilateral axons was estimated by staining stage 15-16 embryos with $\alpha$-FASII Ab. Wild-type and zygotic ttv null homozygous embryos did not show any ventral midline crossing of CNS ipsilateral axons. In $s d c^{23}, t t v^{00681 b}$ homozygous double mutant embryos $39 \%$ of counted segments showed ventral midline crossing of CNS ipsilateral axons in comparison to $s d c^{23}$ homozygous mutant embryos where only $19 \%$ of counted segments showed ventral midline crossing of CNS ipsilateral axons $(\mathrm{p}<0.001)$. b) Ventral midline crossing of muscles was estimated by staining the muscles of stage 14-16 embryos with $\alpha$-MHC Ab. Wildtype and ttv homozygous mutant embryos did not show any ventral midline crossing of muscles. In $s d c^{23}, t t v^{00681 b}$ homozygous double mutant embryos 1.5 muscle crossover per embryo was observed as compared to $s d c^{23}$ homozygous mutant embryos where 1.1 muscle crossover per embryo was observed $(\mathrm{p}>0.001)$. 


\subsection{Participation of DIp in Slit/Robo signalling}

To identify this second HSPG involved in Slit/robo signalling the same experimental approach was employed. Analysis of single mutants of HSPGs dally (Khare and Baumgartner, 2000; Nakato et al., 1995), dlp (Baeg et al., 2001) and trol (Park et al., 2003; Voigt et al., 2002) had disclosed no involvement of these HSPGs in Slit/Robo signalling. Their zygotic homozygous mutant embryos did not show ventral midline crossing of either the CNS ipsilateral axons or the ventral muscles (data not shown). But, an earlier report where the expression of $d l p$ in the $s d c^{23}$ mutant background resulted in partial rescue of the $s d c^{23}$ mutant phenotype (Johnson et al., 2004) suggested that Dlp and Sdc might be partially redundant in function. However, as mentioned above, analysis of zygotic $d l p$ null embryos revealed no slit like phenotype (germ line clones could not be analysed due to the early disruption of CNS development in these mutants). The function of Dlp in Slit/Robo signalling was therefore investigated in the more sensitised $s d c^{23}$ mutant background by generating a $s d c^{23} ; d l p^{A 187}$ double mutant. Analysis of mutant

a)

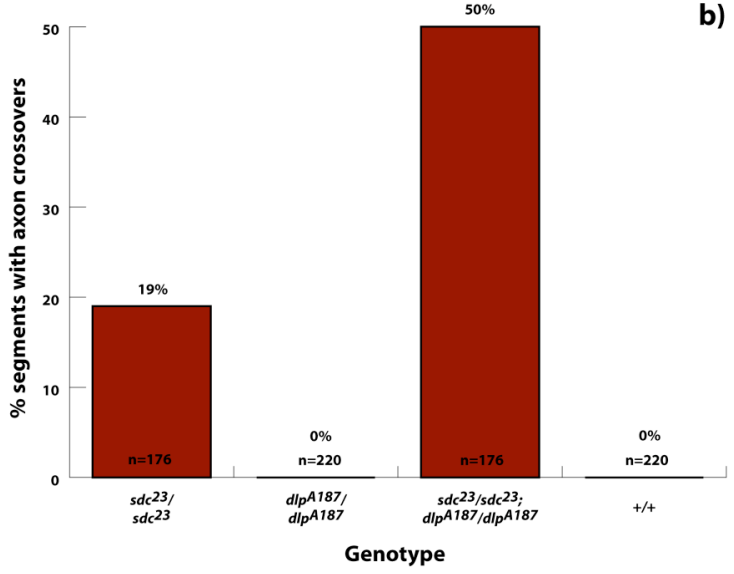

b)

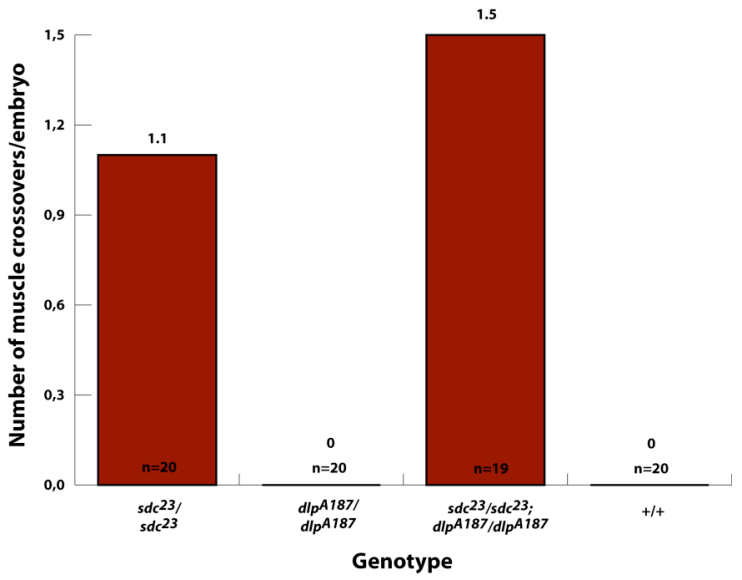

Figure 19: Dlp participates in Slit/Robo signalling. a) Percentage of segments displaying ventral midline crossing of CNS ipsilateral axons was estimated by staining stage 15-16 embryos with $\alpha$-FASII Ab. Wild-type and $d l p$ homozygous mutant embryos did not show any ventral midline crossing of CNS ipsilateral axons. In $s d c^{23} ; d l p^{A 187}$ homozygous double mutant embryos $50 \%$ of counted segments showed ventral midline crossing of CNS ipsilateral axons in comparison to $s d c^{23}$ homozygous mutant embryos where only $19 \%$ of counted segments showed ventral midline crossing of CNS ipsilateral axons $(\mathrm{p}<0.001)$. b) Ventral midline crossing of muscles was estimated by staining the muscles of stage 14-16 embryos with $\alpha$-MHC Ab. Wildtype and $d l p$ homozygous mutant embryos did not show any ventral midline crossing of muscles. In $s d c^{23} ; d l p^{A 187}$ homozygous double mutant embryos 1.5 muscle crossover per embryo was observed in comparison to $s d c^{23}$ homozygous mutant embryos where 1.1 muscle crossover per embryo was observed $(\mathrm{p}>0.001)$. 
embryos revealed an increase in the penetrance of the CNS phenotype from $19 \%$ of counted segments showing ventral midline crossovers of CNS ipsilateral axons in $s d c^{23}$ homozygous mutant embryos to $50 \%$ of counted segments showing ventral midline crossover of CNS ipsilateral axons in $s d c^{23} ; d l p^{A 187}$ homozygous double mutant embryos (Fig. 19a). A small increase in the penetrance of the muscle phenotype was also observed where 1.5 muscles crossed the ventral midline in $s d c^{23} ; d l p^{A 187}$ homozygous double mutant embryos in contrast to $s d c^{23}$ homozygous mutants where 1.1 muscle crossover per embryo was observed (Fig. 19b). However, the increase in the penetrance of muscle phenotype was not significant. These results clearly prove that Dlp is a second HSPG required in Slit/Robo signalling for CNS patterning and suggests that it might promote muscle guidance as well.

Taken together, the results from this study prove that Sdc activity is required on Slit target tissues: the CNS ipsilateral axons and muscles and Sdc has no essential role in the secretion or transport of Slit. The results also indicate that the extracellular domain of Sdc is the functional part of the molecule and it has to be membrane attached to be active though the mode of attachment is functionally exchangeable. Additionally, in the target tissue Sdc does not participate in intracellular signalling or in actin cytoskeleton reorganisation to transduce the repellent Slit signal. Analysis of double mutants also suggests Ttv and Dlp to have a role in Slit/Robo signalling. 


\section{Discussion}

Organisms coordinate body movements by integrating sensory input and exerting motor control, which is dependent on the formation of correct connections between neurons and their targets (reviewed in (Garbe and Bashaw, 2004; Kaprielian et al., 2000)). Among the many regulatory molecules that govern axon guidance during development (reviewed in (Garbe and Bashaw, 2004)) are the Heparan Sulphate Proteoglycans (HSPGs) (reviewed in (Lee and Chien, 2004)). This work aimed at understanding the mechanism by which Syndecan (Sdc), an HSPG, regulates Slit/Robo signalling, the key repellent axon guidance signalling pathway during embryogenesis. The results from this study prove that Sdc function is required on Slit target tissues: the CNS (central nervous system) ipsilateral axons and muscles and Sdc has no essential role in the secretion or transport of Slit. The results also indicate that Sdc acts via its extracellular domain, which has to be membrane associated but its mode of anchorage is functionally exchangeable. Additionally, in the target tissue Sdc does not participate in intracellular signalling or in actin cytoskeleton reorganisation to transduce the repellent Slit signal. Analysis of double mutants also suggests Ttv and Dlp to have a role in Slit/Robo signalling.

\subsection{Syndecan is required specifically on the target tissue}

Drosophila has a single $s d c$ gene (Spring et al., 1994) that is expressed during embryogenesis in the ventral furrow, the ventral nerve cord, the abdominal and the thoracic segments, the epidermis, the differentiating CNS and the tracheal cells (Kopczynski et al., 1998). By late embryogenesis, $s d c$ is expressed in the lymph glands, the PNS (peripheral nervous system) and CNS (Fig. 5a), the basal surface of the gut epithelia and the epidermal muscle attachment sites (MAS) (Spring et al., 1994; Steigemann et al., 2004).

Sdc has been shown to be critical for the fidelity of Slit repellent signalling at the ventral midline where it directs the patterning of the CNS and the musculature (Johnson et al., 2004; Steigemann et al., 2004). Loss of $s d c$ results in ventral midline crossing of CNS ipsilateral axons and ventral muscles (Fig. 5c and e) (Johnson et al., 2004; Steigemann et al., 2004). 
Various models, summarised in Section 1.2, have been proposed for the regulation of developmental signalling by HSPGs. According to these models, Sdc can function in more than one way, neither of which is mutually exclusive.

a)

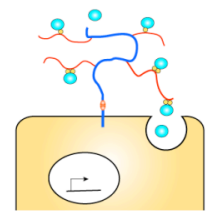

Slit secretion b)

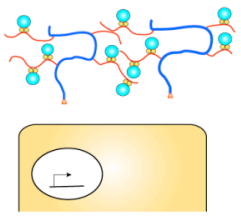

Slit transport c)

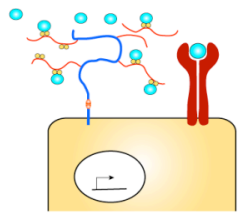

Slit concentration

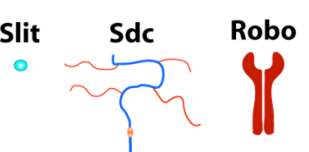

d)

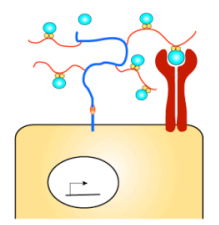

Slit reception e)

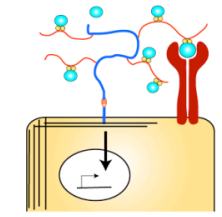

Slit signal transduction

Figure 20: Models for the role of Sdc in Slit repellent signalling. a) Sdc activity is required in the ventral midline cells for secretion of Slit. b) The shed ectodomain of Sdc transports Slit from its source to the target tissues. c) Sdc traps Slit on the surface of target tissue thereby concentrating it in the two-dimension. This increases the probability of interaction between Slit and its receptor Robo. d) Sdc acts as a coreceptor to facilitate and/or stabilise Slit/Robo interaction. e) Sdc cytoplasmic domain transduces the Slit repellent signal into the growth cone or myoblast.

Since Sdc is expressed in the ventral nerve cord of Drosophila where the Slit ligand is secreted, it is possible that Sdc is required in the ventral midline cells for the secretion of Slit (Fig. 20a). Although there is no direct evidence for the role of HSPGs in ligand secretion, a few studies indicate that they act by presenting the ligand to a neighbouring cell (Hufnagel et al., 2006). So it is possible that Sdc binds Slit and presents it to Robo on the axonal growth cones and myoblasts at the ventral midline. HSPGs have been shown to transport signalling molecules to their site of action: Decapentaplegic (Dpp) transport via planar transcytosis (Teleman and Cohen, 2000) and Wingless (Wg) transport in argosomes (Greco et al., 2001) is HSPG-dependent. This raises the possibility that Sdc might be required for the transport of Slit from the ventral midline cells to its target tissues: the axon growth cones and the ventral muscle myotubes (Fig. 20b). This model is attractive as it is well established that Sdcs can be shed from the cell surface via proteolytic cleavage (Anand-Apte et al., 1996). The shed ectodomain with its bound ligand could diffuse over a distance to not only transport its cargo but also protect it against extracellular proteases. This model is further supported by an earlier study 
(Johnson et al., 2004) which reported that loss of $s d c$ reduces the distribution of Slit outside the ventral midline cells which secrete Slit in comparison to wild-type embryos where Slit forms a gradient on both sides of the ventral nerve cord.

Another possible role of Sdc is that of a coreceptor where it promotes and/or stabilises Slit/Robo interaction. It might act so either by capturing Slit from the extracellular milieu and increasing its concentration and restricting its diffusion to a two-dimensional surface thereby increasing the probability of Slit/Robo interaction (Fig. 20c). Infact, studies in Drosophila have shown that Dlp, another HSPG, traps Wg outside of cells and seems to retard its movement (Baeg et al., 2001). Alternatively, Sdc could directly function to stabilise Slit/Robo interaction (Fig. 20d) as it has been reported that Sdc acts as a coreceptor with bFGF receptor (Filla et al., 1998; Steinfeld et al., 1996).

Sdc has a conserved cytoplasmic domain with a terminal EFYA motif that binds to PDZdomain containing proteins resulting in the formation of protein complexes on the inner face of the plasma membrane (Fanning and Anderson, 1996) that link Sdc to the underlying actin cytoskeleton (Woods et al., 1986). Also, it has been reported that the Cterminus of Sdc can bind PtdIns-4,5-P2 and PKC- $\alpha$ (Horowitz and Simons, 1998) and can be phosphorylated by Src family of kinases. It is therefore likely, that Sdc functions downstream of Slit/Robo interaction by serving as an adaptor for the formation of specific signalling complexes and/or remodelling of the actin cytoskeleton in order to transduce the Slit repellent signal (Fig. 20e).

These models are based on the requirement of Sdc activity in different tissues. A function of Sdc for the secretion of Slit would require its activity in the ventral midline cells, whereas a function in transport would require Sdc activity in the intermediate tissue and a function in the reception of the Slit signal would require Sdc activity in the target tissue. It was therefore possible to distinguish between these models by the identification of the tissue in which the activity of Sdc is required. To address this primary question, a tissuespecific $s d c$ rescue experiment was conducted by employing the UAS/GAL4 system (Section 2.2.3) whereby a $s d c$ transgene was expressed in the $s d c^{23}$ mutant background, specifically in different tissues: the ventral midline cells which are the source of Slit, the glia and the CNS which form the intermediate tissue in case of axons and muscles respectively, and in the target tissue, the axons and muscles, to rescue both the CNS and 
the ventral muscle phenotype (Table 1). Rescue was scored by the absence of ventral midline crossing of the CNS ipsilateral axons and the ventral muscles. For this analysis a transgene called $s d c-G F P$ ( $s d c$ ORF (Open Reading Frame) fused to GFP at the carboxylterminus (C-terminal)) was constructed and employed in a tissue-specific $s d c^{23}$ rescue experiment.

In this tissue-specific rescue experiment, the CNS and muscle phenotypes were rescued only when the $s d c-G F P$ transgene was expressed in the target tissue i.e. the axons and muscles (Fig. 6a and b) while no rescue was observed when the $s d c-G F P$ transgene was expressed at the source of the Slit ligand or in the intermediate tissue (Fig. 6a and b). These rescue experiments provided clear proof that Sdc activity in Slit/Robo signalling is required on the target tissue.

The specific requirement of Sdc in the target tissue excluded two of the models of Sdc action: the first model (Fig. 20a) which proposed Sdc to be essential for Slit secretion and the second model (Fig. 20b) in which Sdc was proposed to be essential for the transport and stability of Slit as suggested by Van Vactor and colleagues (Johnson et al., 2004). Johnson et al. (Johnson et al., 2004) were able to detect in vivo the extracellular gradient of Slit on both sides of the ventral midline in wild-type embryos. They further reported that in $s d c$ mutants, Slit staining outside the midline is significantly reduced, leaving staining mostly in the midline glia. The authors discussed this result with a model that suggested Sdc to be required for the active transport of Slit from the ventral midline to the axons and muscles. However, a potential caveat to the above-mentioned staining of the Slit gradient is that the antibody $(\mathrm{Ab})$ used in this study recognises the C-terminus of Slit. Both vertebrate and invertebrate Slit proteins are proteolytically processed (Brose et al., 1999). The cleaved fragments appear to have different cell-association characteristics with the smaller C-terminal fragment (C-Slit) being more diffusible than the larger $\mathrm{N}$ terminal (N-Slit), which is more tightly cell-associated (Wang et al., 1999). However, it is thought that the main biological activity is possessed by the cell-associated N-Slit and not by the diffusible C-Slit (Nguyen Ba-Charvet et al., 2001; Wang et al., 1999). Additionally, in cell overlay assays it was found that N-Slit could bind to Robo receptor while C-Slit could not (Nguyen Ba-Charvet et al., 2001). Therefore, binding to Robo receptor is mediated by $\mathrm{N}$-terminal Slit sequences. This was confirmed by 
immunoprecipitation studies as well (Nguyen Ba-Charvet et al., 2001). Furthermore, in collagen gel-repulsion assays N-Slit could repel axons. In contrast, C-Slit had no repulsion activity (Nguyen Ba-Charvet et al., 2001). Therefore, correlating the loss of diffusion or stability of a functionally inactive part of Slit (C-Slit) to loss of Sdc activity, which results in impaired N-Slit function, seems invalid. Furthermore, localisation studies with a monoclonal $\mathrm{Ab}$ against $\mathrm{N}-\mathrm{S}$ lit revealed no gradient in wild-type or $s d c^{23}$ homozygous mutant embryos (P. Steigemann, unpublished data). Additionally, double staining with $\alpha$-Sdc and $\alpha$-Robo showed a colocalisation of these proteins on the longitudinal axon tracts (Steigemann et al., 2004). So both the target tissue requirement of Sdc and its colocalisation with Robo on axons clearly supports an exclusive requirement of Sdc in the target tissue and proves that Sdc plays no critical role in the secretion or transport of Slit.

\subsection{Cytoplasmic domain of Syndecan is not required for function in Slit/Robo signalling}

The tissue-specific rescue experiment of the $s d c^{23}$ mutant phenotype had revealed the vital requirement of Sdc on the target tissue for its function in Slit/Robo signalling. But it still left three valid modes of action (Fig. 20c, d and e). Two of these models propose Sdc to be acting on the surface of the target tissue: concentrating the ligand Slit (Fig. 20c) or acting as a coreceptor to stabilise Slit/Robo interaction (Fig. 20d) and the third proposes Sdc to function as an active receptor transducing the repellent Slit signal intracellularly (Fig. 20e).

A growth cone continuously extends and retracts its filopodia at the leading edge to constantly reassess its immediate environment (reviewed in (Huber et al., 2003)). Upon receipt of the Slit repellent signal, an intracellular signalling cascade is initiated which leads to a dynamic rearrangement of the actin cytoskeleton in the growth cone leading first to its collapse and then to a change in direction and migration away from the source of Slit. Neither the identity of these downstream signalling components, nor their mode of action is well understood.

Sdc has a highly conserved EFYA sequence at its C-terminus that can bind to PDZ domain-containing proteins (Ethell and Yamaguchi, 1999). PDZ domains in turn organise 
and assemble protein complexes at the inner face of the plasma membrane (Fanning and Anderson, 1996) and are thought to link membrane components to the underlying actin cytoskeleton. Infact, the cytoplasmic domain of vertebrate Sdcs have been shown to form complexes with Src family kinases and actin binding proteins like Cortactin and Tubulin (Kinnunen et al., 1998). These interactions may account for the variety of changes in actin filament organisation associated with the Sdcs, including binding of Sdc1 to a crude preparation of F-actin filaments, colocalisation of Sdc1 and F-actin at the basal surfaces of polarised mammary epithelial cells (reviewed in (Bernfield et al., 1999)) and actin filament reorganisation upon binding of Sdcs to ECM ligands (Woods et al., 1986). This distribution of clustered Sdc can be altered by cytochalasin treatment (Carey et al., 1994) and requires the cytoplasmic domain (Carey et al., 1996). All these studies provide strong support for the participation of the cytoplasmic domain of Sdc in intracellular signalling and/or in regulating the actin cytoskeleton and this might be a mechanism by which the Slit repellent signal is transduced into the growth cone.

However, a $s d c$ transgene that lacks the coding region for the cytoplasmic domain of Sdc, s $d c \Delta C$-GFP (Fig. 7a), was able to rescue the $s d c^{23}$ mutant phenotype (Fig. 7b). This result excluded any contribution of the cytoplasmic domain of Sdc to its function in Slit/Robo signalling. Hence, Sdc is not essential for the formation or activity of any intracellular signalling complex or for the reorganisation of the actin cytoskeleton in response to the repellent Slit signal. Based on this result, a function of Sdc as an active transducer of Slit repellent could be excluded (Fig. 20e).

\subsection{Syndecan has to be membrane anchored for its function in Slit/Robo signalling}

Vertebrate studies report that shedding of the extracellular domain of $\mathrm{Sdc}$ is required to generate a functionally active form of the molecule in cases such as wound healing and microbial pathogenesis (Park et al., 2001). To test for the requirement of shedding of Sdc for Slit mediated repulsion in vivo, a $s d c$ deletion transgene was used to rescue the $s d c^{23}$ mutant phenotype. This $s d c$ deletion transgene, $s d c \Delta T C-G F P$, lacked the coding region for both the transmembrane and the cytoplasmic domain of Sdc. Essentially this transgene codes for the extracellular domain of Sdc without any membrane anchor 
sequence (Fig. 7a). Therefore, the protein encoded by this transgene should be modified and secreted into the extracellular matrix and function as a constitutively shed form of Sdc. Additionally, since the transmembrane domain localises Sdc to discrete membrane domains (Hayashi et al., 1987; Rapraeger et al., 1986; Woods and Couchman, 1994) and interacts within the plane of the membrane with other proteins (Lebakken and Rapraeger, 1996; Yamashita et al., 1999), the protein encoded by $s d c \Delta T C-G F P$ does not have any specific membrane localisation or interacts with other proteins in the membrane as directed by the transmembrane domain of Sdc. This secreted form of Sdc was unable to rescue the $s d c^{23}$ mutant phenotype (Fig. 7b) when expressed in the CNS proving that membrane anchorage of Sdc is essential for its activity in Slit/Robo signalling.

In order to confirm that the protein encoded by $s d c \triangle T C-G F P$ is indeed secreted two independent approaches were undertaken. In the first approach localisation was tested in vivo using either nervous system specific or ubiquitous expression to envision the localisation of the GFP fusion proteins. As a control the wild-type $s d c$ transgene, $s d c$ $G F P$ and the $s d c$ transgene lacking the cytoplasmic domain, $s d c \triangle C$-GFP were used (Fig. 8a). Protein expression and localisation study in the CNS revealed that even though the protein encoded by $s d c-G F P$ and $s d c \Delta C$-GFP were localised to the axon bundles (Fig. $8 \mathrm{~b}$ and c), the protein encoded by $s d c \Delta T C-G F P$ showed no such specific localisation but was expressed in a very diffused manner in the entire CNS (Fig. 8d). Therefore, absence of the transmembrane domain results in the loss of specific transport of the protein from the cell bodies to the axons presumably reflecting the secretion of the protein from the cell bodies.

For further confirmation subcellular localisation of Sdc $\Delta \mathrm{TC}-\mathrm{GFP}$ protein was analysed in two tissues with wide well defined lumens, the hindgut and the dorsal trunk of the tracheal system. The hindgut lumen is surrounded by large epithelial cells that have distinct membrane domains. By staining for the transmembrane protein Crumbs, which is localised to the domain apical of zonula adherens, the border between the lumen and the surrounding polar epithelial cells can be visualised (Tepass et al., 1990). Exploiting this approach in embryos ubiquitously expressing $s d c-G F P$, $s d c \triangle C-G F P$ or $s d c \Delta T C-G F P$, localisation of the proteins in the hindgut was determined by staining for the C-terminal GFP. This analysis revealed that the Sdc-GFP protein was localised to the basal 
membrane of epithelial cells (Fig. 8g) while the Sdc $\Delta$ C-GFP protein was localised to the apical membrane (Fig. 8j). This change in localisation is directly attributable to the loss of the cytoplasmic domain. Thus it appears that the cytoplasmic domain is essential for targeting of Sdc to the basal membrane of the hindgut in wild-type embryos. From vertebrate studies it is known that Sdc function is essential for maintaining epithelial integrity by regulating the actin cytoskeleton (Woods et al., 1986) and E-cadherin expression (Kato et al., 1995). Additionally, loss of Sdc1 leads to impaired and delayed wound and corneal repair (Langford et al., 1998). Therefore, it is possible that mislocalisation of Sdc due to the absence of the cytoplasmic domain might interfere with its function in epithelial tissues. But the expression of the Crumbs protein that marks the apical cell border of the gut cells is not affected proving that the polarity and composition of the polarized tissue is not affected. Furthermore, specific neuronal expression of the $s d c \Delta C-G F P$ transgene rescues the $s d c^{23}$ CNS phenotype (Fig. 7b) (Section 4.2) proving that loss of the cytoplasmic domain of Sdc has no effect on its function in the CNS. Furthermore, transport of Sdc $\Delta$ C-GFP protein to the axons of the CNS (Fig. 8c) clearly excludes a function of the cytoplasmic domain for subcellular localisation in neurons. So the observed localisation at the apical surface of the hindgut tissue reflects an independent sorting or localisation mechanism that is specific to epithelial cells.

Staining for the Sdc $\Delta$ TC-GFP protein showed that it was secreted into the hindgut lumen (Fig. 8m), which had been demarcated by labelling for the Crumbs protein. This was in stark contrast to Sdc-GFP and Sdc $\Delta$ C-GFP proteins, which though expressed in the hindgut epithelia were not secreted as seen by the absence of staining in the lumen for Sdc-GFP and Sdc $\Delta$ C-GFP (Fig. $8 \mathrm{~g}$ and $\mathrm{j}$ ).

Secondly, protein localisation in the lumen of the dorsal trunk of the trachea was determined. The tracheal lumen was labelled, by staining with the $2 \mathrm{~A} 12 \mathrm{Ab}$ that binds an unidentified factor. This analysis also revealed that even though the protein encoded by $s d c \triangle T C-G F P$ is detectable in the tracheal lumen (Fig. 9j), the proteins encoded by $s d c$ GFP (Fig. 9d) and $s d c \triangle C$-GFP are not (Fig. 9g). The above two localisation studies prove that the protein encoded by $s d c \Delta T C-G F P$ is secreted both in polarised tissues such as the hindgut and tracheal system as well as from the cell bodies of the CNS axons while the proteins encoded by $s d c-G F P$ and $s d c \triangle C-G F P$ are not. 


\subsection{The secreted form of Syndecan is modified}

To confirm the results of the localisation experiments in the Drosophila embryo by an independent method, cell culture experiments were performed to test for the secretion of Sdc $\Delta$ TC-GFP protein into the cell supernatant. For this Drosophila S2 cells were transfected with either $s d c-G F P, s d c \triangle C-G F P$ or $s d c \triangle T C-G F P$. Western blot analysis was performed to test for the presence of secreted protein in the supernatant of transfected cells. This analysis showed large amounts of Sdc $\Delta$ TC-GFP protein in the supernatant while no detectable amount of Sdc-GFP or $\operatorname{Sdc} \Delta \mathrm{C}$-GFP protein was present in the supernatant (Fig. 10c) even though western blot of cell extracts demonstrated the expression of all three proteins (Fig. 10b). Thus this experiment showed that the $s d c \Delta T C$ GFP protein is secreted even in a completely different experimental system.

The observed failure of the secreted Sdc to rescue the $s d c^{23}$ mutant phenotype could have been caused by the loss of HSGAG modification. Therefore, the molecular weights of the three proteins encoded by $s d c-G F P, s d c \Delta C-G F P$ and $s d c \triangle T C-G F P$ respectively were compared. The modification of Sdc with HSGAG results in a dramatic increase in its molecular weight and the protein migrates as a diffuse band on SDS-PAGE due to the presence of sugar moieties that are variably modified (Spring et al., 1994). However the western blot analysis of cell extracts of transfected Drosophila S2 cells proved that the Sdc $\Delta$ TC-GFP protein is modified similarly to wild-type Sdc as it migrates identically to Sdc-GFP and Sdc $\Delta C$-GFP on SDS-PAGE (Fig. 10b).

From the above experiments it is clear that the protein encoded by $s d c \triangle T C-G F P$ is indeed secreted and modified and therefore its inability to rescue the $s d c^{23}$ mutant phenotype can be attributed to the absence of the transmembrane domain. However, the rescue experiment with the secreted form of Sdc did not allow to distinguish between the requirement of a membrane tethered Sdc extracellular domain and the dependence on the Sdc transmembrane domain for specific localisation and in mediating protein-protein interactions, as suggested by vertebrate studies (Hayashi et al., 1987; Lebakken and Rapraeger, 1996; Rapraeger et al., 1986; Woods and Couchman, 1994; Yamashita et al., 1999). In order to distinguish between the requirement of Sdc transmembrane domain or the need to be membrane bound, a chimeric transgene was constructed. This chimeric transgene called FLAG-sdc-ext+dlp-GPI (Fig. 11a), codes for a protein that has the 
FLAG-tagged extracellular domain of Sdc fused to the GPI anchor sequence from Dlp. The presence of this GPI anchor sequence would cause the extracellular domain of Sdc to be anchored to the outer leaflet of the plasma membrane by a GPI molecule, a lipid modification. This protein though anchored to the membrane would not span it and would be unable to partake in any protein-protein interaction that might have been mediated by the transmembrane domain. This transgene was able to rescue the $s d c^{23}$ mutant phenotype (Fig. 11b), and presented clear proof that the only essential function of the transmembrane domain of Sdc is to anchor the extracellular domain to the membrane and that it does not participate in any protein-protein interactions that are functionally relevant in Slit/Robo signalling. Therefore, provided that the extracellular domain of Sdc is anchored to the membrane, it will be functionally active, regardless of the mode of anchorage.

\subsection{Heparan sulphate glycosaminoglycan attachment site mutant transgenes encode for proteins that carry high molecular weight modifications}

Based on the exclusion of the cytoplasmic and the transmembrane domains of Sdc for conferring specificity to its role in Slit/Robo signalling, the activity of Sdc in Slit/Robo signalling has to be attributed to its extracellular domain. This extracellular domain is composed of the core protein and its attached HSGAG and CSGAG chains. To examine if any of these three components, singly or in combination are responsible for the activity of Sdc, transgenes were constructed in which the HSGAG attachment sites (reviewed in (Lee and Chien, 2004)) were sequentially mutated from Ser-Gly to Ala-Gly in the sglGFP to sg5-GFP transgenes (Fig. 12a). These transgenes should therefore code for proteins that would carry a decreasing number of HSGAG chains. If the HSGAG chains were essential for the function of Sdc then a gradation of rescue of the $s d c^{23}$ mutant phenotype was expected while for the $s g 5-G F P$ transgene, in which all putative HSGAG attachment sites are mutated, no rescue was anticipated. On the other hand, if the core protein sequence of Sdc alone contributes to Slit/Robo signalling, then the loss of HSGAG chains would not affect the ability of the transgenes to rescue the $s d c^{23}$ mutant phenotype. When the HSGAG attachment site mutant transgenes were tested for their 
ability to rescue the $s d c^{23}$ mutant phenotype, all the transgenes rescued the phenotype completely except $s g 5-G F P$, which resulted in a nearly complete rescue with $2 \%$ of counted segments showing ventral midline crossover of CNS ipsilateral axons (Fig. 12b). This result is in accordance with a model in which the HSGAG chains of Sdc are atleast partially dispensable for its function in Slit/Robo signalling and the core protein is the essential component. However, the presence of HSGAG modifications is dependent on the core protein sequence itself and it was unclear if the mutations in the putative acceptor sites did completely block the modification of the core protein. To verify that the protein encoded by sg5-GFP was indeed devoid of any HSGAG chains, its molecular weight was ascertained in western blots of cell extracts after expression in S2 cells. The protein encoded by $s g 5-G F P$ migrated on an SDS-PAGE similarly to Sdc-GFP (Fig. 13b), indicating that SG5-GFP was modified similarly if not identically to wild-type Sdc. This could be due either to HSGAG modification of unknown cryptic HSGAG attachment sites or an increase in CSGAG modifications to compensate for the absence of HSGAGs. To differentiate between these two possibilities, FLAG-Sdc-GFP and FLAG-SG5-GFP proteins (Fig. 14a) were purified from the supernatant of cells transfected with their respective plasmids. These purified proteins were used for enzymatic assays with heparinase II and chondroitinase ABC enzymes, which specifically depolymerise HSGAG and CSGAG chains respectively. In case a protein bears solely HSGAG or CSGAG chains, loss of modification should cause a change in the mobility of the protein on an SDS-PAGE. However, if a protein bears both HSGAG and CSGAG chains, a change in mobility will be observed only when the protein is treated with both heparinase II and chondroitinase ABC. Western blot analysis of heparinase II and chondroitinase ABC treated FLAG-Sdc-GFP and FLAG-SG5-GFP revealed no differences in mobility in comparison to untreated FLAG-Sdc-GFP and FLAG-SG5-GFP proteins, respectively (Fig. 14c). This result can only be explained by inhibition of one or both enzymes in the experiment. The most appealing explanation for this failure could be the presence of inhibitors in the samples, which are purified from the supernatant of transfected cells. Alternatively, the enzymatic assay may need further optimization with respect to its various parameters. However, the control staining of all proteins on the western blot using Ponceau S, revealed a dramatic change in the 
molecular weight of an unspecific co-purified protein in the case of chondroitinase ABC treatment indicating that chondroitinase $\mathrm{ABC}$ is active under the conditions chosen (Fig. $14 \mathrm{~b}$ ). Based on this assumption, the CSGAG modifications alone can not explain the similar molecular weights of wild-type and SG5 Sdc variants. To prove HSGAG modifications on cryptic sites either a working enzymatic assay for HSGAG modifications needs to be established or antibodies specifically directed against HSGAG and CSGAG epitopes can be used in future to dissect the nature of modifications present on FLAG-Sdc-GFP and FLAG-SG5-GFP proteins.

\subsection{Syndecan is shed in culture by Drosophila S2 cells}

The intact ectodomain of each mammalian Sdc and the single Drosophila Sdc are constitutively shed into the conditioned media of cultured cells (Kim et al., 1994; Spring et al., 1994) as part of cell surface HSPG turn over (Yamagata et al., 1993). However, shedding of vertebrate Sdc has also been shown to be functionally relevant in cases of wound healing and bacterial pathogenesis (Park et al., 2001). Therefore, whether shedding of Drosophila Sdc is essential for its function in Slit/Robo signalling was an intriguing question. The inability of the $s d c \triangle T C-G F P$ transgene (Fig. 7a), which codes for a protein that mimics a constitutively shed ectodomain of Sdc, to rescue the $s d c^{23}$ mutant phenotype (Fig. 7b) (Section 4.3) indicated that shedding is not vital for its function in Slit/Robo signalling. In addition, fusion of an ectopic membrane anchor rendered the extracellular domain active (Fig. 11b). Furthermore, $s d c^{23}$ rescue experiments revealed that Sdc is required exclusively on the target tissue (Fig. 6a and b). All three results are in strong support of a membrane tethered active form of Sdc and would not fit to a mechanism in which Sdc protein has to be shed to be active. However, this does not exclude the possibility that shedding of Sdc terminates rather than facilitates its interaction with Slit and/or Robo. For further affirmation, a transgene, FLAGsdc:D30-GFP (Fig. 15a), was constructed which lacks 30 amino acids of the extracellular domain directly proximal of the membrane region. This transgene was constructed based on vertebrate studies, which report that the site endogenously cleaved is within five amino acids from the transmembrane domain. FLAG-sdc:D30-GFP, was tested in a cellculture based assay (Section 2.3.4) to confirm its non-sheddable nature before using it for 
in vivo analysis. The shed ectodomains were purified from the supernatant of cells transfected with FLAG-sdc-GFP or FLAG-sdc:D30-GFP. Western blot analysis using $\alpha-$ FLAG Ab demonstrated the presence of shed ectodomain of both FLAG-Sdc-GFP and FLAG-Sdc:D30-GFP (Fig. 15b). Therefore, unlike vertebrate Sdc, the cleavage site of Drosophila Sdc does not lie in the membrane proximal region of the extracellular domain or alternatively this result can be interpreted to indicate that the proteolytic cleavage is position-specific rather than sequence-specific. This model would explain why the deletion of 30 amino acids does not abolish shedding of Sdc. However the cleavage of this deletion mutant also raised the possibility that Drosophila Sdc shedding was nonspecific and might be taking place as part of cell-surface turnover.

To test if the observed shedding in cell culture is mediated by a protease, an attempt was made to inhibit shedding in cell culture by addition of a protease inhibitor cocktail, a metalloprotease inhibitor or a serine protease inhibitor to cells transfected with $G F P$-sdc$m$ Cherry (a $s d c$ transgene with N-terminal GFP and C-terminal mCherry) (Fig. 16a). Western blot analysis with $\alpha$-GFP Ab was performed to detect shed ectodomains in the supernatant of transfected cells treated with different protease inhibitors. This analysis showed that Drosophila Sdc shedding is inhibited in the presence of serine protease inhibitor (Fig. 16b). This appears contradictory in the light that shedding still occurs in the presence of protease inhibitor cocktail (Fig. 16b). A probable explanation is that in contrast to the irreversible serine protease inhibitor (4-(2-aminoethyl)benzene-sulphonyl fluoride) used in this study, the serine protease inhibitor constituent of the protease inhibitor cocktail (Complete Mini, Roche) reversibly inhibits the protein thus causing only transient inactivation of the protease. Additionally, the concentration of the irreversible serine protease inhibitor used $(10 \mu \mathrm{g} / \mathrm{ml})$ might be greater than the concentration present in the protease inhibitor cocktail. To clarify this, Sdc shedding can be determined under higher concentrations of protease inhibitor cocktail. However, if Drosophila Sdc ectodomain shedding is indeed due to the proteolytic activity of a serine protease it would be in contrast to vertebrate Sdcs, where studies report Sdc shedding to be sensitive to hydroxamate chelators of $\mathrm{Zn}$ ions (Beckett et al., 1996) and metalloprotease inhibitor III (Anand-Apte et al., 1996) making the protease responsible for shedding a member of the ADAM (A Disintegrin and Metalloproteinase) family of 
cell surface proteases (Wolfsberg et al., 1995b). However, in Drosophila the protease required for shedding is not characterised. In the case of Dlp, the Notum protein has been reported to be required for the release of Dlp from the cell membrane in the wing discs of Drosophila (Giraldez et al., 2002). However, the protein sequence of Notum does not show any clear sequence similarity to serine or ADAM family proteases (Giraldez et al., 2002). However, in Xenopus, a novel secreted serine protease xHtrA1 has been identified that cleaves Xenopus Glypican and Syndecan proteins in cell culture experiments (Hou et al., 2007). Based on sequence similarity Drosophila has an ortholog of this protease, which will be tested in the cell culture based shedding assay.

\subsection{Shedding of Syndecan in vivo}

Since a non-sheddable form of Sdc could not be created, it was not possible to address the importance of shedding directly in vivo by means of a rescue experiment. Therefore, an attempt was made to detect shedding of wild-type Drosophila Sdc in the embryo in vivo. For this, a double-tagged $s d c$ transgene, FLAG-sdc-GFP (Fig. 17a), was expressed using the apterous $G 4$ driver, which drives expression in a pair of CNS ipsilateral axons, one on each side of the ventral midline (Fig. 17b) (Lundgren et al., 1995; Rajagopalan et al., 2000b). The presence of two tags on the Sdc protein, FLAG tag at the N-terminus and GFP tag at the C-terminus, allows for the detection of the extracellular and cytoplasmic domains of Sdc independently of each other. This localisation study demonstrated that both the FLAG (Fig. 17c) and GFP (Fig. 17d) signals colocalised at the axon membrane (Fig. 17e). It therefore appears that Drosophila Sdc is not shed from the surface of Apterous positive CNS axons. However, the possibility of Sdc shedding at certain stages in low amounts cannot be excluded because of technical limitations.

\subsection{Ttv and Slit/Robo signalling: participation of an additional HSPG in Slit/Robo signalling}

To verify if Sdc is the only HSPG participating in Slit/Robo signalling, single mutants of HSPG biosynthetic enzymes ( $s g l$ and ttv) (Bellaiche et al., 1998; Häcker et al., 1997), HSPG modification enzyme (sfl) (Lin et al., 1999) and HSPGs themselves (dally and $d l p$ ) 
(Baeg et al., 2001; Khare and Baumgartner, 2000; Nakato et al., 1995) were analysed for a slit like phenotype. No ventral midline crossover of CNS ipsilateral axons or the ventral muscles were observed in the zygotic homozygous mutants. Since all enzymes tested are maternally contributed and could be fulfilling the embryonic requirement of these proteins, single mutants were tested in a sensitised genetic background. This approach was chosen because analysis of germline clones of these mutants would not be informative due to their affect on $\mathrm{Wg}$, Hedgehog $(\mathrm{Hh})$ and Dpp signal transduction pathways which affect early neurogenesis before effects on Slit/Robo signalling are detectable. To generate a sensitised genetic background, mutants of these genes were combined in with the $s d c^{23}$ mutant allele. Since $s d c^{23}$ is a null allele of $s d c$, a strengthening of the phenotype in the double mutant has to be due to the abolishment or impairment of HSGAG modification of Dlp, Dally or Perlecan, the other HSPGs in Drosophila.

One of the double mutant combinations analysed was the $s d c^{23}, t t v^{00681 b}$ mutant. Staining for CNS ipsilateral axons and muscles in the double mutant embryos showed an increase in the penetrance of both the CNS and muscle phenotype (Fig. 18a and b) though in the case of muscle phenotype this increase was not statistically significant ( $p>0.001)$. In the double mutant, $39 \%$ of counted segments showed ventral midline crossing of CNS ipsilateral axons as compared to $s d c^{23}$ single mutants where only $19 \%$ of counted segments showed ventral midline crossovers (Fig. 18a). The muscle phenotype also showed a small increase in penetrance, from 1.1 muscle crossover per embryo in $s d c^{23}$ homozygous mutant embryos to 1.3 in $s d c^{23}, t t v^{00681 b}$ homozygous double mutant embryos (Fig. 18b). The fact that in zygotic ttv null mutants Slit/Robo signalling is not affected indicates that Sdc must be the major HSPG involved in Slit/Robo signalling. However, in the $s d c^{23}$ mutant background the requirement of one or more additional HSPGs is detectable.

\subsection{DIp: the second HSPG in Slit/Robo signalling}

The strengthening of phenotype in the $s d c^{23}, t t v^{00681 b}$ double mutant indicated that one or more HSPGs are required in addition to Sdc in Slit/Robo signalling. As the zygotic mutants of $d l p$, dally and trol did not show any midline crossover of CNS ipsilateral 
axons and muscles, double mutants with $s d c^{23}$ were generated. The analysis of $s d c^{23} ; d l p^{A 187}$ homozygous double mutant embryos revealed an increase in the penetrance of the CNS and muscle phenotype (Fig. 19a and b) though the increase in muscle phenotype was not statistically significant ( $p>0.001$ ). Phenotypic analysis showed that in $s d c^{23} ; d l p^{A 187}$ homozygous double mutant embryos $50 \%$ of counted segments showed ventral midline crossover of CNS ipsilateral axons in contrast to $s d c^{23}$ homozygous mutant embryos where only $19 \%$ of counted segments showed ventral midline crossovers (Fig. 19a). The muscle phenotype also showed an increase in penetrance from 1.1 muscle crossover per embryo in $s d c^{23}$ homozygous mutant embryos to 1.5 muscle crossover per embryo in $s d c^{23} ; d l p^{A 187}$ homozygous double mutant embryos (Fig. 19b). These results suggest Dlp to be a part of Slit/Robo signalling. The fact that both $s d c^{23}, t t v^{00681 b}$ and $s d c^{23} ; d l p^{A 187}$ double mutants showed an increase in CNS and muscle phenotype strongly suggests that Dlp is the specific additional HSPG that functions in Slit/Robo signalling. In further support is the fact that Dlp is expressed on CNS axons and in stripes that overlap with muscle attachment sites in the embryo.

However, at this time it is premature to specify the mechanism of Dlp action. In analogy
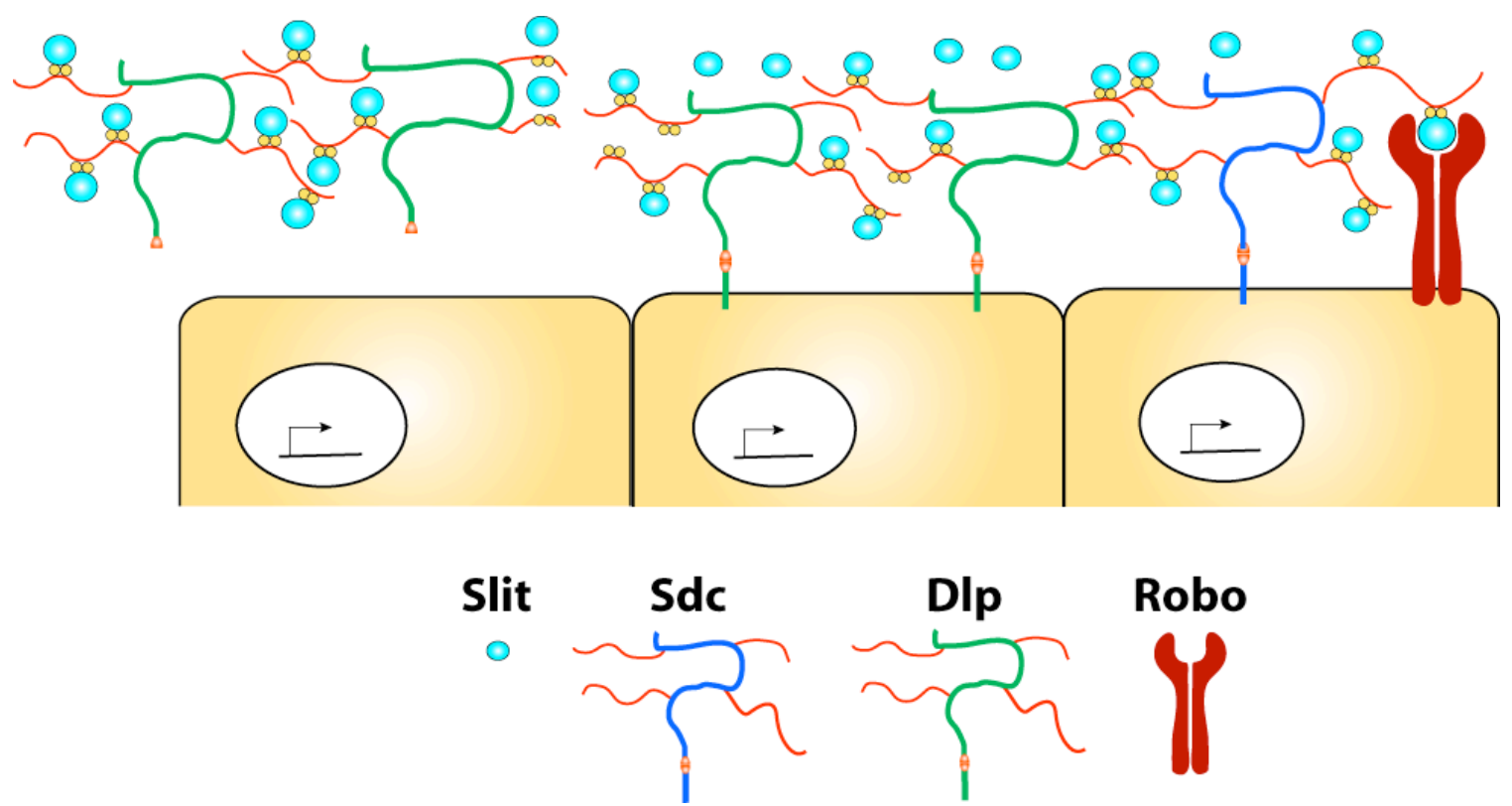

Figure 21: A model for combinatorial mode of action of Sdc and Dlp in Slit/Robo signalling. Dlp serves to transport and/or concentrate Slit on the target tissue and Sdc acts as a coreceptor to stabilise Slit/Robo interaction for efficient transduction of the repellent signal into the cell. 
to the mechanism that has been proposed for the transfer of Dpp and Hh (Belenkaya et al., 2004; Han et al., 2004), it can be speculated that Dlp is involved in the extracellular transport of Slit. Alternatively, Dlp might be increasing the concentration of Slit outside the target cells by trapping it with its HSGAG chains the same way it traps Wg outside cells (Baeg et al., 2001). Absence of a cytoplasmic domain excludes any direct intracellular signalling role of Dlp. However the possibility of the GPI anchor of Dlp, recruiting Robo receptor and other essential signalling components into lipid rafts to facilitate signalling cannot be excluded. Nevertheless, the observation that zygotic $d l p$ null mutants do not have a slit like phenotype strongly suggests that Sdc is the primary HSPG that is required for Slit/Robo signalling with Sdc and Dlp having a combinatorial mode of action. This combinatorial mode of action as proposed in Figure 21 can be verified by tissue-specific expression of $s d c$ and $d l p$ in $s d c^{23} ; d l p^{A 187}$ double mutants. If Dlp indeed functions to transport Slit then expression in $s d c^{23} ; d l p^{A 187}$ double mutants of $d l p$ in the intermediate tissue through which Slit has to be transported should rescue the phenotype to that of a $s d c^{23}$ single mutant.

In conclusion, this work has shed some light on the mechanism of action of Sdc in Slit/Robo signalling. The data proves that Sdc function is required on Slit target tissues: the CNS ipsilateral axons and muscles that express the Slit receptor Robo. Sdc plays no essential role in the secretion of Slit or its transport. Sdc acts via its extracellular domain on the surface of the target tissue and its mode of anchorage causes no disparity in its function. In all probability, Sdc does not only function to trap Slit and increase its concentration on the target tissue thereby enhancing the probability of Slit and Robo interaction but as an active coreceptor to stabilise Slit and Robo interaction. This is supported by the fact that a secreted form of Sdc does not rescue the $s d c$ mutant phenotype. In the target tissue Sdc does not participate in intracellular signalling to transduce the repellent Slit signal. Additionally, Sdc does not direct the reorganisation of actin cytoskeleton in response to the repellent Slit signal.

Indirect evidence suggests that shed ectodomain of Drosophila Sdc is inactive in Slit/Robo signalling. Therefore, shedding of Sdc by the proteolytic activity of an unidentified serine protease, as indicated by cell culture studies, might be another level of 
regulation of Slit/Robo signalling whereby shedding of Sdc terminates Slit and Robo interaction. This model would be in accordance with the described function of Sdc for the recycling of FGF receptor in Drosophila cells (Zimmermann et al., 2005). Therefore the idea that Sdc functions as a coreceptor to stabilise Slit and Robo interaction and shedding of the extracellular domain of Sdc by a serine protease activity results in the recycling of the Robo receptor together with the transmembrane and cytoplasmic domain of Sdc is feasible. This model proposes a function of the intracellular domain of Sdc in intracellular trafficking through the endosomal compartments, which fit to the results of Zimmermann et. al. (Zimmermann et al., 2005). The open question is whether this internalisation of the Sdc/Robo complex is required for the recycling of Robo or whether this process results in the downregulation of Robo activity. A detailed analysis of the rescue experiments with the $s d c$ deletion transgene, $s d c \Delta C-G F P$, which lacks the cytoplasmic domain will be used to distinguish between these models.

Analysis of double mutants also suggests that Dlp plays a role in transducing the Slit repellent signal. A probable model is that Sdc acts in Slit recipient cells like a coreceptor to facilitate/stabilise Slit and Robo interaction while Dlp functions to transport and/or concentrate Slit on the surface of the target tissue. Therefore, when only Sdc is absent there is still a high concentration of Slit at the surface of the target tissue due to Dlp activity, so that the Slit repellent signal is transduced but at a low efficiency resulting in a weak slit like phenotype. In contrast, loss of Dlp results in a lower concentration of Slit on the axon growth cone surface due to impaired transport and/or lack of concentration. Despite this, sufficient amount of Slit is present on the growth cone surface and aided by the coreceptor Sdc, the Slit repellent signal is transduced efficiently into the growth cone. Therefore, no slit like phenotype is observed in the case of $d l p$ homozygous zygotic mutants. However, in the absence of both Dlp and Sdc, Slit is neither transported and/or concentrated on the target surface nor is the coreceptor present to facilitate interaction between the low amounts of Slit present and its receptor Robo. This results in a dramatic reduction in the transduction of the Slit repellent signal into the target tissue, the consequence of which is an increase in the penetrance of slit like phenotype as compared to $s d c^{23}$ homozygous mutants. This model of a combinatorial mode of Sdc and Dlp activity required for two independent steps of signal transduction: ligand transport and 
ligand reception, is worthy of investigation in other signal transduction pathways as well. It has been shown that Dlp is required for Dpp and Wg transport in the wing disc (Belenkaya et al., 2004; Han et al., 2004) but the role of Sdc is not tested yet. Therefore, an interesting point to investigate in other signalling systems is if Dlp always functions for transport and Sdc for reception or if the mechanistic function can change depending on the signalling system and tissue. 


\section{Summary and Conclusions}

Syndecan, a Heparan Sulphate Proteoglycan (HSPG), is critical for the fidelity of Slit repellent signalling at the Drosophila ventral midline where via its receptor Robo, Slit patterns the CNS and the musculature. Embryos homozygous mutant for $s d c$ are embryonic lethal and display a weakly penetrant slit like phenotype characterised by ventral midline crossing of ipsilateral axons and ventral muscles.

To address how Sdc functions in Slit/Robo signalling, the UAS/GAL4 system was employed to express different $s d c$ variants and chimeric transgenes in specific tissues in a $s d c$ mutant background to rescue the phenotype. Tissue-specific rescue experiments were performed to identify the tissue in which Sdc activity is required: in the ventral midline cells to test for a role in Slit secretion, in the intermediate tissue to test for a function in Slit transport and in the target tissue to test for a role in Slit reception. These experiments revealed that Sdc does not play any apparent role in the secretion of Slit or in its transport but is required specifically on the target tissue with the receptor Robo in a cis-cis configuration for the reception of the Slit repellent signal.

Furthermore, rescue experiments with deletion and chimeric transgenes of Sdc proved that $\mathrm{Sdc}$ does not direct the reorganization of the actin cytoskeleton in response to Slit nor does it participate directly in intracellular events downstream of Slit/Robo interaction. The results also prove that the transmembrane domain is not required for the formation of protein-protein complexes but only acts as an inert anchor for the extracellular domain and that this mode of anchorage is functionally exchangeable for an alternate one.

Although shedding of vertebrate Syndecan has been demonstrated to be essential for some of its functions in vivo, the rescue experiment with a secreted form of Drosophila Sdc as well as the analysis of a double tagged Sdc variant indicated that shedding in not required for Sdc activity in Slit repellent signaling and that shedding does not occur in the CNS in detectable amounts. However, cell culture based assays revealed that Drosophila Sdc might be shed by a serine protease, which would be in contrast to vertebrate Sdcs that are proteolytically cleaved by an ADAM family protease.

A double mutant analysis of $s d c^{23}$ in combination with mutants of an HSPG biosynthetic enzyme (ttv) and another HSPG ( $d l p)$, provided evidence for a combinatorial role of Sdc 
and Dlp in Slit/Robo signalling to pattern the CNS and indicated that a similar mechanism might exist for the patterning of the musculature as well.

Taken together, the results from this work represent the first systematic functional analysis of an HSPG in a signal transduction pathway showing that Sdc functions exclusively as a co-receptor with Robo on the target tissue. Furthermore, the results provide strong evidence for a combinatorial model in which both Sdc and Dlp function in an independent but not mutually exclusive manner to facilitate the transduction of the Slit repellent signal. According to this model, Dlp transports and/or concentrates Slit on axon growth cone surfaces while Sdc acts as a coreceptor to stabilise Slit and Robo interaction. 


\section{References}

Alexander, C. M., Reichsman, F., Hinkes, M. T., Lincecum, J., Becker, K. A., Cumberledge, S. and Bernfield, M. (2000). Syndecan-1 is required for Wnt-1-induced mammary tumorigenesis in mice. Nat Genet 25, 329-32.

Anand-Apte, B., Bao, L., Smith, R., Iwata, K., Olsen, B. R., Zetter, B. and Apte, S. S. (1996). A review of tissue inhibitor of metalloproteinases-3 (TIMP-3) and experimental analysis of its effect on primary tumor growth. Biochem Cell Biol 74, 853-62.

Baeg, G. H., Lin, X., Khare, N., Baumgartner, S. and Perrimon, N. (2001). Heparan sulfate proteoglycans are critical for the organization of the extracellular distribution of Wingless. Development 128, 87-94.

Bass, M. D. and Humphries, M. J. (2002). Cytoplasmic interactions of syndecan-4 orchestrate adhesion receptor and growth factor receptor signalling. Biochem J 368, 1-15.

Battye, R., Stevens, A. and Jacobs, J. R. (1999). Axon repulsion from the midline of the Drosophila CNS requires slit function. Development 126, 2475-2481.

Beckett, R. P., Davidson, A. H., Drummond, A. H., Huxley, P. and Whittaker, M. (1996). Recent advances in matrix metalloproteinase inhibitor research. Drug Discovery Today 1, 16.

Belenkaya, T. Y., Han, C., Yan, D., Opoka, R. J., Khodoun, M., Liu, H. and Lin, X. (2004). Drosophila Dpp morphogen movement is independent of dynamin-mediated endocytosis but regulated by the glypican members of heparan sulfate proteoglycans. Cell 119, 231-44.

Bellaiche, Y., The, I. and Perrimon, N. (1998). Tout-velu is a Drosophila homologue of the putative tumour suppressor EXT-1 and is needed for Hh diffusion. Nature 394, 85-8.

Bernfield, M., Gotte, M., Park, P. W., Reizes, O., Fitzgerald, M. L., Lincecum, J. and Zako, M. (1999). Functions of cell surface heparan sulfate proteoglycans. Annu Rev Biochem 68, 729-77.

Bishop, J. R., Schuksz, M. and Esko, J. D. (2007). Heparan sulphate proteoglycans fine-tune mammalian physiology. Nature 446, 1030-7.

Brand, A. H. and Perrimon, N. (1993). Targeted gene expression as a means of altering cell fates and generating dominant phenotypes. Development 118, 401-15.

Brose, K., Bland, K. S., Wang, K. H., Arnott, D., Henzel, W., Goodman, C. S., Tessier-Lavigne, M. and Kidd, T. (1999). Slit proteins bind Robo receptors and have an evolutionarily conserved role in repulsive axon guidance. Cell 96, 795-806. 
Bülow, H. E. and Hobert, O. (2004). Differential sulfations and epimerization define heparan sulfate specificity in nervous system development. Neuron 41, 723-36.

Carey, D. J. (1997). Syndecans: multifunctional cell-surface co-receptors. Biochem J 327 (Pt 1), 1-16.

Carey, D. J., Bendt, K. M. and Stahl, R. C. (1996). The cytoplasmic domain of syndecan-1 is required for cytoskeleton association but not detergent insolubility. Identification of essential cytoplasmic domain residues. J Biol Chem 271, 15253-60.

Carey, D. J. and Stahl, R. C. (1990). Identification of a lipid-anchored heparan sulfate proteoglycan in Schwann cells. J Cell Biol 111, 2053-62.

Carey, D. J., Stahl, R. C., Tucker, B., Bendt, K. A. and Cizmeci-Smith, G. (1994). Aggregation-induced association of syndecan-1 with microfilaments mediated by the cytoplasmic domain. Exp Cell Res 214, 12-21.

Chan, S. S. Y., Zheng, H., Su, M. W., Wilk, R., Killeen, M. T., Hedgecock, E. M. and Culotti, J. G. (1996). UNC-40, a C-elegans homolog of DCC (Deleted in Colorectal Cancer), is required in motile cells responding to UNC-6 netrin cues. Cell 87, 187-195.

Chisholm, A. and Tessier-Lavigne, M. (1999). Conservation and divergence of axon guidance mechanisms. Curr Opin Neurobiol 9, 603-15.

Choi, S., Lee, E., Kwon, S., Park, H., Yi, J. Y., Kim, S., Han, I. O., Yun, Y. and Oh, E. S. (2005). Transmembrane domain-induced oligomerization is crucial for the functions of syndecan-2 and syndecan-4. J Biol Chem 280, 42573-9.

Cirulli, V. and Yebra, M. (2007). Netrins: beyond the brain. Nat Rev Mol Cell Biol 8, 296-306.

Cooper, H. M. (2002). Axon guidance receptors direct growth cone pathfinding: rivalry at the leading edge. Int J Dev Biol 46, 621-31.

Couchman, J. R. (2003). Syndecans: proteoglycan regulators of cell-surface microdomains? Nat Rev Mol Cell Biol 4, 926-37.

Delehedde, M., Seve, M., Sergeant, N., Wartelle, I., Lyon, M., Rudland, P. S. and Fernig, D. G. (2000). Fibroblast growth factor-2 stimulation of p42/44MAPK phosphorylation and IkappaB degradation is regulated by heparan sulfate/heparin in rat mammary fibroblasts. J Biol Chem 275, 33905-10.

Ethell, I. M. and Yamaguchi, Y. (1999). Cell surface heparan sulfate proteoglycan syndecan-2 induces the maturation of dendritic spines in rat hippocampal neurons. $J$ Cell Biol 144, 575-86. 
Eugster, C., Panakova, D., Mahmoud, A. and Eaton, S. (2007). Lipoprotein-heparan sulfate interactions in the Hh pathway. Dev Cell 13, 57-71.

Fanning, A. S. and Anderson, J. M. (1996). Protein-protein interactions: PDZ domain networks. Curr Biol 6, 1385-8.

Fannon, M. and Nugent, M. A. (1996). Basic fibroblast growth factor binds its receptors, is internalized, and stimulates DNA synthesis in Balb/c3T3 cells in the absence of heparan sulfate. J Biol Chem 271, 17949-56.

Filla, M. S., Dam, P. and Rapraeger, A. C. (1998). The cell surface proteoglycan syndecan-1 mediates fibroblast growth factor-2 binding and activity. J Cell Physiol 174, 310-21.

Fransson, L. A., Carlstedt, I., Coster, L. and Malmstrom, A. (1983). Proteoheparan sulfate from human skin fibroblasts. Evidence for self-interaction via the heparan sulfate side chains. J Biol Chem 258, 14342-5.

Friedl, A., Chang, Z., Tierney, A. and Rapraeger, A. C. (1997). Differential binding of fibroblast growth factor-2 and -7 to basement membrane heparan sulfate: comparison of normal and abnormal human tissues. Am J Pathol 150, 1443-55.

Gallagher, J. T. (2001). Heparan sulfate: growth control with a restricted sequence menu. J Clin Invest 108, 357-61.

Garbe, D. S. and Bashaw, G. J. (2004). Axon guidance at the midline: from mutants to mechanisms. Crit Rev Biochem Mol Biol 39, 319-41.

Giraldez, A. J., Copley, R. R. and Cohen, S. M. (2002). HSPG modification by the secreted enzyme Notum shapes the Wingless morphogen gradient. Dev Cell 2, 667-76.

Gleizes, P. E., Noaillac-Depeyre, J., Dupont, M. A. and Gas, N. (1996). Basic fibroblast growth factor (FGF-2) is addressed to caveolae after binding to the plasma membrane of BHK cells. Eur J Cell Biol 71, 144-53.

Greco, V., Hannus, M. and Eaton, S. (2001). Argosomes: a potential vehicle for the spread of morphogens through epithelia. Cell 106, 633-45.

Guthrie, S. (1997). Axon Guidance - Netrin Receptors Are Revealed. Current Biology 7, R 6-R 9.

Häcker, U., Lin, X. and Perrimon, N. (1997). The Drosophila sugarless gene modulates Wingless signaling and encodes an enzyme involved in polysaccharide biosynthesis. Development 124, 3565-73. 
Han, C., Belenkaya, T. Y., Wang, B. and Lin, X. (2004). Drosophila glypicans control the cell-to-cell movement of Hedgehog by a dynamin-independent process. Development 131, 601-11.

Harris, R., Sabatelli, L. M. and Seeger, M. A. (1996). Guidance cues at the Drosophila CNS midline: identification and characterization of two Drosophila Netrin/UNC-6 homologs. Neuron 17, 217-28.

Hayashi, K., Hayashi, M., Jalkanen, M., Firestone, J. H., Trelstad, R. L. and Bernfield, M. (1987). Immunocytochemistry of cell surface heparan sulfate proteoglycan in mouse tissues. A light and electron microscopic study. J Histochem Cytochem 35, 1079-88.

Hedgecock, E. M., Culotti, J. G. and Hall, D. H. (1990). The Unc-5, Unc-6, and Unc40 Genes Guide Circumferential Migrations of Pioneer Axons and Mesodermal Cells on the Epidermis in C-Elegans. Neuron 4, 61-85.

Higuchi, R., Krummel, B. and Saiki, R. K. (1988). A general method of in vitro preparation and specific mutagenesis of DNA fragments: study of protein and DNA interactions. Nucleic Acids Res 16, 7351-67.

Horowitz, A. and Simons, M. (1998). Phosphorylation of the cytoplasmic tail of syndecan-4 regulates activation of protein kinase Calpha. J Biol Chem 273, 25548-51.

Hou, S., Maccarana, M., Min, T. H., Strate, I. and Pera, E. M. (2007). The secreted serine protease xHtrA1 stimulates long-range FGF signaling in the early Xenopus embryo. Dev Cell 13, 226-41.

Hu, H. (2001). Cell-surface heparan sulfate is involved in the repulsive guidance activities of Slit2 protein. Nat Neurosci 4, 695-701.

Huber, A. B., Kolodkin, A. L., Ginty, D. D. and Cloutier, J. F. (2003). Signaling at the growth cone: ligand-receptor complexes and the control of axon growth and guidance. Annu Rev Neurosci 26, 509-63.

Hufnagel, L., Kreuger, J., Cohen, S. M. and Shraiman, B. I. (2006). On the role of glypicans in the process of morphogen gradient formation. Dev Biol 300, 512-22.

Inatani, M., Irie, F., Plump, A. S., Tessier-Lavigne, M. and Yamaguchi, Y. (2003). Mammalian brain morphogenesis and midline axon guidance require heparan sulfate. Science 302, 1044-6.

Jacobs, J. R. (2000). The midline glia of Drosophila: a molecular genetic model for the developmental functions of glia. Prog Neurobiol 62, 475-508. 
Johnson, K. G., Ghose, A., Epstein, E., Lincecum, J., O'Connor, M. B. and Van Vactor, D. (2004). Axonal heparan sulfate proteoglycans regulate the distribution and efficiency of the repellent slit during midline axon guidance. Curr Biol 14, 499-504.

Kamimura, K., Koyama, T., Habuchi, H., Ueda, R., Masu, M., Kimata, K. and Nakato, H. (2006). Specific and flexible roles of heparan sulfate modifications in Drosophila FGF signaling. J Cell Biol 174, 773-8.

Kamimura, K., Rhodes, J. M., Ueda, R., McNeely, M., Shukla, D., Kimata, K., Spear, P. G., Shworak, N. W. and Nakato, H. (2004). Regulation of Notch signaling by Drosophila heparan sulfate 3-O sulfotransferase. J Cell Biol 166, 1069-79.

Kaprielian, Z., Imondi, R. and Runko, E. (2000). Axon guidance at the midline of the developing CNS. Anat Rec 261, 176-97.

Kato, M., Saunders, S., Nguyen, H. and Bernfield, M. (1995). Loss of cell surface syndecan-1 causes epithelia to transform into anchorage-independent mesenchyme-like cells. Mol Biol Cell 6, 559-76.

Kato, M., Wang, H., Bernfield, M., Gallagher, J. T. and Turnbull, J. E. (1994). Cell surface syndecan-1 on distinct cell types differs in fine structure and ligand binding of its heparan sulfate chains. J Biol Chem 269, 18881-90.

Keino-Masu, K., Masu, M., Hinck, L., Leonardo, E. D., Chan, S. S., Culotti, J. G. and Tessier-Lavigne, M. (1996). Deleted in Colorectal Cancer (DCC) encodes a netrin receptor. Cell 87, 175-85.

Keleman, K., Rajagopalan, S., Cleppien, D., Teis, D., Paiha, K., Huber, L. A., Technau, G. M. and Dickson, B. J. (2002). Comm sorts robo to control axon guidance at the Drosophila midline. Cell 110, 415-27.

Khare, N. and Baumgartner, S. (2000). Dally-like protein, a new Drosophila glypican with expression overlapping with wingless. Mech Dev 99, 199-202.

Kidd, T., Bland, K. S. and Goodman, C. S. (1999). Slit is the midline repellent for the robo receptor in Drosophila. Cell 96, 785-94.

Kidd, T., Brose, K., Mitchell, K. J., Fetter, R. D., Tessier-Lavigne, M., Goodman, C. S. and Tear, G. (1998). Roundabout controls axon crossing of the CNS midline and defines a novel subfamily of evolutionarily conserved guidance receptors. Cell 92, 205215.

Kim, C. W., Goldberger, O. A., Gallo, R. L. and Bernfield, M. (1994). Members of the syndecan family of heparan sulfate proteoglycans are expressed in distinct cell-, tissue-, and development-specific patterns. Mol Biol Cell 5, 797-805. 
Kinnunen, T., Kaksonen, M., Saarinen, J., Kalkkinen, N., Peng, H. B. and Rauvala, H. (1998). Cortactin-Src kinase signaling pathway is involved in N-syndecan-dependent neurite outgrowth. $J$ Biol Chem 273, 10702-8.

Kolodziej, P. A., Timpe, L. C., Mitchell, K. J., Fried, S. R., Goodman, C. S., Jan, L. Y. and Jan, Y. N. (1996). Frazzled Encodes A Drosophila Member Of The Dcc Immunoglobulin Subfamily And Is Required For Cns And Motor Axon Guidance. Cell 87, 197-204.

Kooyman, D. L., Byrne, G. W., McClellan, S., Nielsen, D., Tone, M., Waldmann, H., Coffman, T. M., McCurry, K. R., Platt, J. L. and Logan, J. S. (1995). In vivo transfer of GPI-linked complement restriction factors from erythrocytes to the endothelium. Science 269, 89-92.

Kopczynski, C. C., Noordermeer, J. N., Serano, T. L., Chen, W. Y., Pendleton, J. D., Lewis, S., Goodman, C. S. and Rubin, G. M. (1998). A high throughput screen to identify secreted and transmembrane proteins involved in Drosophila embryogenesis. Proc Natl Acad Sci U S A 95, 9973-8.

Kramer, K. L. and Yost, H. J. (2003). Heparan sulfate core proteins in cell-cell signaling. Annu Rev Genet 37, 461-84.

Kramer, S. G., Kidd, T., Simpson, J. H. and Goodman, C. S. (2001). Switching repulsion to attraction: changing responses to slit during transition in mesoderm migration. Science 292, 737-40.

Langford, J. K., Stanley, M. J., Cao, D. and Sanderson, R. D. (1998). Multiple heparan sulfate chains are required for optimal syndecan-1 function. J Biol Chem 273, 29965-71.

Lebakken, C. S. and Rapraeger, A. C. (1996). Syndecan-1 mediates cell spreading in transfected human lymphoblastoid (Raji) cells. J Cell Biol 132, 1209-21.

Lee, J. S. and Chien, C. B. (2004). When sugars guide axons: insights from heparan sulphate proteoglycan mutants. Nat Rev Genet 5, 923-35.

Liang, Y., Annan, R. S., Carr, S. A., Popp, S., Mevissen, M., Margolis, R. K. and Margolis, R. U. (1999). Mammalian homologues of the Drosophila slit protein are ligands of the heparan sulfate proteoglycan glypican-1 in brain. J Biol Chem 274, 1788592.

Lin, X., Buff, E. M., Perrimon, N. and Michelson, A. M. (1999). Heparan sulfate proteoglycans are essential for FGF receptor signaling during Drosophila embryonic development. Development 126, 3715-23. 
Lundgren, S. E., Callahan, C. A., Thor, S. and Thomas, J. B. (1995). Control of neuronal pathway selection by the Drosophila LIM homeodomain gene apterous. Development 121, 1769-73.

Maccarana, M., Sakura, Y., Tawada, A., Yoshida, K. and Lindahl, U. (1996). Domain structure of heparan sulfates from bovine organs. J Biol Chem 271, 17804-10.

Marois, E., Mahmoud, A. and Eaton, S. (2006). The endocytic pathway and formation of the Wingless morphogen gradient. Development 133, 307-17.

Mitchell, K. J., Doyle, J. L., Serafini, T., Kennedy, T. E., Tessierlavigne, M., Goodman, C. S. and Dickson, B. J. (1996). Genetic Analysis Of Netrin Genes In Drosophila - Netrins Guide Cns Commissural Axons And Peripheral Motor Axons. Neuron 17, 203-215.

Miyoshi, J. and Takai, Y. (2005). Molecular perspective on tight-junction assembly and epithelial polarity. Adv Drug Deliv Rev 57, 815-55.

Nakato, H., Futch, T. A. and Selleck, S. B. (1995). The division abnormally delayed (dally) gene: a putative integral membrane proteoglycan required for cell division patterning during postembryonic development of the nervous system in Drosophila. Development 121, 3687-702.

Nguyen Ba-Charvet, K. T., Brose, K., Ma, L., Wang, K. H., Marillat, V., Sotelo, C., Tessier-Lavigne, M. and Chedotal, A. (2001). Diversity and specificity of actions of Slit2 proteolytic fragments in axon guidance. J Neurosci 21, 4281-9.

Nüsslein-Volhard, C. and Wieschaus, E. (1980). Mutations affecting segment number and polarity in Drosophila. Nature 287, 795-801.

Oh, E. S., Couchman, J. R. and Woods, A. (1997). Serine phosphorylation of syndecan-2 proteoglycan cytoplasmic domain. Arch Biochem Biophys 344, 67-74.

Park, P. W., Pier, G. B., Hinkes, M. T. and Bernfield, M. (2001). Exploitation of syndecan-1 shedding by Pseudomonas aeruginosa enhances virulence. Nature 411, 98102.

Park, Y., Rangel, C., Reynolds, M. M., Caldwell, M. C., Johns, M., Nayak, M., Welsh, C. J., McDermott, S. and Datta, S. (2003). Drosophila perlecan modulates FGF and hedgehog signals to activate neural stem cell division. Dev Biol 253, 247-57.

Pellegrini, L., Burke, D. F., von Delft, F., Mulloy, B. and Blundell, T. L. (2000). Crystal structure of fibroblast growth factor receptor ectodomain bound to ligand and heparin. Nature 407, 1029-34. 
Prasthofer, T., Ek, B., Ekman, P., Owens, R., Hook, M. and Johansson, S. (1995). Protein kinase $\mathrm{C}$ phosphorylates two of the four known syndecan cytoplasmic domains in vitro. Biochem Mol Biol Int 36, 793-802.

Princivalle, M. and de Agostini, A. (2002). Developmental roles of heparan sulfate proteoglycans: a comparative review in Drosophila, mouse and human. Int J Dev Biol 46, 267-78.

Rajagopalan, S., Nicolas, E., Vivancos, V., Berger, J. and Dickson, B. J. (2000a). Crossing the midline: roles and regulation of Robo receptors. Neuron 28, 767-77.

Rajagopalan, S., Vivancos, V., Nicolas, E. and Dickson, B. J. (2000b). Selecting a longitudinal pathway: Robo receptors specify the lateral position of axons in the Drosophila CNS. Cell 103, 1033-45.

Rapraeger, A., Jalkanen, M. and Bernfield, M. (1986). Cell surface proteoglycan associates with the cytoskeleton at the basolateral cell surface of mouse mammary epithelial cells. J Cell Biol 103, 2683-96.

Rosenberg, R. D., Shworak, N. W., Liu, J., Schwartz, J. J. and Zhang, L. (1997). Heparan sulfate proteoglycans of the cardiovascular system. Specific structures emerge but how is synthesis regulated? J Clin Invest 100, S67-75.

Rothberg, J. M., Jacobs, J. R., Goodman, C. S. and Artavanistsakonas, S. (1990). Slit - an Extracellular Protein Necessary for Development of Midline Glia and Commissural Axon Pathways Contains Both Egf and Lrr Domains. Genes \& Development 4, 2169-2187.

Rubin, G. M. and Spradling, A. C. (1982). Genetic transformation of Drosophila with transposable element vectors. Science 218, 348-53.

Sanderson, R. D., Hinkes, M. T. and Bernfield, M. (1992). Syndecan-1, a cell-surface proteoglycan, changes in size and abundance when keratinocytes stratify. $J$ Invest Dermatol 99, 390-6.

Sanderson, R. D., Turnbull, J. E., Gallagher, J. T. and Lander, A. D. (1994). Fine structure of heparan sulfate regulates syndecan-1 function and cell behavior. J Biol Chem 269, 13100-6.

Saunders, S., Jalkanen, M., O'Farrell, S. and Bernfield, M. (1989). Molecular cloning of syndecan, an integral membrane proteoglycan. J Cell Biol 108, 1547-56.

Schlessinger, J., Plotnikov, A. N., Ibrahimi, O. A., Eliseenkova, A. V., Yeh, B. K., Yayon, A., Linhardt, R. J. and Mohammadi, M. (2000). Crystal structure of a ternary FGF-FGFR-heparin complex reveals a dual role for heparin in FGFR binding and dimerization. Mol Cell 6, 743-50. 
Schnorrer, F. and Dickson, B. J. (2004). Muscle building; mechanisms of myotube guidance and attachment site selection. Dev Cell 7, 9-20.

Seeger, M., Tear, G., Ferresmarco, D. and Goodman, C. S. (1993). Mutations Affecting Growth Cone Guidance in Drosophila - Genes Necessary for Guidance toward or Away from the Midline. Neuron 10, 409-426.

Serafini, T., Colamarino, S. A., Leonardo, E. D., Wang, H., Beddington, R., Skarnes, W. C. and Tessierlavigne, M. (1996). Netrin-1 Is Required For Commissural Axon Guidance In The Developing Vertebrate Nervous System. Cell 87, 1001-1014.

Simpson, J. H., Kidd, T., Bland, K. S. and Goodman, C. S. (2000). Short-range and long-range guidance by slit and its Robo receptors. Robo and Robo2 play distinct roles in midline guidance. Neuron 28, 753-66.

Spradling, A. C. and Rubin, G. M. (1982). Transposition of cloned P elements into Drosophila germ line chromosomes. Science 218, 341-7.

Spring, J., Paine-Saunders, S. E., Hynes, R. O. and Bernfield, M. (1994). Drosophila syndecan: conservation of a cell-surface heparan sulfate proteoglycan. Proc Natl Acad Sci U S A 91, 3334-8.

Steigemann, P., Molitor, A., Fellert, S., Jäckle, H. and Vorbrüggen, G. (2004). Heparan sulfate proteoglycan syndecan promotes axonal and myotube guidance by slit/robo signaling. Curr Biol 14, 225-30.

Steinfeld, R., Van Den Berghe, H. and David, G. (1996). Stimulation of fibroblast growth factor receptor-1 occupancy and signaling by cell surface-associated syndecans and glypican. J Cell Biol 133, 405-16.

Stepp, M. A., Gibson, H. E., Gala, P. H., Iglesia, D. D., Pajoohesh-Ganji, A., PalGhosh, S., Brown, M., Aquino, C., Schwartz, A. M., Goldberger, O. et al. (2002). Defects in keratinocyte activation during wound healing in the syndecan-1-deficient mouse. J Cell Sci 115, 4517-31.

Subramanian, S. V., Fitzgerald, M. L. and Bernfield, M. (1997). Regulated shedding of syndecan-1 and -4 ectodomains by thrombin and growth factor receptor activation. $J$ Biol Chem 272, 14713-20.

Tear, G. (1999). Axon guidance at the central nervous system midline. Cell Mol Life Sci 55, 1365-76.

Teleman, A. A. and Cohen, S. M. (2000). Dpp gradient formation in the Drosophila wing imaginal disc. Cell 103, 971-80. 
Tepass, U., Theres, C. and Knust, E. (1990). crumbs encodes an EGF-like protein expressed on apical membranes of Drosophila epithelial cells and required for organization of epithelia. Cell 61, 787-99.

Voigt, A., Pflanz, R., Schafer, U. and Jäckle, H. (2002). Perlecan participates in proliferation activation of quiescent Drosophila neuroblasts. Dev Dyn 224, 403-12.

Volk, T. (1999). Singling out Drosophila tendon cells: a dialogue between two distinct cell types. Trends Genet 15, 448-53.

Walker, A., Turnbull, J. E. and Gallagher, J. T. (1994). Specific heparan sulfate saccharides mediate the activity of basic fibroblast growth factor. $J$ Biol Chem 269, 9315 .

Wang, K. H., Brose, K., Arnott, D., Kidd, T., Goodman, C. S., Henzel, W. and Tessier-Lavigne, M. (1999). Biochemical purification of a mammalian slit protein as a positive regulator of sensory axon elongation and branching. Cell 96, 771-84.

Wang, Z., Gotte, M., Bernfield, M. and Reizes, O. (2005). Constitutive and accelerated shedding of murine syndecan-1 is mediated by cleavage of its core protein at a specific juxtamembrane site. Biochemistry 44, 12355-61.

Wolfsberg, T. G., Primakoff, P., Myles, D. G. and White, J. M. (1995a). ADAM, a novel family of membrane proteins containing A Disintegrin And Metalloprotease domain: multipotential functions in cell-cell and cell-matrix interactions. J Cell Biol 131, $275-8$.

Wolfsberg, T. G., Straight, P. D., Gerena, R. L., Huovila, A. P., Primakoff, P., Myles, D. G. and White, J. M. (1995b). ADAM, a widely distributed and developmentally regulated gene family encoding membrane proteins with a disintegrin and metalloprotease domain. Dev Biol 169, 378-83.

Woods, A. and Couchman, J. R. (1994). Syndecan 4 heparan sulfate proteoglycan is a selectively enriched and widespread focal adhesion component. Mol Biol Cell 5, 183-92.

Woods, A., Couchman, J. R., Johansson, S. and Hook, M. (1986). Adhesion and cytoskeletal organisation of fibroblasts in response to fibronectin fragments. Embo $J \mathbf{5}$, 665-70.

Yamagata, M., Saga, S., Kato, M., Bernfield, M. and Kimata, K. (1993). Selective distributions of proteoglycans and their ligands in pericellular matrix of cultured fibroblasts. Implications for their roles in cell-substratum adhesion. J Cell Sci 106 (Pt 1), $55-65$. 
Yamashita, Y., Oritani, K., Miyoshi, E. K., Wall, R., Bernfield, M. and Kincade, P. W. (1999). Syndecan-4 is expressed by B lineage lymphocytes and can transmit a signal for formation of dendritic processes. J Immunol 162, 5940-8.

Zimmermann, P., Zhang, Z., Degeest, G., Mortier, E., Leenaerts, I., Coomans, C., Schulz, J., N'Kuli, F., Courtoy, P. J. and David, G. (2005). Syndecan recycling [corrected] is controlled by syntenin-PIP2 interaction and Arf6. Dev Cell 9, 377-88.

Zinn, K. and Sun, Q. (1999). Slit branches out: A secreted protein mediates both attractive and repulsive axon guidance. Cell 97, 1-4. 


\section{Curriculum vitae}

Name

Date of Birth

Place of Birth

Nationality

\section{Education}

1984-1998

1998-2001

2001-2003

2003-Present
Bhavna Chanana

14 august 1980

New Delhi, India

Indian
St. Anthony's Senior Secondary School, New Delhi, India Bachelor Of Science in Microbiology, University of Delhi, Delhi, India. Master of Science in Biomedical Sciences, Dr. B. R. Ambedkar Centre for Biomedical Sciences, University of Delhi, Delhi, India Master thesis at the Institute of Genomics and Integrative Biology, Delhi, India (Supervised by Prof. Yogendra Singh)

Title: A Study on the kinases and a phosphatase of Mycobacterium tuberculosis $\mathrm{H} 37 \mathrm{Rv}$

Program in Molecular Biology, International Max-Planck Research School, Göttingen, Germany

$\mathrm{PhD}$ thesis at the Department of Molecular Developmental Biology, Max-Planck Institute for Biophysical Chemistry, Göttingen, Germany (Supervised by Dr. Gerd Vorbrüggen)

Title: Functional characterisation of Syndecan, a heparan sulphate proteoglycan, in Slit/Robo signalling 